Portland State University

PDXScholar

7-19-2021

\title{
Kinematic Demands on Pile-Supported Wharves Due to Liquefaction-Induced Lateral Ground Deformations
}

Thomas John Torkelson II Portland State University

Follow this and additional works at: https://pdxscholar.library.pdx.edu/open_access_etds

Part of the Civil Engineering Commons, and the Geological Engineering Commons Let us know how access to this document benefits you.

\section{Recommended Citation}

Torkelson, Thomas John II, "Kinematic Demands on Pile-Supported Wharves Due to Liquefaction-Induced Lateral Ground Deformations" (2021). Dissertations and Theses. Paper 5780.

https://doi.org/10.15760/etd.7651

This Thesis is brought to you for free and open access. It has been accepted for inclusion in Dissertations and Theses by an authorized administrator of PDXScholar. Please contact us if we can make this document more accessible: pdxscholar@pdx.edu. 
Kinematic Demands on Pile-Supported Wharves Due to Liquefaction-Induced

Lateral Ground Deformations

by

Thomas John Torkelson II

A thesis submitted in partial fulfillment of the requirements for the degree of

\author{
Master of Science \\ in \\ Civil and Environmental Engineering
}

\author{
Thesis Committee: \\ Arash Khosravifar, Chair \\ Diane Moug \\ Peter Dusicka
}

Portland State University

2021 
(C) 2021 Thomas John Torkelson II 


\begin{abstract}
Kinematic demands from lateral soil deformations can be a major cause of damage to maritime and highway transportation structures such as wharves, ports, and bridges. Data from five centrifuge tests on pile-supported wharves were used to evaluate the accuracy of Newmark Sliding Block Analysis in estimating the kinematic demands on piles. The piles in the centrifuge tests were subjected to varying degrees of liquefaction-induced lateral ground deformations. Pile-pinning effects were included in the analysis by incorporating the lateral pile resistance in the limit-equilibrium slope stability analysis. The results of the analysis have shown that the median Newmark displacements better estimated the centrifuge permanent end-of-shaking displacements but underestimated the measured peak transient displacements. On the other hand, the median $+1 \sigma$ Newmark displacements better estimated the peak transient displacements. The measured peak transient displacements were on average 2.3 times larger than the measured permanent displacements in these centrifuge tests. The median $+1 \sigma$ Newmark displacements were on average 1.4 times larger than the median displacements.
\end{abstract}




\section{Acknowledgements}

I would like to thank Dr. Arash Khosravifar for first kindling my interest in the practice of geotechnical engineering. My professors, Dr. Khosravifar, Dr. Diane Moug, Dr. Seth Reddy, and Dr. Trevor Smith have been great mentors throughout my academic career. I would also like to thank my associates, Jim Imbrie and Ben Anderson for providing me with excellent mentorship and guidance as I begin my professional engineering career. I am eternally grateful to my wife Laura Lazorski for supporting me while I complete this important milestone. I am very grateful to have such quality influences in my life.

Lastly, I would like to express my appreciation to the Civil and Environmental Engineering Department at the Maseeh College of Computer Science and Engineering for providing excellent academic services and extending my capabilities for a professional career. 


\section{TABLE OF CONTENTS}

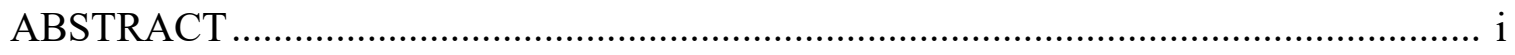

ACKNOWLEDGEMENTS ………………………..................................................ii

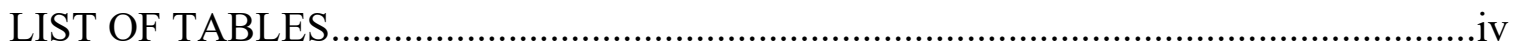

LIST OF FIGURES …………………………………..........................................

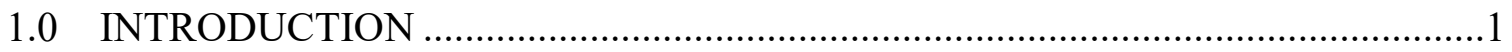

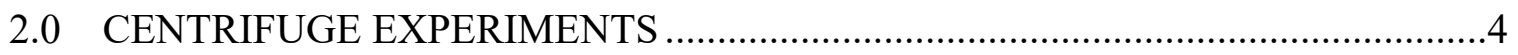



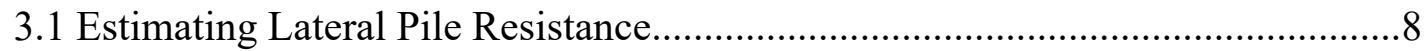

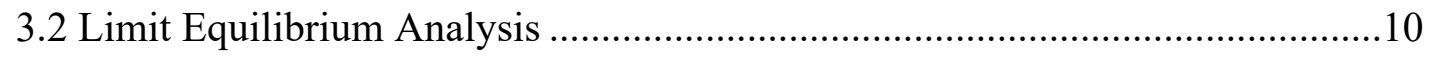

3.3 Newmark Sliding Block Analysis.................................................................12

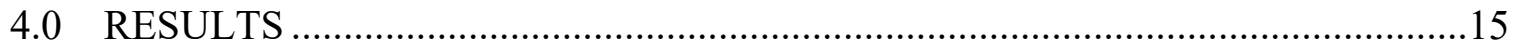

4.1 Comparison of Newmark vs Centrifuge Soil Displacements …………..............15

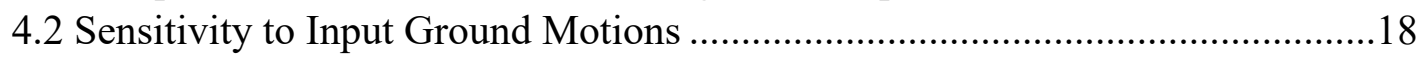

4.3 Sensitivity to Pile Spacing ..............................................................................

4.4 Sensitivity to Residual Strength of Liquefied Soils (Sr)...................................20

4.5 Sensitivity to Pile Group Effect ........................................................................21

4.6 Sensitivity to Equivalent Static Analysis Model Boundary Conditions .............22



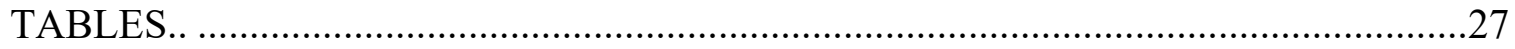

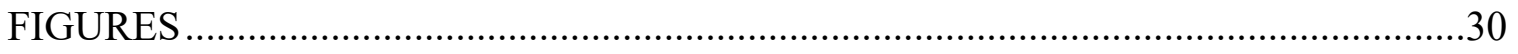

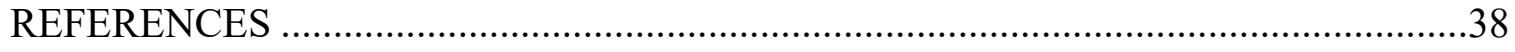

APPENDIX: RESULTS OF SLOPE STABILITY MODELS .........................................42 


\section{List of Tables}

Table 1. Pile, superstructure, and soil properties and ground motions in centrifuge tests (in prototype scale) 27

Table 2. P-Y spring properties used in LPILE $\mathbf{2 8}$

Table 3. Soil shear strength, pore pressure properties, yield acceleration, and calculated Newmark displacement in the five centrifuge tests. 29 


\section{List of Figures}

Figure 1. Lateral load behavior of piles in LPILE: (a) soil displacements applied to the end node of p-y springs, (b) shear forces along the piles and at the failure surface. 30

Figure 2. Representative limit equilibrium analysis in SlopeW Model for NJM01 Event 11 incorporating pile pinning effects. Shear resistance from LPILE Applied at Failure Surface. 30

Figure 3. (Left) Five centrifuge models with inferred and modeled Failure Surfaces, and accelerometers used for calculations. (Right) Pile-pinning curves from sliding mass and pile shear resistance for each event. 31

Figure 4. Displacement time histories from ten centrifuge shaking events. The measured centrifuge displacement is compared to the calculated Newmark displacement throughout each time history. 32

Figure 5. (Left) Measured permanent (end of shaking) centrifuge displacements in comparison to calculated Newmark displacements (Median and Median +16 ). (Right) Measured maximum transient centrifuge displacements in comparison to calculated Newmark displacements (Median and Median +16). 33

Figure 6. Predicted Newmark displacements from all the accelerometers in the centrifuge model for NJM01 Event 11.33

Figure 7. Plan view for NJM01 centrifuge test with pile spacing and dimensions. 34

Figure 8. Predicted pile-pinning curves based upon different pile spacings for NJM01, Event 11.34

Figure 9. (Left) Calculated soil shear strength with depth for NJM01 using different methodologies. (Right) Estimated pile resistances and sliding mass displacements utilizing two different shear strength models (Kramer and Wang and Ebeling and Morrison). 35

Figure 10. Comparison of piles with different pile head conditions. Piles with uniform head displacement and piles without group framing effect. 36

Figure 11. Representative limit equilibrium analysis in SlopeW Model for NJM01 Event 11 with extended model boundary. 36

Figure 12. Predicted pile-pinning curves based upon different model boundary conditions for NJM01, Event 11.37 


\subsection{Introduction}

Past earthquakes have shown that kinematic demands from lateral soil deformations can be a major cause of damage to maritime and highway transportation structures such as wharves, ports, and bridges (e.g. Hamada et al. 1986, Finn 2005, Turner et al. 2016, and Cubrinovski et al. 2017). Lateral ground deformations can be caused due to liquefaction and cyclic softening and degradation of foundation soils due to earthquake loads. Design of pile foundations under kinematic, lateral ground deformations is commonly performed by estimating free-field soil displacements profile with depth, adjusting the free-field displacements for the restraining effects of pile foundations (i.e. pile pinning effects) and applying the pile-restrained soil displacements to the end-nodes of p-y springs as explained in Caltrans (2012). In practice, free-field displacements are estimated either by empirical methods based on case history observations such as Youd 1981, empiricalmechanistic approaches such as Idriss and Boulanger 2008, variations of Newmark sliding block analysis such as Newmark 1965 and Makdisi and Seed 1978, or nonlinear dynamic analysis. Pile-pining effects of pile foundations are evaluated by incorporating the resisting forces from the piles in limit equilibrium using methods with varying complexities such a Broms 1964, and Caltrans (2012; 2016).

In research performed by Armstrong et al. (2014), they compared equivalent static analysis with and without pile pinning effects to three centrifuge models and found that the estimated residual shear strength for liquefied sand played an important role in estimated soil displacements and illustrates the uncertainty and sensitivity of residual shear strength correlations and its effect on equivalent static models. They developed a 
method for determining the soil displacement profile based on the maximum shear strain in the soil. In the study presented here, the method provided by Armstrong et al. (2014) resulted in negligible deformations in the rock fill and dense sand, and approximately linear deformation in the loose sand.

In research performed by Kramer and Makdisi (2018), an investigation to the applicability of Newmark analysis to lateral spreading soil was performed as soil shear resistance changes during the course of ground shaking, which is generally inconsistent with the assumptions of Newmark sliding block analysis. This research has showed that large uncertainty exists when predicting lateral spreading displacements and that selection of ground motions, calculation method, and shear strength can have a significant effect on the estimated displacements.

The objective of this study was to evaluate the accuracy of Caltrans's pile-pinning method that is specifically developed for highway and bridge foundations in estimated the soil displacements for typical pile-supported wharf structures. Data from 5 centrifuge tests on pile-supported wharves (McCullough et al. 2001) were used to evaluate the accuracy of Newmark Sliding Block Analysis and Caltrans pile pinning method to estimate the kinematic demands on piles. The piles in the centrifuge tests were subjected to varying degrees of liquefaction-induced lateral ground deformations. Pile-pinning effects were included in the analysis by incorporating the lateral pile resistance in the limit-equilibrium slope stability analysis. In evaluating this method in comparison to the centrifuge data, we were able to determine how well incorporating pile-pinning effects estimate the lateral ground displacements and kinematic demands on piles.

The following section of this paper describes the properties and geometry of the five 
centrifuge tests and the results. Section 3 of this report describes how the soil displacements were computed using the Newmark method incorporating pile pinning effects generally consistent with the procedures outlined in Caltrans $(2012 ; 2016)$. These calculated soil displacements using the Newmark analysis were then compared to the measured displacement of the centrifuge tests. Section 4 of this report describes the kinematic demand on the piles based upon the seismically induced soil displacements. The comparison between the measured centrifuge displacements and estimated Newmark displacement as well as the kinematic demands of the piles are discussed in the concluding remarks of this paper. 


\subsection{Centrifuge Experiments}

The results of five centrifuge tests on pile-supported wharves were used in this study to evaluate the accuracy of current methods in estimating kinematic demands on piles. The piles in these centrifuge tests were subjected to varying magnitudes of ground deformations. The pile-supported wharf structures generally consisted of a wharf deck, supported by piles installed on or near sloping ground. The sloping ground generally consisted of loose sand, dense sand, or a rock dike. Below the sloping area, the soils consisted of either dense sand or clay. The piles were embedded through the rock, sand, or clay into dense, foundation sand. The centrifuge tests included a range of soil relative densities that resulted in no-liquefaction, partial liquefaction, or full liquefaction which provided a wide range of conditions against which the existing design methods could be evaluated. This research project primarily focused on geotechnical portions of the structure such as the pile foundations, and soil characteristics. Other structural elements such as the wharf deck and pile connections were not analyzed or modeled in the centrifuge experiments.

Details for the centrifuge tests can be found in a series of data reports in McCullough et al. (2000), Schlechter et al. (2000a, b), and Boland et al. (2001a, b). The pile, superstructure, and soil properties and the applied input motions are provided in Souri et al. (2019). All tests included a wharf deck supported by 21 piles configured in a 7-by-3 
setup. The piles consisted of aluminum pipe piles with outer diameters ranging from 0.38 $\mathrm{m}$ to $0.64 \mathrm{~m}$ (in prototype scale). The centrifuge scale factor was 40.1 for all tests. 


\subsection{Estimating Soil Displacements}

The kinematic demands on piles can be estimated using different methods with varying levels of complexity, including the simplified Newmark sliding block analysis (Newmark 1965) to a more detailed two- or three-dimensional dynamic analysis that incorporates soil-structure interaction. In the subsequent analysis, the soil displacements were computed using the Newmark method incorporating pile pinning effects generally consistent with the procedures outlined in Caltrans $(2012,2016)$. The procedure includes estimating the yield acceleration using pseudo-static limit equilibrium analysis (this analysis was performed using the computer program SlopeW using the Spencer method of slices). The pile pinning effects were incorporated by estimating pile resistances using p-y analysis (this analysis was performed in LPILE). The yield acceleration was used in Newmark analysis to compute soil displacements (this analysis was performed using the computer program SLAMMER). The Newmark sliding block analysis, pseudo-static slope stability analysis, and p-y analysis was used concurrently to estimate displacement demand. The reduction in ground displacement resulting from the resisting shear force from of the piles was assessed by determining the displacement equivalence between the deflecting foundation and sliding block displacement. The loading of the piles by the soil displacement is assessed where the base of the $p-y$ springs is displaced an amount equal to the ground displacement. The amount of displacement from a sliding block analysis where the peak displacement is determined by the yield coefficient of the block $(k y)$ and modeled ground accelerations. A pseudo-static slope stability analysis was performed to 
determine the geometry of the failure mass and its corresponding yield coefficient. This yield coefficient was then used in the sliding block analysis using the computer program SLAMMER to determine the estimated ground displacement.

As described above, the estimated of soil displacement incorporating pile-pinning effects includes three steps that are performed by three steps in parallel. More details are provided in sections 3.1 through 3.3 below.

1: SlopeW, Equilibrium slope stability analysis to estimate Ky which is an input for Newmark Sliding Block Analysis (Step 3). The pile-pinning effects were included in the limit equilibrium slope stability analysis using pile shear forces that are estimated in the p-y analysis (Step 2). Full details of SlopeW analysis are provided in the appendix of this report.

2: LPILE, p-y analysis was performed in LPILE to estimate pile shear forces along the failure surface to be used in the limit equilibrium analysis (Step 1). The analysis is performed for a range of soil displacements between zero and the estimated free-field displacement. The estimated shear force applied in each SlopeW analysis is provided in the appendix of this report.

3: SLAMMER, The Ky values determined from the limit equilibrium slope stability analysis (Step 1) are incorporated into the Newmark Sliding Block Analysis to determine estimated soil displacements. The Ky values derived from each SlopeW analysis is provided in the appendix of this report 


\subsection{Estimating Lateral Pile Resistance}

Pile shear forces along the ground failure surface provide resisting forces that act as reinforcements and result in a reduction of cyclically induced ground displacements. These resisting forces can be estimated by performing lateral load analysis on piles using p-y analysis. These analyses were performed in LPILE v.9.09 (Itasca 2016). Soil displacements were applied to the end node of $\mathrm{p}-\mathrm{y}$ springs, shear forces were extracted at the approximate depth of shear failure surface for each pile and were applied in a slope stability analysis that is described in the next section.

LPILE analysis was performed to get a pile shear resistance for a range of soil displacements. An idealized soil displacement profile was used to impose soil displacements to the end nodes of p-y springs and incrementally increased to develop pile resisting curves. Soil displacements were applied using the idealized soil displacement profiles assuming zero shear strain in rockfill, linear reduction within the loose sand and zero shear strain in dense sand. Details on how the idealized soil displacements were developed and comparison with centrifuge results are discussed later in this paper. These properties used in the LPILE analysis were calibrated against the centrifuge results and described in detail in Souri et al. (2020). The p-y springs were modified using pmultipliers $\left(P_{m}\right)$ proportional to the pore water pressure ratio $R_{u}$ generated during the ground motion: $P_{m}=1.2-1.1 * R u$ for $R u>0.2$ and $P_{m}=1.0$ for $R u \leq 0.2$, as the effect of pore pressure generation is assumed to be negligible when $R u$ is below 0.2. The recorded excess pore pressure ratios in centrifuge tests were used in this study. In practice, these values can be estimated from effective stress site response analysis or from simplified correlations with the factor of safety against liquefaction. Each pile was modeled as a 
single pile. Group framing effects were not considered in the baseline analysis and it was found that including group effect (i.e., equal displacement at pile head) has negligible effect when the failure surface is deeper than 10D because the group effect affects the pile head shear which dissipates by 10D depth. Sensitivity on group effect is provided later. Pile head was assumed to be fixed against rotation since the wharf deck was relatively rigid. The pile spacing ranged between approximately $7 \mathrm{D}$ and 16D. Therefore, no group reduction factor was used in accordance with AASHTO (2014).

Figure 1 shows representative LPILE analysis results for NJM01 Event 11. Figure 1 shows the soil displacements that were imposed to the end node of $p-y$ springs in LPILE for a case where the ground surface displacement was $0.07 \mathrm{~m}$ (this displacement corresponds to the value estimated using Newmark analysis as described later). These displacements were only applied for the piles that passed through the failure mass. As seen in this figure, it was assumed that the rockfill moved monolithically with equal displacements throughout. The shear strains were assumed to be uniform within the liquefying loose sand. It was assumed that the underlying dense sand did not accumulate significant shear strain. The accuracy of these assumptions is evaluated against the centrifuge test measurements later in this paper. The pile shear forces were extracted at the depth of failure surface. The failure surface is determined using slope stability analysis that is described later. As seen in the figure, the shear force in piles at the failure surface depends on the thickness of the liquefiable layer and the overlying nonliquefiable crust (i.e., rockfill). Caltrans (2016) recommends extracting the shear forces in the center of the liquefying layer. The analysis here shows that extracting shear force from the center or at the depths corresponding to the failure surface are the same. 


\subsection{Limit Equilibrium Analysis}

The yield accelerations for each test were determined by using pseudo-static limit equilibrium analysis and were assumed to be constant during throughout the acceleration time histories while performing the Newmark analysis. Because the pile foundations are embedded through the estimated failure surface, the foundation can partially restrain the movement of the slope with the shear strength of the piles. This beneficial resistance of the piles against the laterally moving ground (i.e., the pile pinning effects) were considered by including the piles as reinforcement elements in the limit equilibrium analysis.

Limit equilibrium in SlopeW was performed for a range of pile shear resistance values calculated from LPILE (Vi) to calculate a corresponding yield acceleration (Ky). The Spencer method of slices was utilized for modeling. For defining trial slip surfaces, both rigid block and circular failure surfaces were analyzed for each centrifuge test. The failure surface that generated the lowest yield acceleration that results in a factor of safety of 1 under seismic loading was considered the critical failure surface and used in the analysis. The critical failure surfaces for each centrifuge test are provided in the appendix of this report. In this study, the failure surface was modeled such that the centrifuge box was modeled as the boundary. Therefore, the trial slip surfaces in this study did not pass beyond the centrifuge box. The effect of this assumption on the boundary condition on the critical failure surface and estimated soil displacements are evaluated in the sensitivity analysis section.

The shear strength in the liquefiable sand layer in the limit equilibrium analysis was determined based on the maximum value of equivalent friction angle (Ebeling and 
Morrison 1992) and residual undrained shear strength of liquefied soil (Kramer and Wang 2007). An equivalent friction angle was calculated that was proportional to the pore water pressure ratio recorded in the centrifuge tests.. The friction angle for drained conditions for Nevada sand with different relative densities were obtained from McCullough et. al 2001 (relative densities are presented on Table 1) Because the effective friction angle determined from the Ebeling and Morrison method is not applicable to large pore pressure ratios (Ebeling and Morrison 1992), a residual undrained shear strength was specified where $\mathrm{Ru}$ values were greater than $90 \%$. The residual undrained shear strength of liquefied soil using Kramer and Wang (2007) was consistent with the weighted approach proposed by Kramer (2008) using correlations by Kramer and Wang (2007), Idriss (1998), Olson and Stark (2002), and Idriss and Boulanger (2008). The properties of the equivalent friction angle and residual shear strength are presented on Table 3. In the ten centrifuge experiments studied here, the equivalent friction angle determined by Ebeling and Morrison (1992) was controlled when Ru was generally less than 90 percent. Sensitivity of the predicated displacements to the $\mathrm{Sr}$ values are evaluated later in this paper. The pore pressure ratios and the corresponding $\mathrm{Sr}$ values are presented in Table 3 for two shaking events for each test.

Figure 2 shows a representative limit equilibrium analysis utilizing SlopeW for NJM01 Event 11. The shear resistance from LPILE with a specific displacement was incorporated into the analysis. The horizontal yield acceleration that provides a factor of safety of 1.0 is used in the subsequent Newmark analysis.

The yield acceleration in the example shown in Figure 2 was $0.053 \mathrm{~g}$. Since the pile resistances depend on soil displacements, which in turn depend on Newmark analysis, 
which in turn depend on the yield accelerations, a trial-and-error approach needs to be used to reach to equilibrium. This process is described in the next section. The final Ky values (after reaching equilibrium) for two shaking events in each test is provided in Table 3.

\subsection{Newmark Sliding Block Analysis}

Newmark was performed using acceleration time histories recorded in the centrifuge tests within the failure mass for a range of $\mathrm{Ky}$ values to calculate the magnitude of accumulated soil displacement at the ground surface during cyclic loading.

The Java computer program SLAMMER developed by the United States Geological Survey (USGS) to estimate slope displacement was used to calculate the slope displacements using the critical yield acceleration developed from the pseudo-static limit equilibrium analysis and accelerometer data from accelerometers within the inferred failure mass. The uncoupled, rigid block methods were utilized for performing the calculations. Newmark analyses are typically performed in practical applications using accelerations that are obtained from site response modeling; however, in this study, the recorded accelerations from centrifuge tests were used as the input for the Newmark analysis. Therefore, uncertainties in ground motion estimation associated with site response analysis are minimized. The location of the accelerometers that were used in the Newmark analysis are shown in Figure 3 (left figures) on the cross sections for all the five centrifuge tests. These accelerometers were selected based on the location of the shear failure plane. The accelerometers that were located inside the failure mass were used as input to the Newmark analysis. This resulted in 6 to 12 input accelerations for 
Newmark analysis which were used later to calculate slope displacements corresponding to median and median +1 standard deviation $(\sigma)$ to evaluate the uncertainties in the predicted displacements.

The shear failure planes were determined from slope stability analyses (black lines in Figure 3 (left). These failure planes were generally in agreement with the inferred failure planes from the centrifuge tests (red lines in Figure 3 left). The inferred failure planes from the centrifuge tests were determined from the peak transient soil displacement profiles that were back-calculated by double integrating the acceleration time histories at the location of accelerometers. The difference between the failure surfaces from slope stability analysis and inferred from centrifuge tests were more significant for cases where a deep-seated failure occurred due to soft Bay Mud in NJM01 or shear failure underneath CDSM layer in SMS01 which was not keyed in the underlying dense sand.

The pile pinning curves for each test (two shaking events per test) are shown in Figure 3 (right). The soil properties used in the equivalent static slope stability models for each centrifuge test is presented on Table 1. Each figure includes the following curves: (a) Pile shear resistances show the pile shear resistances summed for all the piles that pass through the failure surface. These curves are developed from LPILE analysis for a range of imposed soil displacements. (b) Sliding mass shear resistance curves which show the inverse relationship between the sum of resisting forces from the piles along the failure surface and the slope displacements calculated from Newmark analysis. Results for two 
shaking events are shown for each centrifuge test. The pile shear resistance curves are generally similar for the two events except minor differences from the difference in $p-y$ properties in each event due to different pore pressure ratios in each event. The sliding mass curves are different for each event since the input accelerations are different in each shaking event. The sliding mass curves are plotted for the median and median $+1 \sigma$ for each shaking event. The median $+1 \sigma$ displacement results in larger shear resistance from the piles compared to the median soil displacements, which consequently results in smaller increases in displacement as $+1 \sigma$ displacements calculated in the free-field condition. Therefore, the compatible displacement should be estimated based on an intersection of the pile-resisting curve and the resisting force vs sliding mass displacement curve. The intersection of the pile shear resistance curve and the sliding mass curve denote the 'equilibrium' point where the imposed displacements in LPILE analysis are compatible with the calculated displacements from Newmark analysis. For example, in NJM01, the predicted slope displacements in the first shaking event are 7.3 $\mathrm{cm}$ and $10 \mathrm{~cm}$ for the median and median $+1 \sigma$, respectively. It is useful to note that the measured slope displacement in the centrifuge test was $9 \mathrm{~cm}$. The predicted and measured displacements are compared later in the next section. In the centrifuge test SMS02, the estimated failure plane was near the bottom of the piles. Therefore, the shear resistance provided by the piles was minimal and had little effect on the analysis.

It is worth noting that the displacement corresponding to zero resisting force (i.e., the intersection of the sliding mass shear resistance curve with the horizontal axis) shows the free field displacements without considering pile pinning effects. The significant difference between the free-field slope displacements and the pile-restraint displacements 
highlights the benefits of including pile-pinning effects in the analysis.

The pile spacing is an input parameter in the limit equilibrium analysis. The pile resistance forces are assumed to be applied over the defined pile spacing. In the analysis in this study, it was assumed that the resistances from three rows of piles was distributed over the width of the centrifuge container (i.e., pile spacing $=6.1 \mathrm{~m}$ and container width $=15.2 \mathrm{~m})$. However, in practical applications in estimating embankment deformations, other methods such as those described in Caltrans (2012) may be more appropriate. Sensitivity of the predicted displacements to pile spacing is provided later in this paper. 


\subsection{Results}

The results of the estimated soil displacements were compared to the measured centrifuge displacements in section 4.1 below. Sensitivity analyses were performed to provide insight on some key assumptions that are made in design, including selection of input ground motions, pile spacing, soil shear strength, and pile group effect. The results of the sensitivity analysis are presented in sections 4.2 through 4.5 .

\subsection{Comparison of Newmark vs Centrifuge Soil Displacements}

Time histories for measured centrifuge soil displacement data is compared to the predicted soil displacements from Newmark analysis for individual acceleration data using the estimated critical yield accelerations. This comparison was performed to validate the Newmark analysis. The displacement time history should somewhat resemble the measured centrifuge in the negative direction as our analysis calculated displacements in one direction. As explained earlier, the accelerometers within the failure mass were selected for the analysis. As shown in this figure, the Newmark Displacements incrementally accumulate at every large bayward cycle that exceeds the yield acceleration. In SMS02, where the yield acceleration was large since liquefaction was not triggered (i.e. $\mathrm{Ky}=0.195 \mathrm{~g}$ for SMS02 Event 30 and $0.184 \mathrm{~g}$ for SMS02 Event 35), the acceleration cycles did not exceed the yield acceleration in the first event and resulted in zero predicted displacements. These time histories are also used to compare the Newmark displacements to the measured permanent and peak transient displacements. Acknowledging that the Newmark analysis is developed to predict the permanent slope deformations, it is observe 
from the time histories that in some cases, the predicted Newmark displacements are closer to the permanent measured displacements (such as NJM01 Event 11) and in other cases the Newmark displacement time histories do not closely fit the centrifuge displacement data. These comparisons are discussed in more detail in the next section.

The Newmark displacements are compared against the measured permanent (end of shaking) displacements in Figure 5 (left) and the peak transient displacements in Figure 5 (right) for all the ten shaking events considered in this study. The results show that the median Newmark displacements better estimated the centrifuge permanent end of shaking displacements but underestimated the measured peak transient displacements. On the other hand, the median $+1 \sigma$ Newmark displacements better estimated the peak transient displacements. The measured peak transient displacements were on average 2.3 times larger than the measured permanent displacements in these centrifuge tests. The median + $1 \sigma$ Newmark displacements were on average 1.4 times larger than the median displacements when compatibility of the displacements is considered (i.e. when pilepinning curves were developed for median and median +1 standard deviation displacements separately. For cases where compatibility of displacements are not considered (i.e. pile-pinning curves developed for median displacements are used), the median $+1 \sigma$ were on average 2.0 times larger than the median displacements. For comparison, the median $+1 \sigma$ displacements estimated from Bray and Travasarou (2007) prediction models are approximately 1.9 times larger than the median values. 


\subsection{Sensitivity to Input Ground Motions}

As described earlier data from the accelerometers within the estimated failure mass were used in the Newmark analysis in this study. Figure 6 shows the predicted displacements from all the accelerometers in the model for NJM01 Event 11 as an example. Considering that the measured permanent displacement was approximately $0.1 \mathrm{~m}$, the contour corresponding to $0.1 \mathrm{~m}$ delineates the accelerometers that over- or under- predict permanent soil displacements. It is observed that the failure surface that is determined from slope stability analysis reasonably flags the accelerations that should be used in Newmark analysis to reasonably predict the permanent soil displacements. It is also observed that using the accelerations at the base of the model (i.e. within the dense sand) underestimate measured displacements. It is also observed that the predicated Newmark displacements using accelerations that locate just below the failure surface also underpredict the measured displacements. It is also observed that the accelerations at the ground surface overpredict the measured displacements. Therefore, it is recommended for design to use the accelerations estimated within the failure mass as a basis for performing Newmark analysis. In practice, these accelerations are derived from site response analysis.

\subsection{Sensitivity to Pile Spacing}

Characterizing the extent of the foundation influence zone on the laterally spreading ground depends on the width and length of the lateral spreading as explained in Brandenberg and Turner (2017). Caltrans (2016), on a basis of embankment geometries typically encountered for highway bridge structures, recommends using an effective width based on the width and height of the embankment or 1.5 times foundation width in case of 
no embankments where the width of the failure mass is much larger than the foundation width.

The plan view of NJM01 is shown in Figure 7. The actual center-to-center pile spacing was $6.1 \mathrm{~m}$. The foundation width times 1.5 divided by three rows of piles was $7.6 \mathrm{~m}$. The total width of the centrifuge box divided by three rows of piles was $9.15 \mathrm{~m}$. Based on the geometry of the centrifuge test and the results of dissected data after the tests, it appeared that the slope moved fairly uniformly across the width of the centrifuge box. Therefore, the total width of the centrifuge box was used as the effective width and the pile spacing of 9.15 $\mathrm{m}$ was used as the baseline analysis in this study.

To evaluate the sensitivity of the predicted slope displacements to this assumption, the baseline pile spacing was 9 meters, and the spacing for sensitivity was analyzed at $12 \mathrm{~m}$ and $6 \mathrm{~m}$ for NJM01. The results are presented in the Figure 8 . The results from the pile spacing of $6 \mathrm{~m}$ and $12 \mathrm{~m}$ resulted in slope displacements ranging from $5 \mathrm{~cm}$ to $8.5 \mathrm{~cm}$ respectively for NJM01 Event 11. In general, increasing the pile spacing for NJM01 by 50 percent (12 meters) increased the estimated slope displacement by approximately 15 percent. Decreasing the pile spacing by 50 percent decreased the estimated slope displacement by roughly 10 percent. Considering that the measured permanent displacement was approximately $10 \mathrm{~cm}$ in the centrifuge test, the equivalent width approach proposed by Caltrans (2012) did not improve the soil displacement estimates. 


\subsection{Sensitivity to Residual Strength of Liquefied Soils (Sr)}

Various approaches have been proposed to determine the residual strength (Sr) of liquefied soils for the purpose of slope stability analysis. As explained earlier, in this study, we used the greater value from effective friction angle approach by Ebeling and Morrison (1992) and Kramer and Wang (2007). As a result, in cases where liquefaction was not triggered (with Ru generally lower than 85\%) Ebeling and Morrison (1992) was applied, and in cases where liquefaction either triggered or Ru was greater than 85\%, Kramer and Wang (2007) were applied. In cases where liquefaction was triggered, the Sr estimated from Kramer and Wang (2007) and other commonly used correlations were similar. This is shown in Figure 9 (Left) where the shear resistance profile for NJM01 is shown as an example. While the shear resistance calculated from Ebeling and Morrison in the middle of the loose sand layer was approximately $22 \mathrm{kPa}$ for NJM01 on both events, the estimated $\mathrm{Sr}$ value from several different residual shear strength correlations ranged from $8.0 \mathrm{kPa}$ to $18.4 \mathrm{kPa}$. The Kramer and Wang (2007) weighted approach provided a shear strength of $11.7 \mathrm{kPa}$.

To evaluate the sensitivity of the predicted slope displacement to the assumed $\mathrm{Sr}$ value, the slope stability analysis was performed for two different methods: Ebeling and Morrison (1992) and Kramer and Wang (2007). The different pile shear resisting forces for the two Sr approaches are plotted in Figure 9 (Right). Note that the pile shear force curve is not changed because the liquefied soil in LPILE analyses was modeled with API Sand p-y curve with a Ru-proportional p-multiplier. Therefore, the choice of residual shear strength model in the slope stability analysis did not affect the pile lateral load analysis. Using a 
residual shear strength (Kramer and Wang) for NJM01 Event 11, the Newmark analysis yielded a median displacement of $12 \mathrm{~cm}$ as opposed to $7 \mathrm{~cm}$ from the Ebeling and Morrison method. Considering that the measured permanent displacement was approximately $10 \mathrm{~cm}$ in the centrifuge test, both $\mathrm{Sr}$ methods illustrated the same level of accuracy in predicting the slope stability (Kramer and Wang method slightly overpredicting the slope displacements).

\subsection{Sensitivity to Pile Group Effect}

Ideally, the pile group effects should be considered in design since the piles are attached at top and move together. However, this boundary condition is sometimes ignored in design especially if piles are modeled individually (such as LPILE). The effects of including or ignoring pile group effects on the predicted slope displacements are evaluated in this section. Figure 10 displays two shear forces along the piles in NJM01 as an example. Results from two types of LPILE analyses are shown. One where pile grouping effect is included by forcing the pile heads to move equally, and the other assuming single piles that are fixed against rotation at pile head but do not necessarily move equally. It was found that boundary conditions at the pile head have negligible effect on the shear forces in the piles at the location of failure surface when the failure surface was at depths greater than 10D (pile diameters) below the ground surface.

Pile shear force at the failure surface depth is generally the same with and without group effect for the profiles studied here as the failure surfaces were typically more than 10 pile diameters in depth. The critical failure surface in NJM01 did not pass through all of the

piles. Therefore, this centrifuge test would have the greatest contrast in displacements and 
forces since the wharf deck would have an assumed uniform displacement and piles 5 through 7 would not have a displacement applied from the failure surface. Because of these attributes, NJM01 was assumed to be the centrifuge test that would be most affected by the pile grouping effect.

\subsection{Sensitivity of the Equivalent Static Analysis to Model Boundary Conditions}

The centrifuge tests were designed such that the centrifuge box would behave as free-field condition. However, it is acknowledged that this assumption was not exactly the case, because of imbalanced mass of soil on the left and right side of the model as well as the transient change of stiffness in the loose, liquefiable soil during ground motions. In this study, the equivalent static analysis models created in SlopeW were bounded by the geometry of the centrifuge models. To evaluate the effect of this assumption to the estimated soil displacements, this sensitivity analyses was performed by extending the boundary of the SlopeW model beyond the centrifuge box to reach free field conditions. The centrifuge model for NJM01, event 11 was extended to a width of approximately $100 \mathrm{~m}$ as opposed to the $69 \mathrm{~m}$ width of the centrifuge box. Figure 11 displays the example of the equivalent static SlopeW model with extended boundary and Figure 12 displays two pilepinning curves; one from the analysis presented in previous sections, and one based upon the extended boundary. The results of this analysis have shown that the median estimated Newmark displacement with the extended boundary is approximately $18 \mathrm{~cm}$ as opposed to a median Newmark displacement of $7.3 \mathrm{~cm}$ from the initial analysis. The two boundary conditions analyzed in this sensitivity analysis envelope the real boundary conditions in 
the centrifuge tests which is supported by the measured displacement of $10 \mathrm{~cm}$ in the centrifuge test. 


\subsection{Summary and Conclusions}

Data from 5 centrifuge tests on pile-supported wharfs were used to evaluate the accuracy of Newmark Sliding Block Analysis to estimate the kinematic demands on piles. The piles in the centrifuge tests were subjected to varying degrees of liquefaction-induced lateral ground deformations. Pile-pinning effects were included in the analysis by incorporating the lateral pile resistance in the limit-equilibrium slope stability analysis. The accuracy of incorporating pile-pinning effects in estimating the ground displacements and kinematic demands on piles were evaluated by comparing the estimated displacements to the measured data from centrifuge tests. Sensitivity analyses were performed to provide insight on some key assumptions that are made in design, including, selection of input ground motions, pile spacing, soil shear strength, and pile group effect.

The results of the analysis showed that the median Newmark displacements better estimated the centrifuge permanent end-of-shaking displacements but underestimated the measured peak transient displacements. On the other hand, the median $+1 \sigma$ Newmark displacements better estimated the peak transient displacements. The measured peak transient displacements were on average 2.3 times larger than the measured permanent displacements in these centrifuge tests. The median $+1 \sigma$ Newmark displacements were on average 1.4 times larger than the median displacements when compatibility of the displacements are considered (i.e. when pile-pinning curves were developed for median and median +1 standard deviation displacements separately. For case where compatibility of displacements are not considered (i.e. pile-pinning curves developed for median displacements are used), the median $+1 \sigma$ were on average 2.0 times larger than the median 
displacements. For comparison, the median $+1 \sigma$ displacements estimated from Bray and Travasarou (2007) prediction models are approximately 1.9 times larger than the median values.

Sensitivity analyses showed that predicated Newmark displacements using acceleration time histories below the failure surface underpredict the measured displacements, and that the accelerations at the ground surface overpredict the measured displacements. Therefore, it is recommended for design to use the accelerations estimated within the failure mass as a basis for performing Newmark analysis using procedures such as Makdisi and Seed (1978).

The extent of the foundation influence zone on the laterally spreading ground affects the pile spacing that is used in the limit equilibrium analysis. Sensitivity analyses were performed to evaluate the applicability of the equivalent width approach (i.e. foundation width times 1.5) proposed by Caltrans on the basis of highway bridge foundations, for wharf structures. The sensitivity analyses performed for centrifuge test NJM01 (representative of a typical marginal pile-supported wharf) showed that increasing the pile spacing by 50 percent increased the estimated slope displacement by approximately 15 percent and decreasing the pile spacing by 50 percent decreased the estimated slope displacement by roughly 10 percent. On the basis of this sensitivity analysis, the equivalent width approach proposed by Caltrans (2012) did not improve the soil displacement estimates. 
Utilizing different shear strength using different residual strength methods for NJM01 Event 11, the Newmark analysis yielded a median displacement of $12 \mathrm{~cm}$ using the Kramer and Wang method as opposed to $7 \mathrm{~cm}$ from the Ebeling and Morrison method.

Considering that the measured permanent displacement was approximately $10 \mathrm{~cm}$ in the centrifuge test, both $\mathrm{Sr}$ methods illustrated the similar level of accuracy in predicting the slope stability. It is recommended to estimate the residual shear strength using the weighted approach proposed by Kramer (2008) in liquefied soils when pore pressure ratio is greater than 90\% and the Ebeling and Morrison (1992) in cases where pore pressure ratio is less than $90 \%$.

For NJM01, pile shear force at the failure surface depth is generally the same with and without group effect for the profiles studied here. The pile head condition appears to have a negligible effect at the depth of the failure surface if the failure surface is more than 10 pile diameters in depth.

Uncertainty of estimated accelerations were not considered in this study. In practice, accelerations are obtained from performing site response analysis. Uncertainly for developing pore water pressures were not considered. In practice, the pore pressures can be estimated using correlations of $\mathrm{Ru}$ and factor of safety against liquefaction such as Marcuson et al. (1990). The potential effects after multiple shaking events of soil properties were not considered in this study. The results presented here are based on the geometries of the centrifuge tests that were analyzed in this study. 


\section{Tables}

Table 1. Pile, superstructure, soil properties and ground motions in centrifuge tests (in prototype scale)

\begin{tabular}{|c|c|c|c|c|c|}
\hline $\begin{array}{l}\text { Test } \\
\text { ID }^{1} \\
\end{array}$ & Pile properties ${ }^{2}$ & $\begin{array}{l}\text { Superstructure } \\
\text { properties }\end{array}$ & Soil properties & $\begin{array}{c}\text { Applied } \\
\text { ground } \\
\text { motions at } \\
\text { base } \\
\end{array}$ & $\begin{array}{l}\text { Scaled } \\
\text { PGA } \\
\text { at base } \\
(\mathrm{g}) \\
\end{array}$ \\
\hline NJM01 & $\begin{array}{l}\text { Pile } \mathrm{D}=0.64 \mathrm{~m} \\
\mathrm{t}=0.036 \mathrm{~m} \\
\mathrm{~L}=27.2 \mathrm{~m} \\
\mathrm{EI}=2.1 \mathrm{e} 5 \mathrm{kPa}^{4} \mathrm{~m}^{4}\end{array}$ & $\begin{array}{l}\text { Wharf deck } \\
33.7 \mathrm{~m} \times 15.2 \\
\mathrm{~m} \times 0.25 \mathrm{~m} \\
\operatorname{mass}=714.8 \\
\mathrm{Mg}\end{array}$ & $\begin{array}{l}\text { Nevada loose sand } D_{R}=39 \% \\
\text { Nevada dense sand, } D_{R}=82 \% \\
\text { Rockfill, friction angle }=45 \mathrm{deg}\end{array}$ & $\begin{array}{l}\text { Event 11: } \\
\text { Loma } \\
\text { Prieta }^{3} / \\
\text { Event 13: } \\
\text { Northridge }^{4}\end{array}$ & $\begin{array}{l}0.15 / \\
0.73\end{array}$ \\
\hline NJM02 & $\begin{array}{l}\text { Pile } \mathrm{D}=0.38 \mathrm{~m} \\
\mathrm{t}=0.036 \mathrm{~m} \\
\mathrm{~L}=25.1 \mathrm{~m} \\
\mathrm{EI}=4.1 \mathrm{e} 4 \mathrm{kPa}-\mathrm{m}^{4}\end{array}$ & $\begin{array}{l}\text { Wharf deck } \\
24.9 \mathrm{~m} \times 12.2 \\
\mathrm{~m} \times 0.25 \mathrm{~m} \\
\operatorname{mass}=265.8 \\
\mathrm{Mg}\end{array}$ & $\begin{array}{l}\text { Nevada loose sand } D_{R}=45 \% \\
\text { Nevada dense sand, } D_{R}=85 \% \\
\text { Bay Mud, undrained shear } \\
\text { strength }=38 \mathrm{kPa} \\
\text { Rockfill, friction angle }=45 \mathrm{deg}\end{array}$ & $\begin{array}{l}\text { Event 42: } \\
\text { Loma } \\
\text { Prieta }^{3} / \\
\text { Event 55: } \\
\text { Northridge }^{4}\end{array}$ & $\begin{array}{l}0.19 / \\
0.72\end{array}$ \\
\hline SMS01 & $\begin{array}{l}\text { Pile } \mathrm{D}=0.38 \mathrm{~m} \\
\mathrm{t}=0.036 \mathrm{~m} \\
\mathrm{~L}=25.1 \mathrm{~m} \\
\mathrm{EI}=4.1 \mathrm{e} 4 \mathrm{kPa}-\mathrm{m}^{4}\end{array}$ & $\begin{array}{l}\text { Wharf deck } \\
24.9 \mathrm{~m} \times 12.2 \\
\mathrm{~m} \times 0.25 \mathrm{~m} \\
\operatorname{mass}=265.8 \\
\mathrm{Mg}\end{array}$ & $\begin{array}{l}\text { Nevada loose sand } D_{R}=30 \% \\
\text { Nevada dense sand, } D_{R}=70 \% \\
C D S M \text {, unconfined compressive } \\
\text { strength }=0.9 \mathrm{MPa} \\
\text { Rockfill, friction angle }=45 \mathrm{deg}\end{array}$ & $\begin{array}{l}\text { Event 25: } \\
\text { Loma } \\
\text { Prieta }^{3} / \\
\text { Event 44: } \\
\text { Northridge }^{4}\end{array}$ & $\begin{array}{l}0.42 / \\
0.40\end{array}$ \\
\hline SMS02 & $\begin{array}{l}\text { Pile } \mathrm{D}=0.64 \mathrm{~m} \\
\mathrm{t}=0.036 \mathrm{~m} \\
\mathrm{~L}=24.3 \mathrm{~m} \\
\mathrm{EI}=2.1 \mathrm{e} 5 \mathrm{kPa}-\mathrm{m}^{4}\end{array}$ & $\begin{array}{l}\text { Wharf deck } \\
28.1 \mathrm{~m} \times 12.0 \\
\mathrm{~m} \times 0.78 \mathrm{~m} \\
\operatorname{mass}=951.6 \\
\mathrm{Mg}\end{array}$ & $\begin{array}{l}\text { Nevada dense sand, } D_{R}=70 \% \\
\text { Rockfill, friction angle }=45 \mathrm{deg}\end{array}$ & $\begin{array}{l}\text { Event 30: } \\
\text { Loma } \\
\text { Prieta }^{3} / \\
\text { Event 35: } \\
\text { Northridge }^{4}\end{array}$ & $\begin{array}{l}0.20 / \\
0.56\end{array}$ \\
\hline JCB01 & $\begin{array}{l}\text { Pile } \mathrm{D}=0.64 \mathrm{~m} \\
\mathrm{t}=0.036 \mathrm{~m} \\
\mathrm{~L}=24.3 \mathrm{~m} \\
\mathrm{EI}=2.1 \mathrm{e} 5 \mathrm{kPa}-\mathrm{m}^{4}\end{array}$ & $\begin{array}{l}\text { Wharf deck } \\
28.1 \mathrm{~m} \times 12.0 \\
\mathrm{~m} \times 0.78 \mathrm{~m} \\
\operatorname{mass}=951.6 \\
\mathrm{Mg}\end{array}$ & $\begin{array}{l}\text { Nevada loose sand } D_{R}=40 \% \\
\text { Nevada dense sand, } D_{R}=74 \% \\
\text { Rockfill, friction angle }=45 \mathrm{deg}\end{array}$ & $\begin{array}{l}\text { Event 18: } \\
\text { Loma } \\
\text { Prieta }^{3} / \\
\text { Event 23: } \\
\text { Loma } \\
\text { Prieta }^{3}\end{array}$ & $\begin{array}{l}0.15 / \\
0.15\end{array}$ \\
\hline
\end{tabular}

1. The centrifuge scale factor was 40.1 for all tests.

2. Pile group consists of 21 piles (in a 3-by-7 setup).

3. 1989 Loma Prieta Outer Harbor Station.

4. 1994 Northridge Rinaldi Station. This time history was recorded less than $10 \mathrm{~km}$ from the fault and included a velocity pulse. 
Table 2. P-Y spring properties used in LPILE

\begin{tabular}{|c|c|c|c|c|c|c|c|c|}
\hline Test ID & Material & $\begin{array}{c}\text { P-Y } \\
\text { Spring }\end{array}$ & $\begin{array}{c}\text { Total } \\
\text { Unit } \\
\text { Weight, } \gamma \\
\left(\mathrm{kN} / \mathrm{m}^{3}\right)\end{array}$ & $\begin{array}{l}\text { Friction } \\
\text { Angle, } \\
\phi(\text { deg })\end{array}$ & $\begin{array}{c}\text { Modulus of } \\
\text { Subgrade } \\
\text { Reaction, } K \\
\left(\mathrm{kN} / \mathrm{m}^{3}\right) \\
\end{array}$ & $\begin{array}{l}\text { Undrained } \\
\text { Shear } \\
\text { Strength, } \\
C\left(\mathrm{kN} / \mathrm{m}^{2}\right)\end{array}$ & $\begin{array}{c}\text { Strain } \\
\text { Factor } \\
\text { E50 }\end{array}$ & $\begin{array}{l}\text { p-Multiplier } \\
\text { due to } \\
\text { Dynamic } \\
\text { Excess } \\
\text { PWP }\end{array}$ \\
\hline \multirow[t]{3}{*}{$\overline{\text { NJM01 }}$} & $\begin{array}{l}\text { Loose Nevada } \\
\text { Sand } \\
(\mathrm{DR}=39 \%)\end{array}$ & API Sand & 19.4 & 33 & 3500 & -- & -- & 0.2 \\
\hline & $\begin{array}{l}\text { Dense Nevada } \\
\text { Sand } \\
(\mathrm{DR}=82 \%)\end{array}$ & API Sand & 20.4 & 37 & 3500 & -- & -- & -- \\
\hline & Rockfill & $\begin{array}{l}\text { Cemented } \\
\text { c-phi }\end{array}$ & 20.5 & 45 & 5200 & 15 & -- & -- \\
\hline \multirow[t]{4}{*}{ NJM02 } & $\begin{array}{l}\text { Loose Nevada } \\
\text { Sand } \\
(\mathrm{DR}=45 \%)\end{array}$ & API Sand & 18.7 & 33 & 3500 & -- & -- & 0.6 \\
\hline & $\begin{array}{l}\text { Dense Nevada } \\
\text { Sand } \\
(\mathrm{DR}=85 \%)\end{array}$ & API Sand & 20.8 & 37 & 3500 & -- & -- & 0.8 \\
\hline & Bay Mud & $\begin{array}{l}\text { Soft Clay } \\
\text { (Matlock) }\end{array}$ & 15.7 & -- & -- & 38 & 0.02 & -- \\
\hline & Rockfill & $\begin{array}{l}\text { Cemented } \\
\text { c-phi }\end{array}$ & 20.8 & 45 & 5200 & 15 & -- & -- \\
\hline \multirow[t]{3}{*}{ SMS01 } & Dense Nevada & & 20.1 & 37 & 3500 & -- & -- & 0.3 \\
\hline & $\begin{array}{l}\text { Sand } \\
(\mathrm{DR}=70 \%) \\
\text { Cement Deep } \\
\text { Soil } \\
\text { Mixing (CDSM) }\end{array}$ & & 19.6 & -- & -- & 450 & 0.1 & 0.7 \\
\hline & Rockfill & $\begin{array}{l}\text { Cemented } \\
\text { c-phi }\end{array}$ & 20.3 & 45 & 5200 & -- & -- & 0.6 \\
\hline \multirow[t]{2}{*}{ SMS02 } & $\begin{array}{l}\text { Dense Nevada } \\
\text { Sand } \\
(\mathrm{DR}=82 \%)\end{array}$ & API Sand & 20.1 & 37 & 3500 & -- & -- & -- \\
\hline & Rockfill & $\begin{array}{l}\text { Cemented } \\
\text { c-phi }\end{array}$ & 20.0 & 45 & 5200 & 15 & -- & $0.5-0.8$ \\
\hline \multirow[t]{3}{*}{ JCB01 } & $\begin{array}{l}\text { Loose Nevada } \\
\text { Sand } \\
(\mathrm{DR}=40 \%)\end{array}$ & API Sand & 19.4 & 33 & 3500 & -- & -- & $0.2-0.6$ \\
\hline & $\begin{array}{l}\text { Dense Nevada } \\
\text { Sand } \\
(\mathrm{DR}=74 \%)\end{array}$ & API Sand & 20.2 & 37 & 3500 & -- & -- & 0.7 \\
\hline & Rockfill & $\begin{array}{l}\text { Cemented } \\
\text { c-phi }\end{array}$ & 20.0 & 45 & 5200 & 15 & -- & -- \\
\hline
\end{tabular}

1. $\mathrm{PWP}=$ pore water pressure 
Table 3. Soil shear strength, pore pressure properties, yield acceleration, and calculated Newmark displacement in the five centrifuge tests

\begin{tabular}{|c|c|c|c|c|c|c|c|c|}
\hline \multirow[b]{2}{*}{ Model } & \multirow[b]{2}{*}{ Event } & \multicolumn{2}{|c|}{$\begin{array}{c}\text { Sr (Middle of } \\
\text { Soil Layer) } \\
\text { kPa }\end{array}$} & \multicolumn{2}{|c|}{$\begin{array}{c}\text { Excess PP Ratio, Ru, } \\
(\%)\end{array}$} & \multirow[b]{2}{*}{$\begin{array}{c}\text { Yield } \\
\text { Acceleration, } \\
\text { Ky }(\mathrm{g})\end{array}$} & \multicolumn{2}{|c|}{$\begin{array}{c}\text { Newmark } \\
\text { Displacement } \\
(\mathrm{cm})\end{array}$} \\
\hline & & $\begin{array}{c}\text { Loose } \\
\text { Sand }\end{array}$ & $\begin{array}{l}\text { Dense } \\
\text { Sand }\end{array}$ & $\begin{array}{l}\text { Loose } \\
\text { Sand }\end{array}$ & $\begin{array}{l}\text { Dense } \\
\text { Sand }\end{array}$ & & Mean & $\begin{array}{l}\text { Std. } \\
\text { Dev }\end{array}$ \\
\hline NJM01 & 11 & 22.8 & 103.9 & 80 & 24 & 0.053 & 7.3 & 2.7 \\
\hline NJM01 & 13 & 21.7 & 102.5 & 81 & 25 & 0.098 & 25.5 & 7.5 \\
\hline NJM02 & 42 & 36 & 70.1 & 52 & 21 & 0.063 & 5.8 & 1.2 \\
\hline NJM02 & 55 & 30 & 70.1 & 60 & 21 & 0.127 & 23.9 & 5.1 \\
\hline SMS01 & 25 & $* 7.4$ & 26.7 & 100 & 47 & 0.085 & 15.0 & 7.0 \\
\hline SMS01 & 44 & 8.3 & 32.3 & 81 & 36 & 0.135 & 15.6 & 8.4 \\
\hline SMS02 & 30 & n.a. & 119.1 & n.a. & 30 & 0.195 & 0.0 & 0.0 \\
\hline SMS02 & 35 & n.a. & 119.1 & n.a. & 30 & 0.184 & 9.6 & 2.35 \\
\hline JCB01 & 18 & $* 9.5$ & 39.6 & 94 & 30 & 0.043 & 17.3 & 5.7 \\
\hline JCB01 & 23 & $* 9.5$ & 46.3 & 84 & 18 & 0.036 & 15.6 & 10.4 \\
\hline
\end{tabular}

1. Ebeling and Morrison (1992) method was utilized for calculation of Sr with exception to some loose sand layers, these layers are marked with "**" where Kramer and Wang (2007) method were utilized. 


\section{Figures}

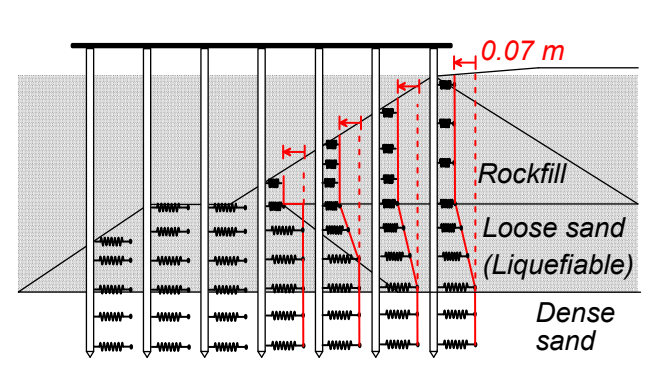

Note: Soil displacements estimated from Newmark and applied to end-node of $p$-y springs assuming no deformations within rockfill

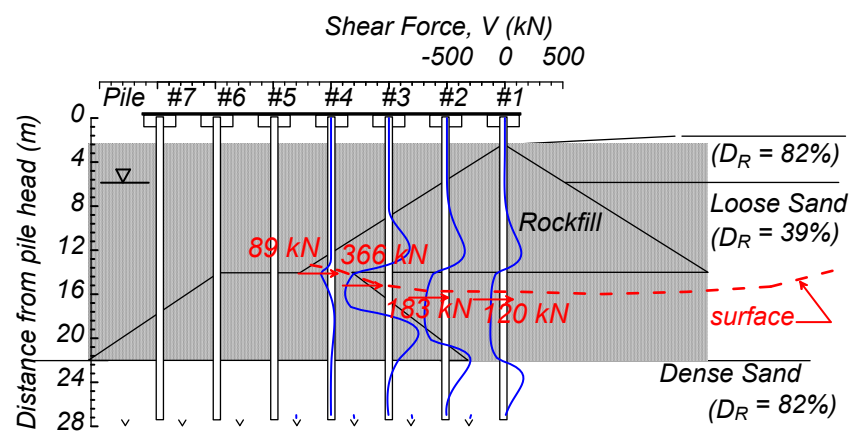

Note: Shear forces in piles at intersection with failure surface extracted from $p-y$ models and applied in slope stability analysis

Fig. 1. Lateral load behavior of piles in LPILE: (a) soil displacements applied to the end node of p-y springs, (b) shear forces along the piles and at the failure surface.

\section{Distance from Edge of Centrifuge Box (m)}

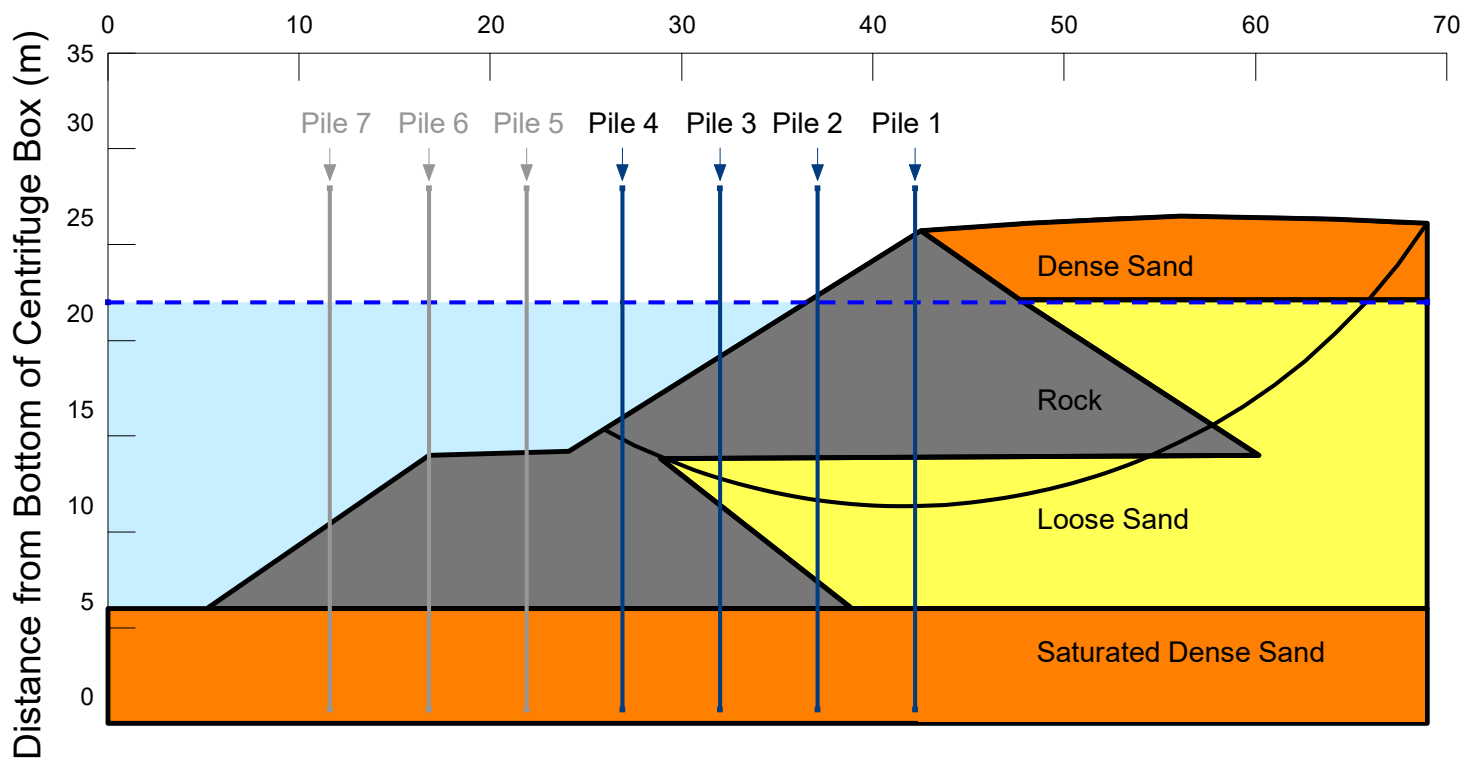

Fig. 2. Representative limit equilibrium analysis in SlopeW Model for NJM01 Event 11 incorporating pile pinning effects. Shear resistance from LPILE Applied at Failure Surface. 

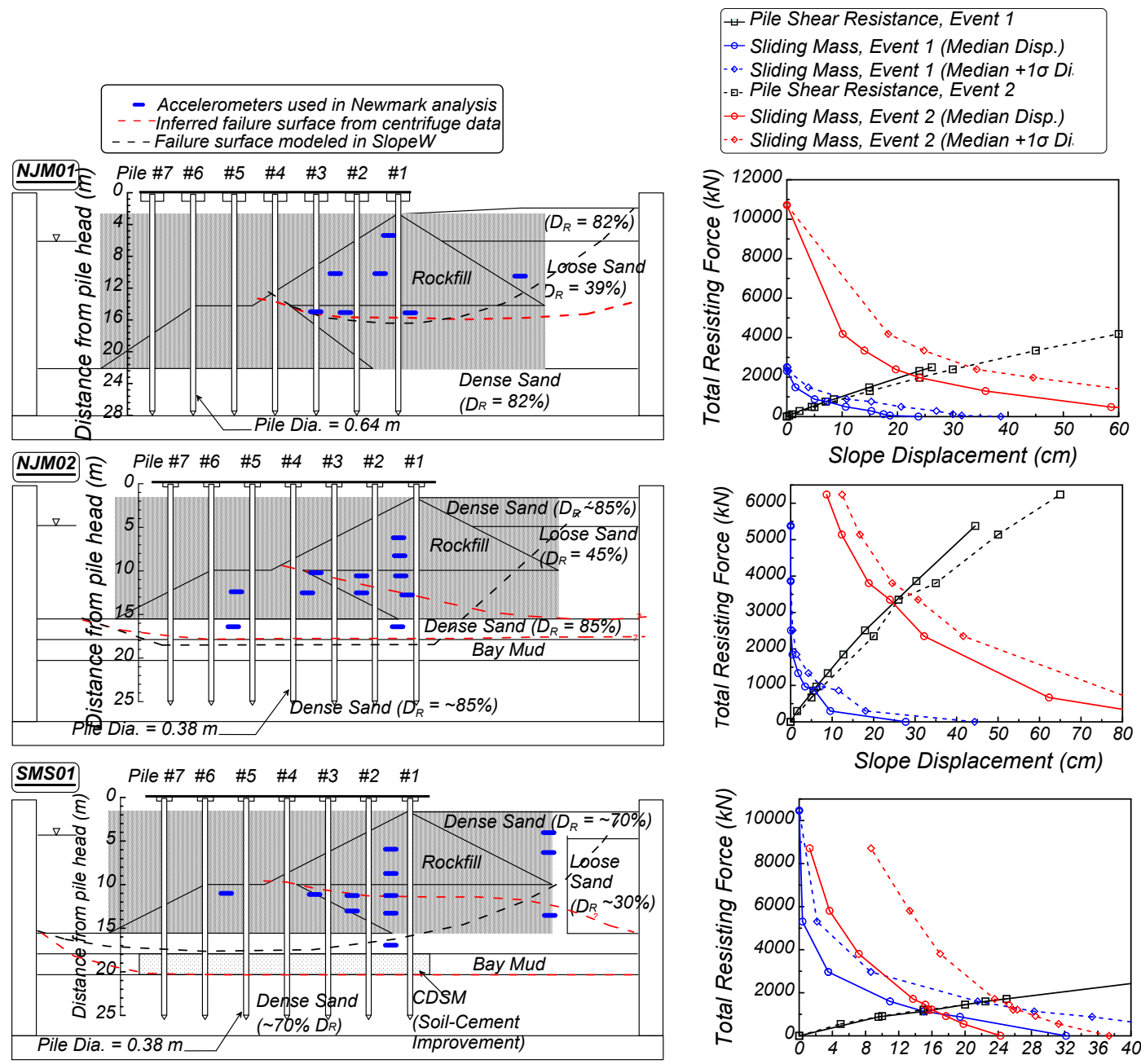

\section{$\underline{\underline{S M S 02}}$}

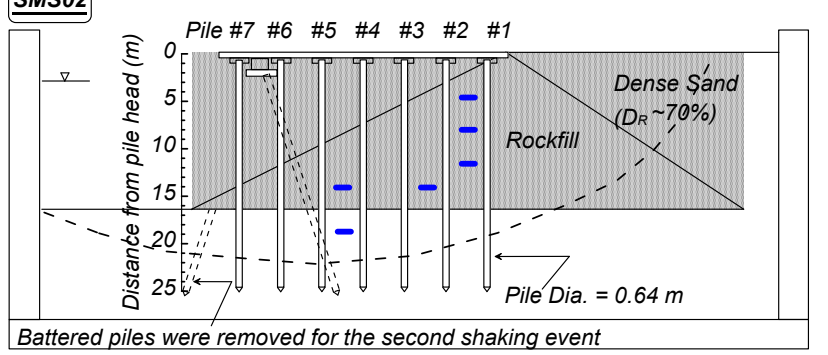

Battered piles were removed for the second shaking event
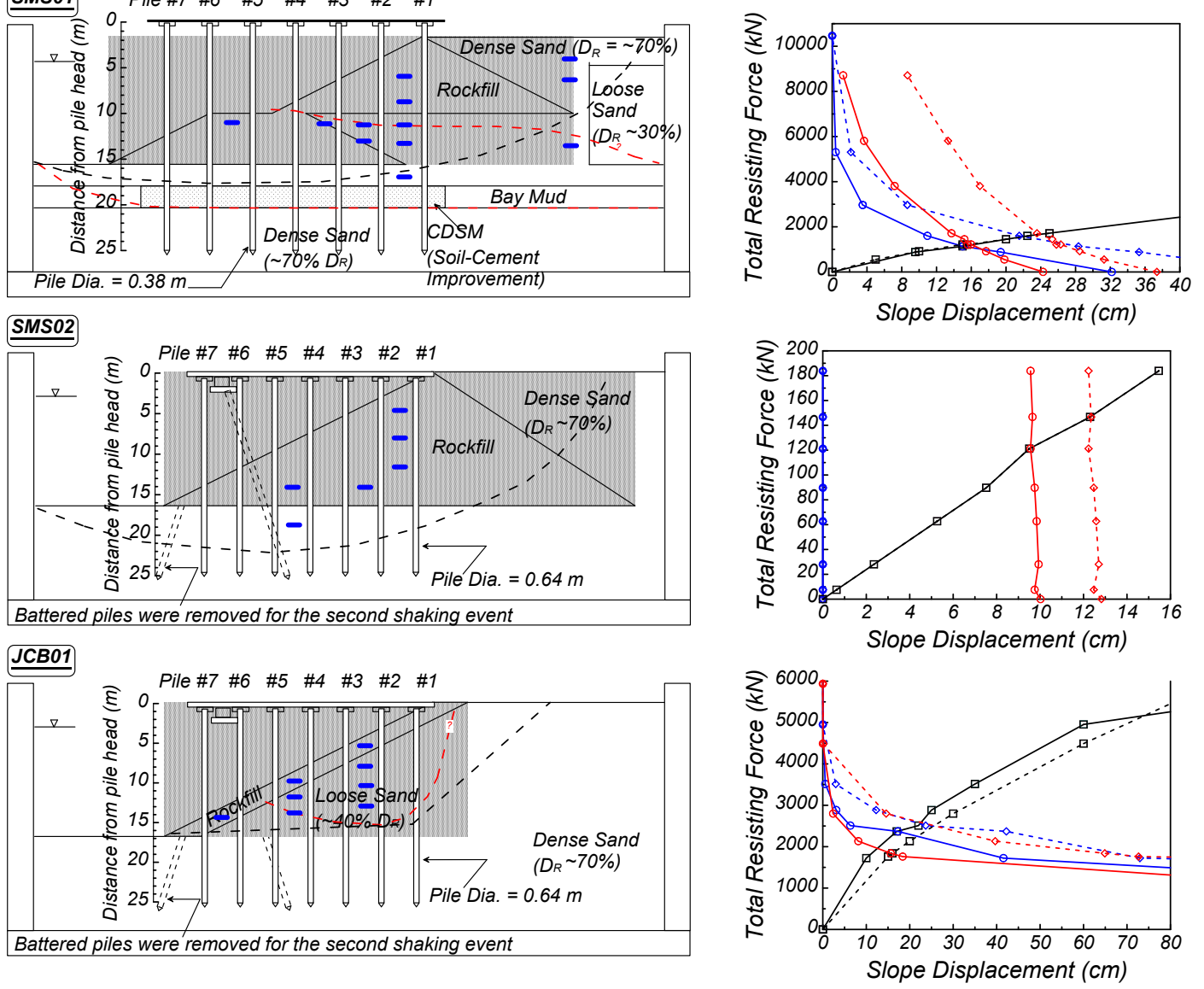

Fig. 3. (Left) Five centrifuge models with inferred and modeled Failure Surfaces, and accelerometers used in Newmark displacements. (Right) Pile-pinning curves from sliding mass and pile shear resistance for each event. 


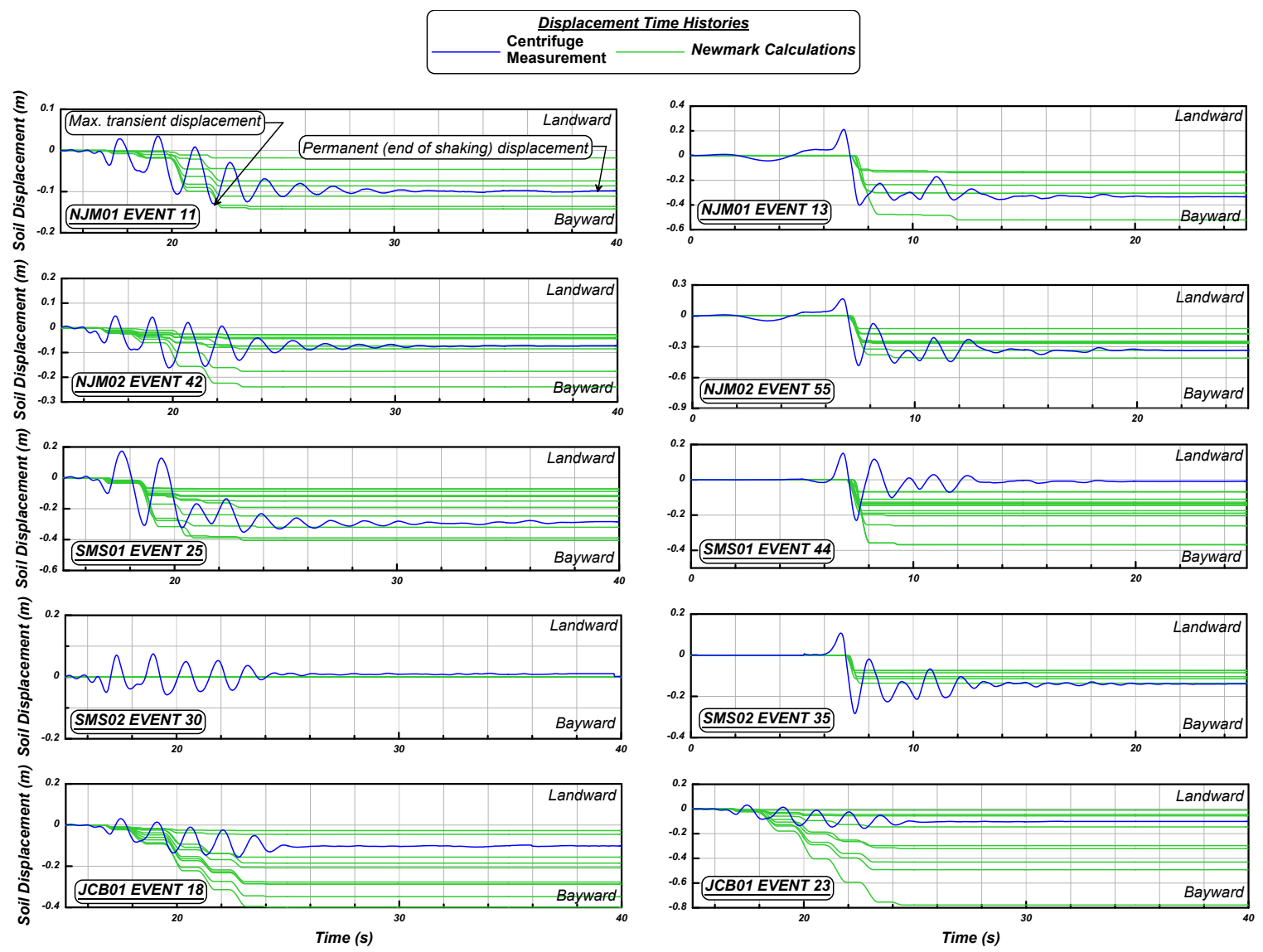

Fig. 4. Displacement time histories from ten centrifuge shaking events. The measured centrifuge displacement is compared to the calculated Newmark displacement throughout each time history. 


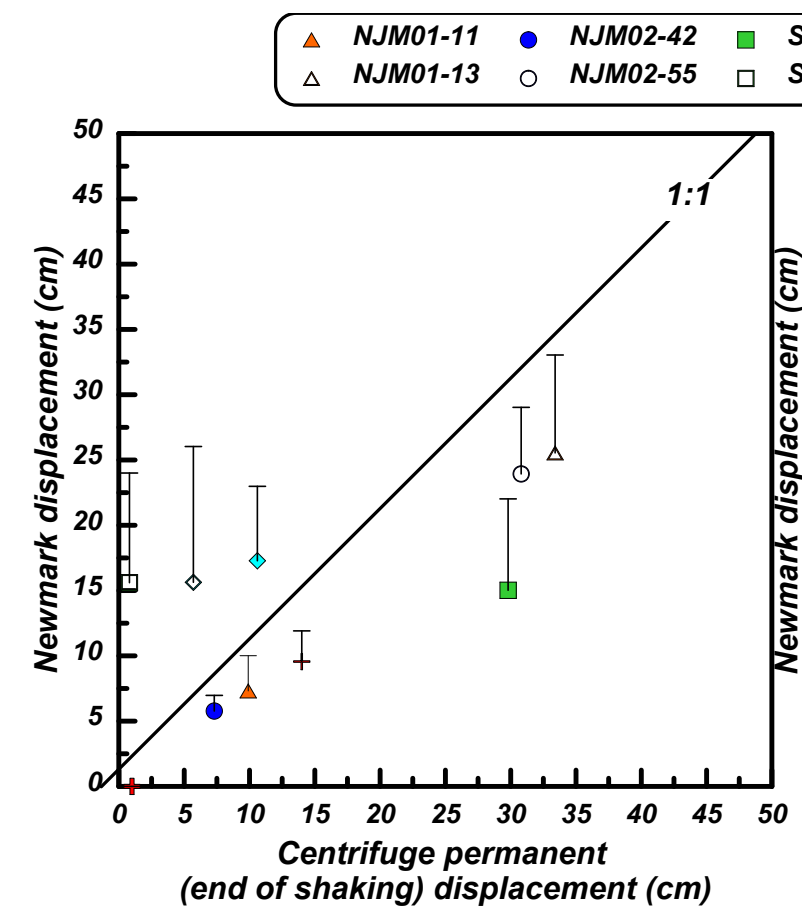

$\begin{array}{lllll}S M S 01-25 & +S M S 02-30 & \diamond & J C B 01-18 \\ S M S 01-44 & + & S M S 02-35 & \diamond & J C B 01-23\end{array}$

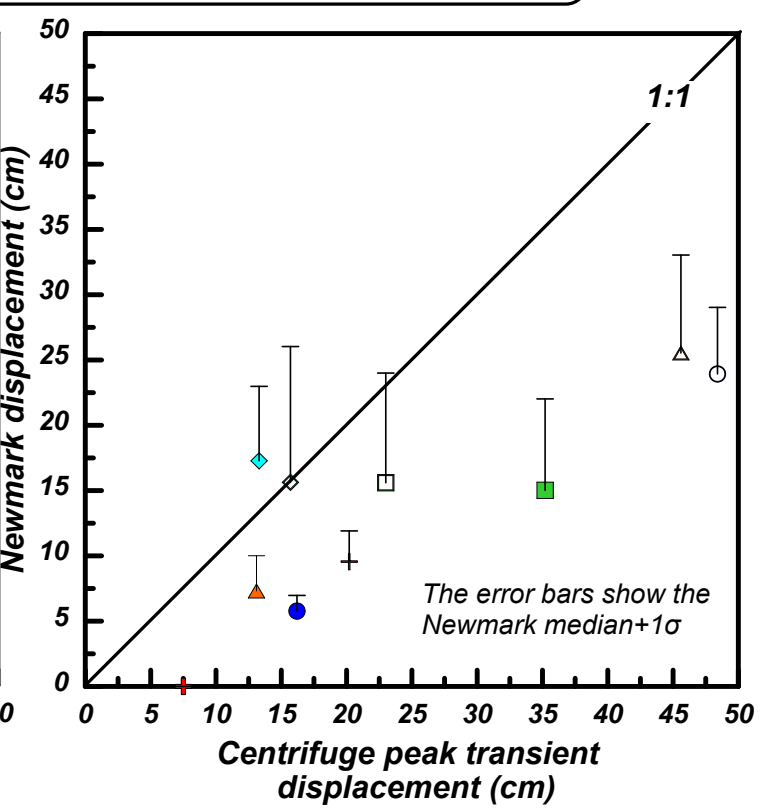

Fig. 5. (Left) Measured permanent (end-of-shaking) centrifuge displacements in comparison to calculated Newmark displacements (Median and Median $+1 \sigma$ ). (Right) Measured maximum transient centrifuge displacements in comparison to calculated Newmark displacements (Median and Median $+1 \sigma$ ).

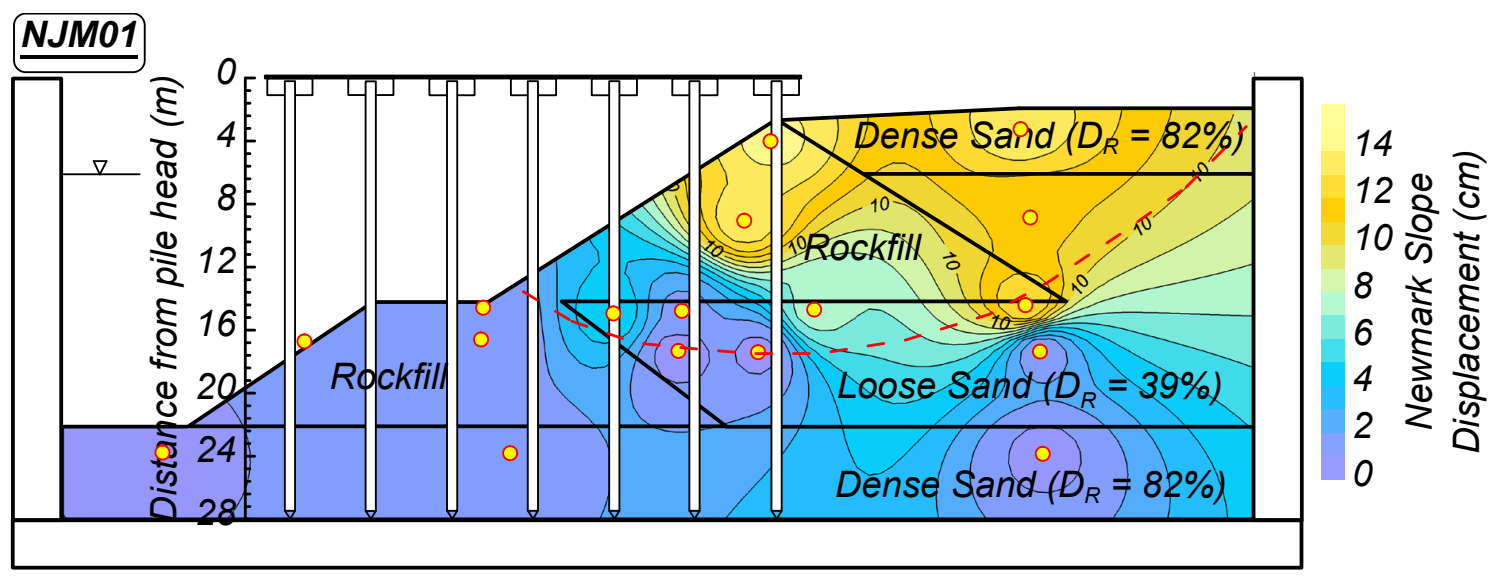

Fig. 6. Predicted Newmark displacements from all the accelerometers in the centrifuge model for NJM01 Event 11. 


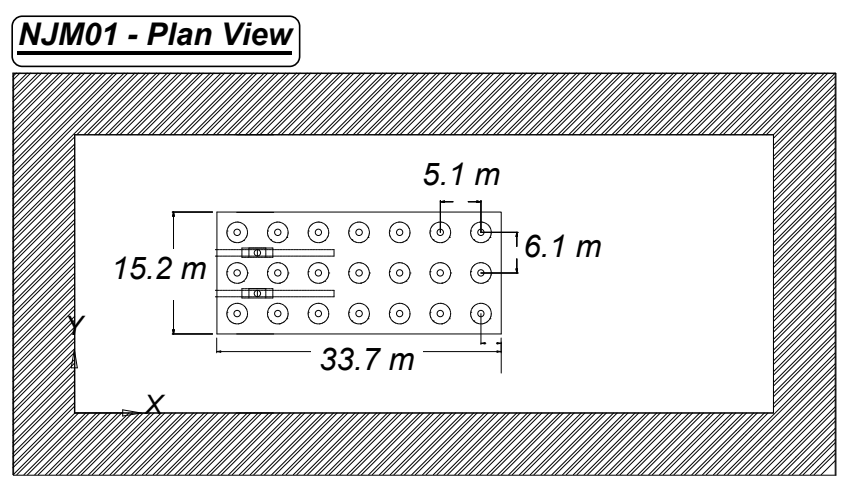

Fig. 7. Plan view for NJM01 centrifuge test with pile spacing and dimensions.

- - Sliding Mass Shear Resistance, 6m Spacing $\square$ Sliding Mass Shear Resistance, $12 m$ Spacing
- Sliding Mass Shear Resistance, 9.15m Spacing $\rightarrow$ - Pile Shear Resistance



Fig. 8. Pile-pinning curves based upon different pile spacings for NJM01, Event 11. 


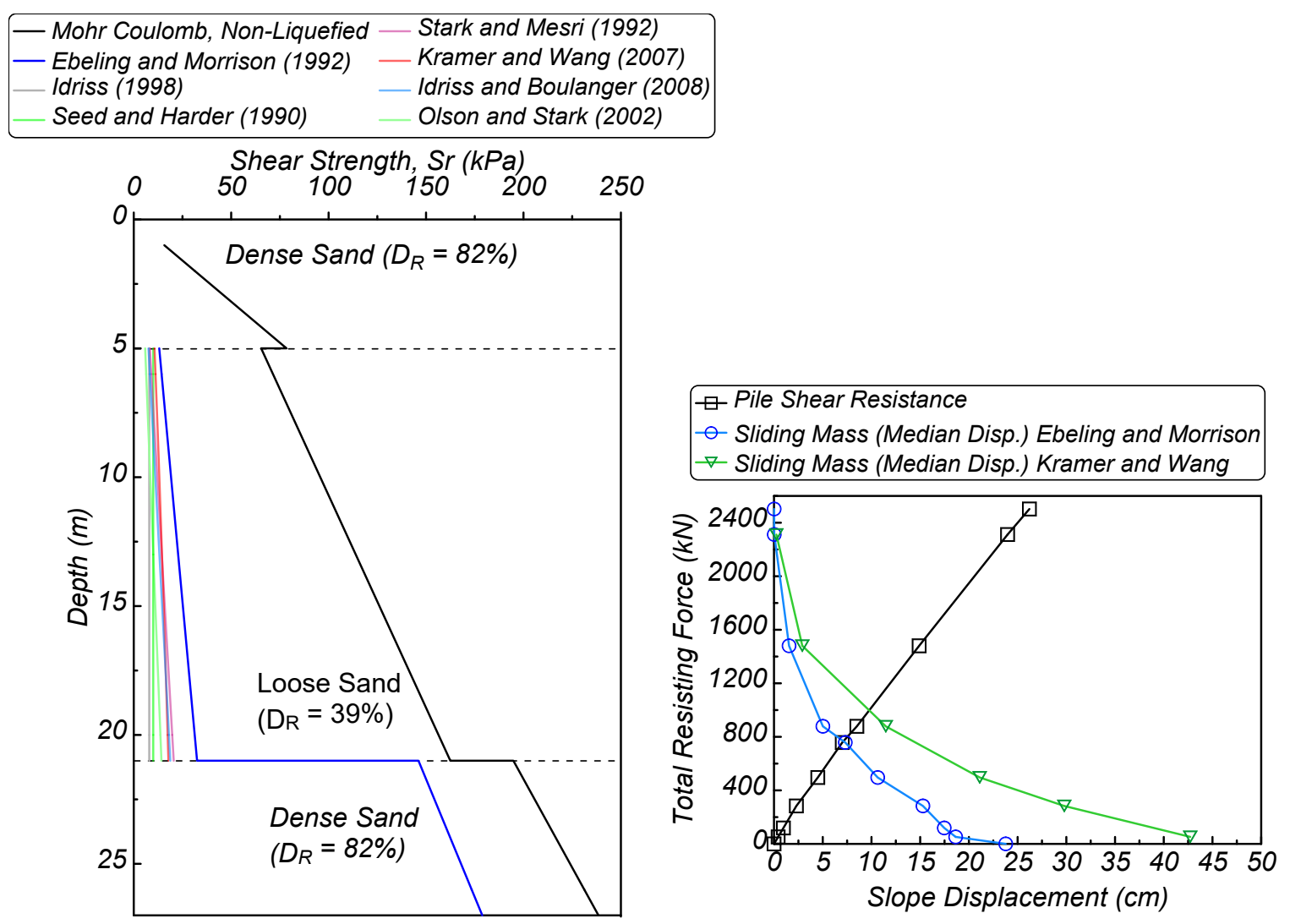

Fig. 9. (Left) Calculated soil shear strength with depth for NJM01 using different methodologies. (Right) Estimated pile resistances and sliding mass displacements utilizing two different shear strength models (Kramer and Wang and Ebeling and Morrison). 


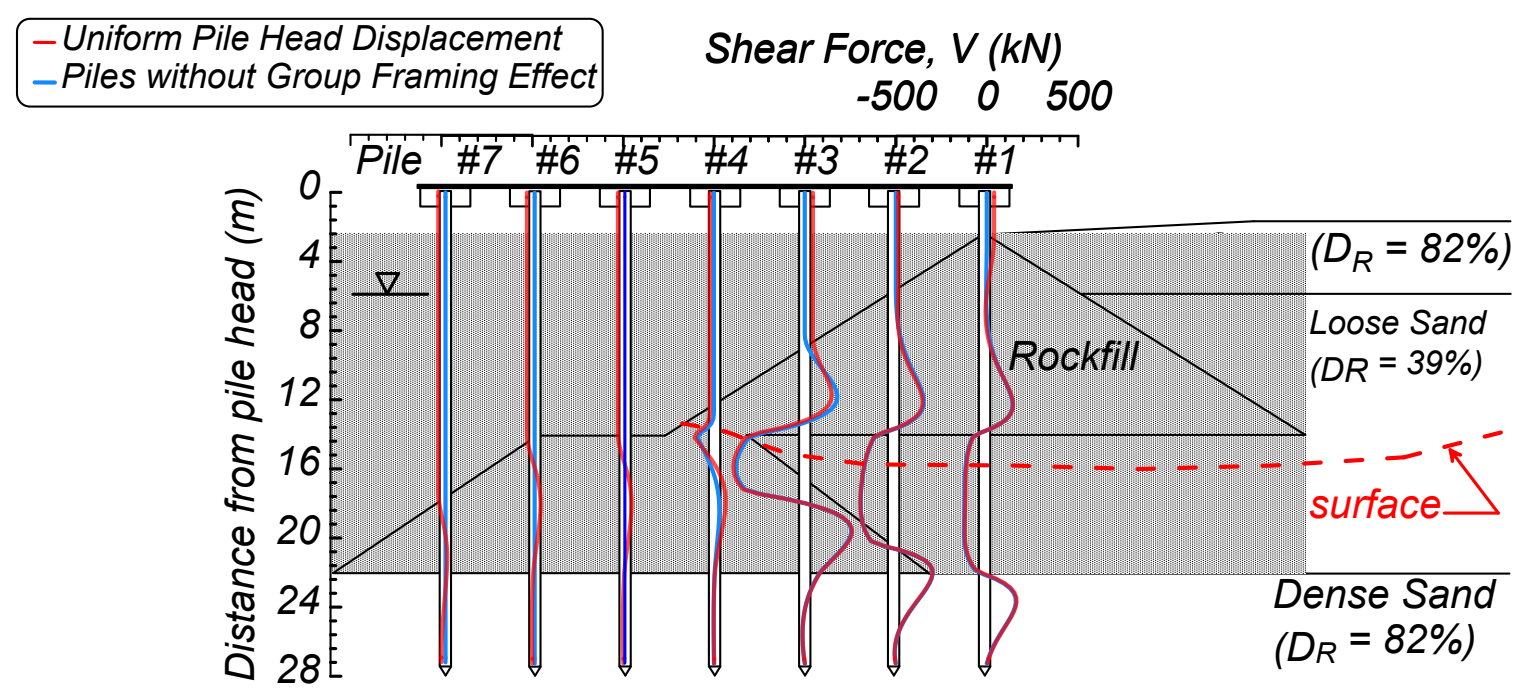

Fig. 10. Comparison of piles with different pile head conditions. Piles with uniform head displacement and piles without group framing effect.

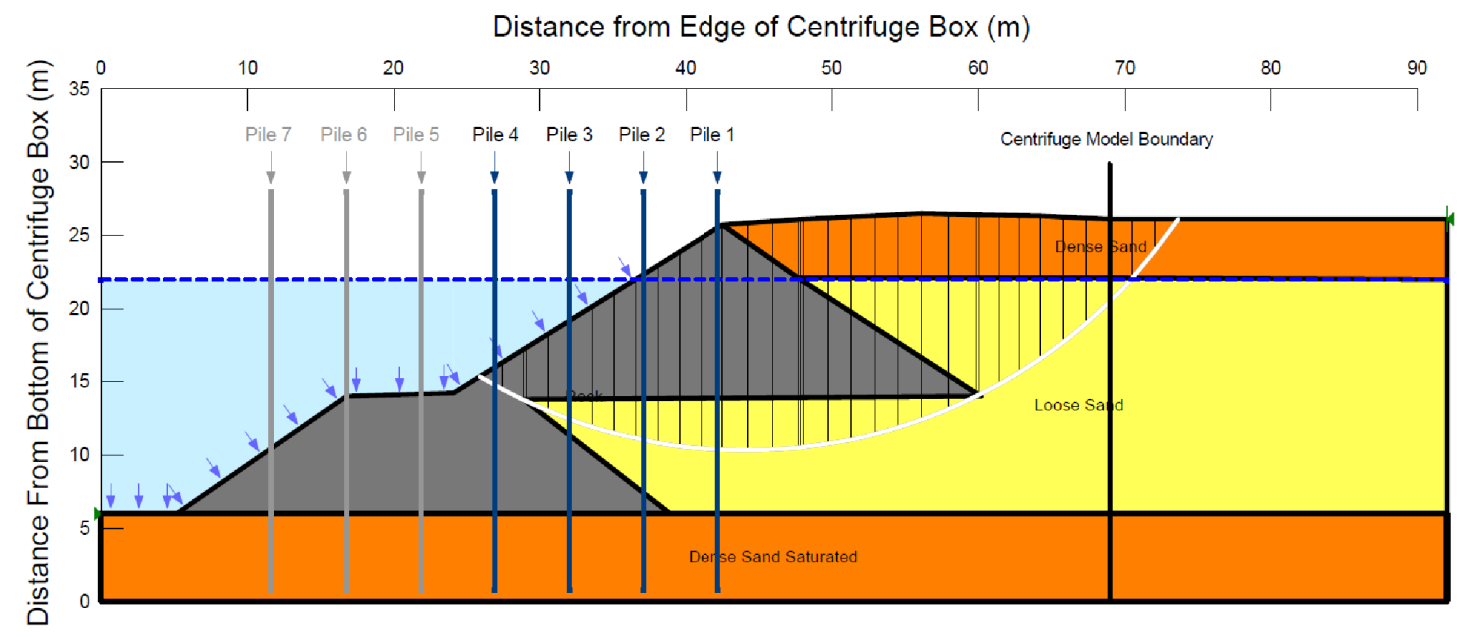

Fig. 11. Representative limit equilibrium analysis in SlopeW Model for NJM01 Event 11 with extended model boundary. 


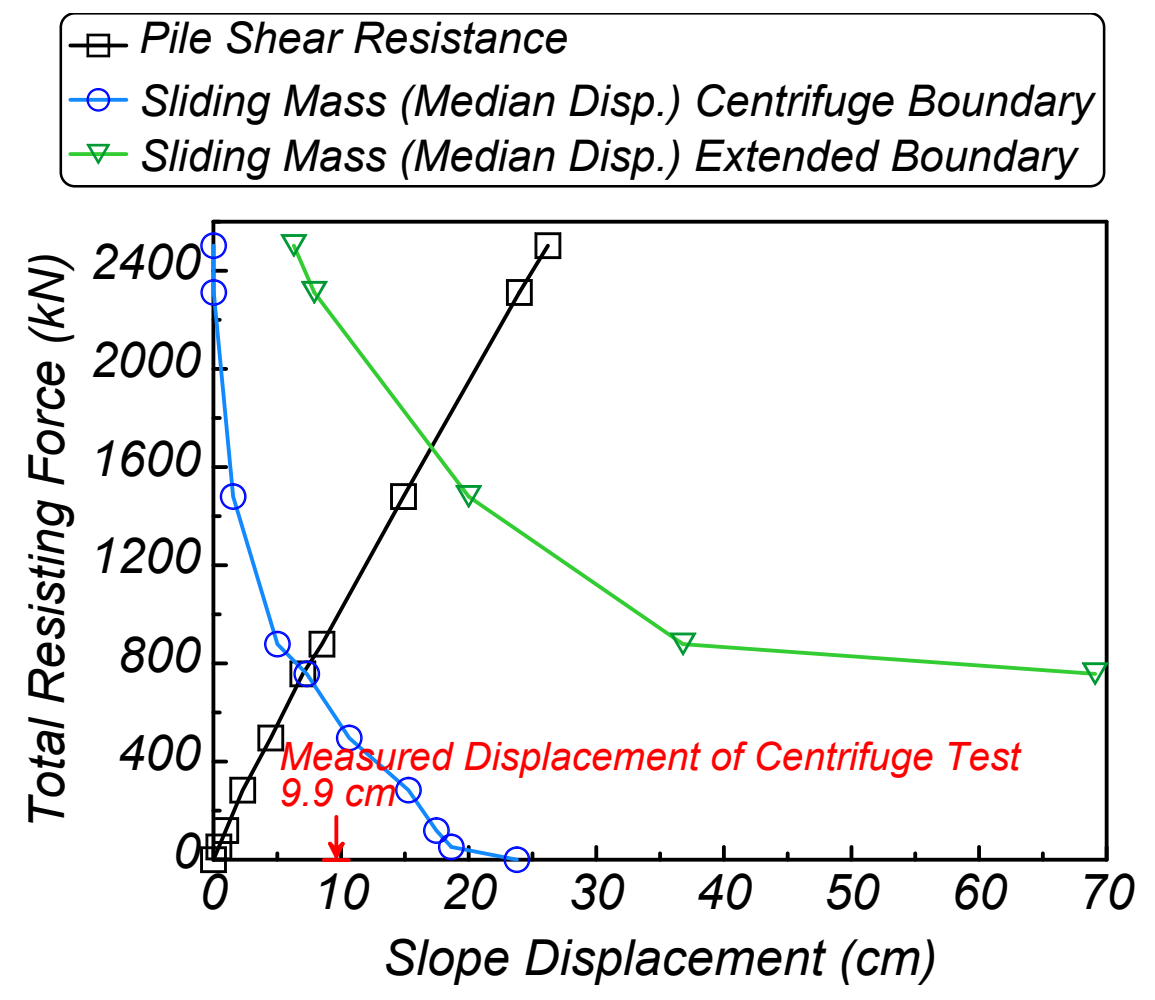

Fig. 12. Estimated pile-pinning curves based upon different model boundary conditions for NJM01, Event 11. 


\section{References}

AASHTO, (2014). “Guide Specifications for LRFD Seismic Bridge Design.” Second Edition with 2014 Interim, AASHTO, Washington, D.C.

Abdoun, T., Dobry, R., O’Rourke, T. D., and Goh, S. H., (2003). "Pile Response to lateral spreads: Centrifuge modeling." J. Geotech. Geoenviron. Eng., 129, 10, 869-878.

ASCE/COPRI 61-14, (2014). "Seismic Design of Piers and Wharves, prepared by the ASCE Standards Comm. on Seismic Design of Piers and Wharves.” ASCE, Reston, VA.

Brandenberg, S. J., Chang, D., Boulanger, R. W., and Kutter, B. L., (2003). "Behavior of piles in laterally spreading ground during earthquakes - centrifuge data report for SJB03.” In press, Center for Geotechnical Modeling, Department of Civil Engineering, University of California, Davis.

Brandenberg, S. J., Boulanger, R. W., Kutter, B. L., and Chang, D. (2005). "Behavior of pile foundations in laterally spreading ground during centrifuge tests." Journal of Geotechnical and Geoenvironmental Engineering, ASCE, 131(11), 1378-1391.

Brandenberg, S. J., Boulanger, R. W., Kutter, B. L., and Chang, D., (2007). "Static pushover analyses of pile groups in liquefied and laterally spreading ground in centrifuge tests." Journal of Geotechnical and Geoenvironmental Engineering, ASCE, 133, 9, 10551066.

Boland, C.B., Schlechter S.M., McCullough, N.J., Dickenson, S.E., Kutter, B.L. and Wilson, D.W., (2001). "Pile-Supported Wharf - Centrifuge Model SMS02.” Report No. GEG04-2000, OSU-Geotechnical Engr.

Boland, C.B., Schlechter S.M., McCullough, N.J., Dickenson, S.E., Kutter, B.L. and Wilson, D.W., (2001). "Pile-Supported Wharf - Centrifuge Model JCB01." Report No. GEG05-2000, OSU-Geotechnical Engr.

Boulanger, R. W., Chang, D., Gulerce, U., Brandenberg, S. J., and Kutter, B. L., (2006). "Evaluating pile pinning effects on abutments over liquefied ground." Proc., Seismic Performance and Simulation of Pile Foundations in Liquefied and Laterally Spreading Ground, R., Geotechnical Special Publication, ASCE, pp.306-318.

Boulanger, R.W., Chang, D., Brandenberg, S.J., Armstrong, R.J., and Kutter, B.L., (2007). "Seismic design of pile foundations for liquefaction effects." 4th International Conference on Earthquake Geotechnical Engineering, The Netherlands, 277-302.

Broms, B. B. (1964). "Lateral Resistance of Piles in Cohesionless Soils." Journal of the Soil Mechanics and Foundations Division, 90(3), 123-156. 
California Department of Transportation (Caltrans), (2012). "Guidelines for Foundation Loading and Deformation Due to Liquefaction Induced Lateral Spreading." Sacramento, CA.Chang, D., Boulanger, R. W., Kutter, B. L., and Brandenberg, S. J., (2006). "Dynamic analyses of soil-pile-structure interaction in laterally spreading ground during earthquake shaking." Seismic Performance and Simulation of Pile Foundations in Liquefied and Laterally Spreading Ground, GSP 145, ASCE, 218-229.

Chang D, Boulanger RW, Brandenberg SJ, Kutter BL., (2013). "FEM analysis of dynamic soil-pile structure interaction in liquefied and laterally spreading ground." Earthq Spectra;29(3):733-55

Cubrinovski, M., Bray, J. D., de la Torre, C., Olsen, M. J., Bradley, B. A., Chiaro, G., Stocks, E. and L. Wotherspoon. 2017. "Liquefaction effects and associated damages observed at the Wellington Centreport from the 2016 Kaikoura earthquake." Bull. N. Z. Soc. Earthq. Eng., 50 (2): 152-173.

Dobry, R., Abdoun, T., O'Rourke, T.D., and Goh, S.H., (2003). "Single piles in lateral spreads: Field bending moment evaluation", J. Geotech. Geoenviron. Eng. 129, 10, 879889.

Ensoft, (2014). "User's Technical Manual for LPILE”

Finn, W. D. L. 2005. "A study of piles during earthquakes: Issues of design and analysis.” B. Earthq. Eng., 3(2), 141-234. https://doi.org/10.1007/s10518-005-1241-3

Hamada, M., Yasuda, S., Isoyama, R., and Emoto, K. 1986. "'Study on liquefaction induced permanent ground displacements." Research Rep., Association for Development of Earthquake Prediction, Japan, November, 87.

Idriss, I. M., \& Boulanger, R. W. (2008). Soil liquefaction during earthquakes. Earthquake Engineering Research Institute.

Makdisi, F. I., \& Seed, H. B. (1978). Simplified procedure for estimating dam and embankment earthquake-induced deformations. Journal of the Geotechnical Engineering Division, 104(7), 849-867.

Makdisi, A. J., \& Kramer, S. L. (2018). Applicability of sliding block analysis for lateral spreading problems. Soil Dynamics and Earthquake Engineering, 124, 374-388.

Marcuson, W.F. III, M.E. Hynes and A.G. Franklin (1990). Evaluation of use of residual strength in the seismic stability of embankments. Earthquake Spectra, 6(3), pp 529572.McCullough, N.J., Dickenson, S.E., Kutter, B.L. and Wilson, D.W., (2000). "PileSupported Wharf - Centrifuge Model NJM01.” Report No. GEG01-2000, OSUGeotechnical Engr. 
McCullough, N. J., Dickenson, S. E., \& Schlechter, S. M., (2001). "The seismic performance of piles in waterfront applications." In Ports' 01: America's Ports: Gateway to the Global Economy (pp. 1-10).

McCullough, N.J., Dickenson, S.E., Kutter, B.L. and Wilson, D.W., (2000). "PileSupported Wharf - Centrifuge Model NJM01.” Report No. GEG01-2000, OSUGeotechnical Engr.

Nasr, J., Khosravifar, A., (2018). "The Effects of Long-Duration Subduction Earthquakes on Inelastic Behavior of Bridge Pile Foundations Subjected to Liquefaction-Induced Lateral Spreading" DFI Journal - The Journal of the Deep Foundations Institute.

Oregon Dept. of Transportation, (2014). "Geotechnical design manual." Tech. Services Branch, Salem, OR.

Seed, R.B., Dickenson, S.E., Riemer, M.F., Bray, J.D., Sitar, N., Mitchell, J.K., Idriss,

I.M., Kayen, R.E., Kropp, A., Hander Jr., L.F., Power, M.S., (1990). "Preliminary Report on the Principal Geotechnical Aspects of the October 17, 1989, Loma Prieta Earthquake." Report No. UCB/EERC-90/05. Earthquake Engineering Research Center. UC, Berkeley, CA.

Singh, P., Subramanian, P. K., Boulanger, R. W., and Kutter, B. L., (2000.a). "Piles under earthquake loading - centrifuge data report for PDS01.” Report No.

UCD/CGMDR-00/05, R-7 Center for Geotechnical Modeling, Department of Civil Engineering, University of California, Davis.

Schlechter S.M., McCullough, N.J., Dickenson, S.E., Kutter, B.L. and Wilson, D.W., (2000). "Pile-Supported Wharf - Centrifuge Model NJM02." Report No. GEG02-2000, OSU-Geotechnical Engr.

Schlechter S.M., McCullough, N.J., Dickenson, S.E., Kutter, B.L. and Wilson, D.W., (2000). "Pile-Supported Wharf - Centrifuge Model SMS01." Report No. GEG03-2000, OSU-Geotechnical Engr.

Travasarou, T., Chen, W. Y., \& Chacko, J. M., (2011). "Liquefaction-induced uplift of buried structures: insights from the study of an immersed railway tunnel." In Proc. of 5th International Conference on Earthquake Geotechnical Engineering, Chile, January.

Turner, B., Brandenberg, S. J., and Stewart, J. P. (2014). "Evaluation of collapse and non-collapse of parallel bridges affected by liquefaction and lateral spreading." PEER Rep. 2014/10, Pacific Earthquake Engineering Research Center, UC, Berkeley, CA, 122. Washington Department of Transportation (WSDOT), (2015). "Geotechnical Design Manual.” M 46-03.11, May 2015. 
Wilson, D. W., Boulanger, R. W., and Kutter, B. L. (1997a). "Soil-Pile-Superstructure Interaction at Soft of Liquefiable Soil Sites - Centrifuge Data Report for CSP2." Report No. UCD/CGMDR-97/03, Center for Geotechnical Modeling, Department of Civil Engineering, University of California, Davis.

Youd, T. L., and Wieczorek, G. F. (1981). "Liquefaction during the 1981 and previous earthquakes near Westmorland, California." Open-File Report. 
Appendix: Results of Slope Stability Models 


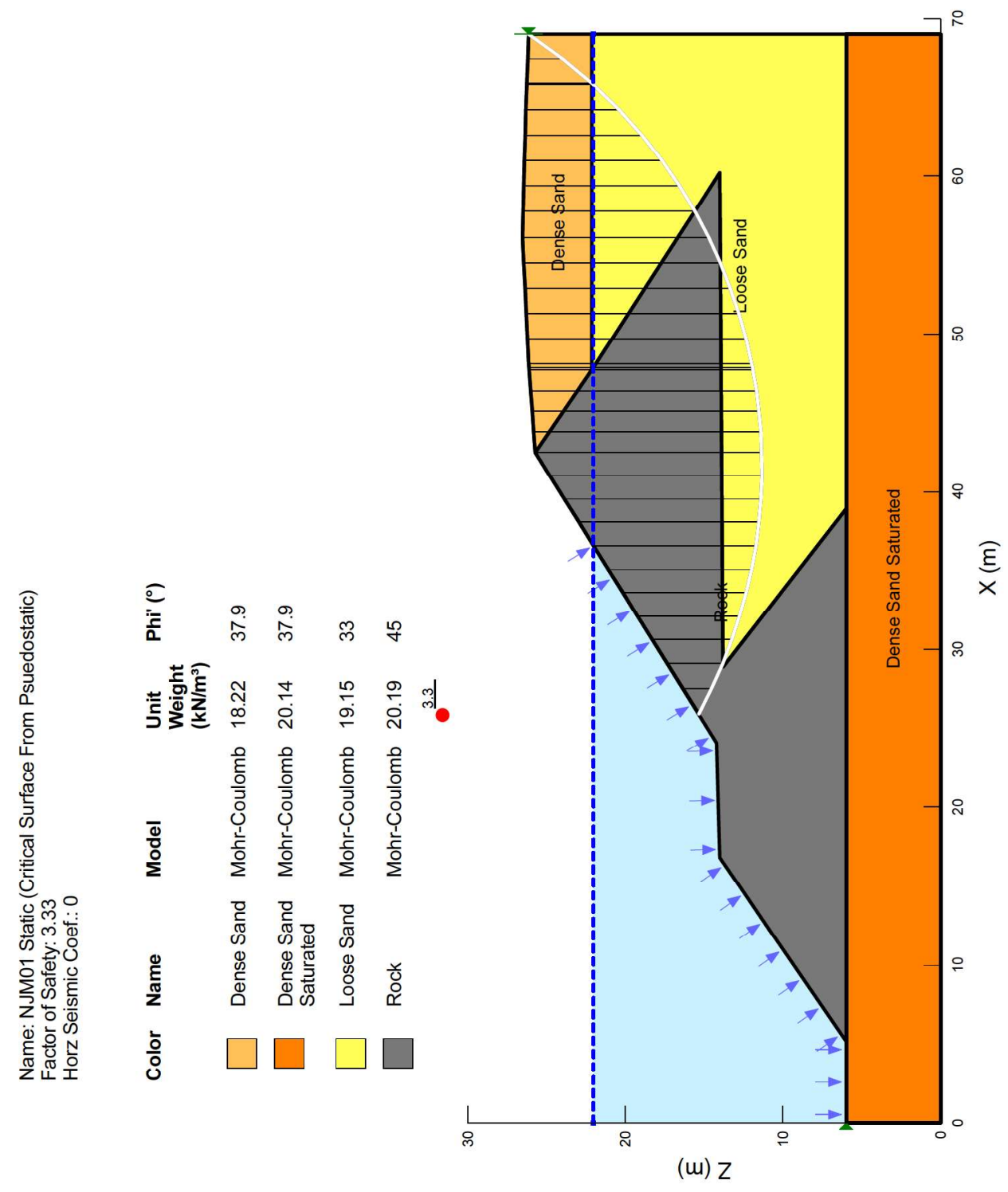




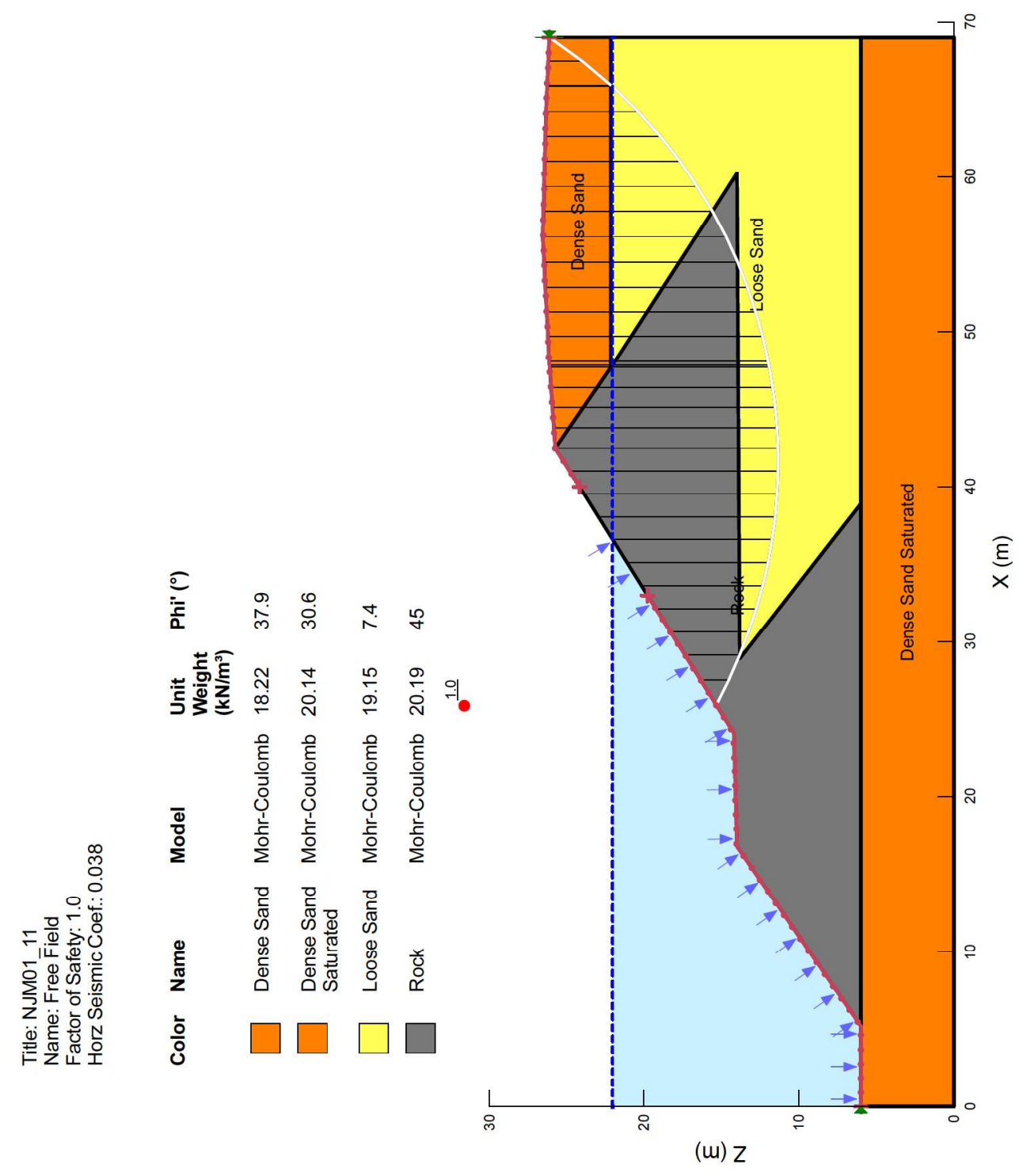



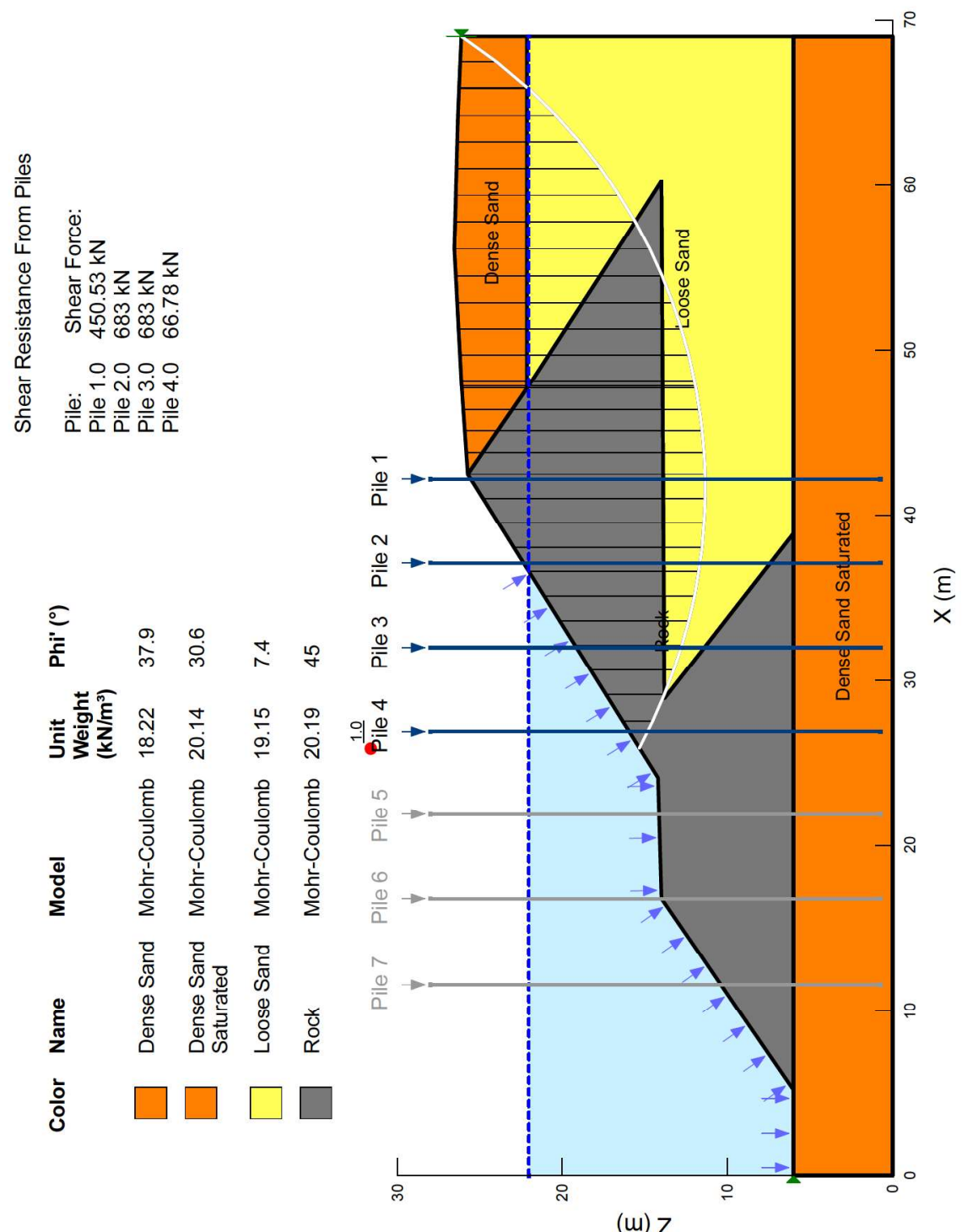

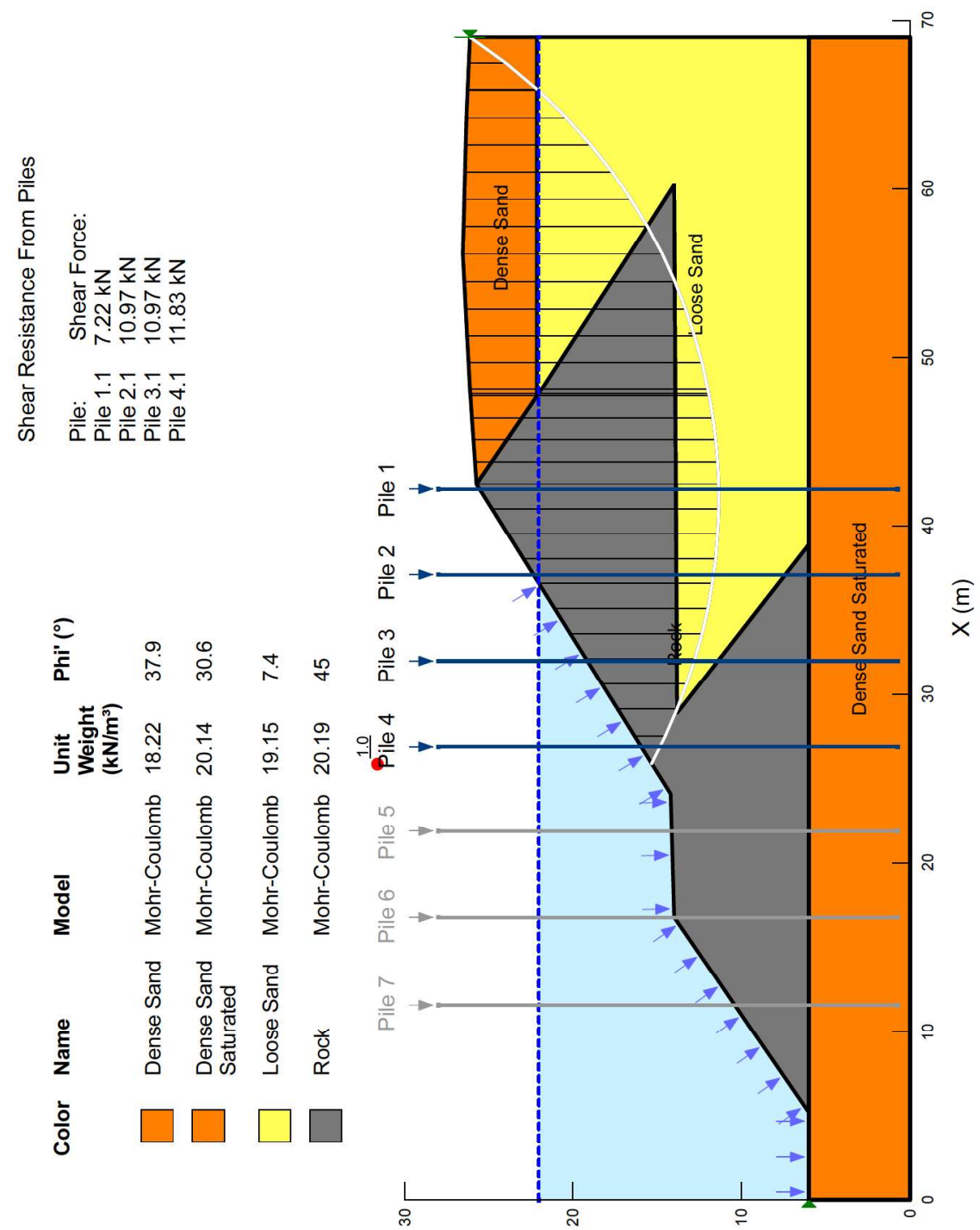

(u) Z 

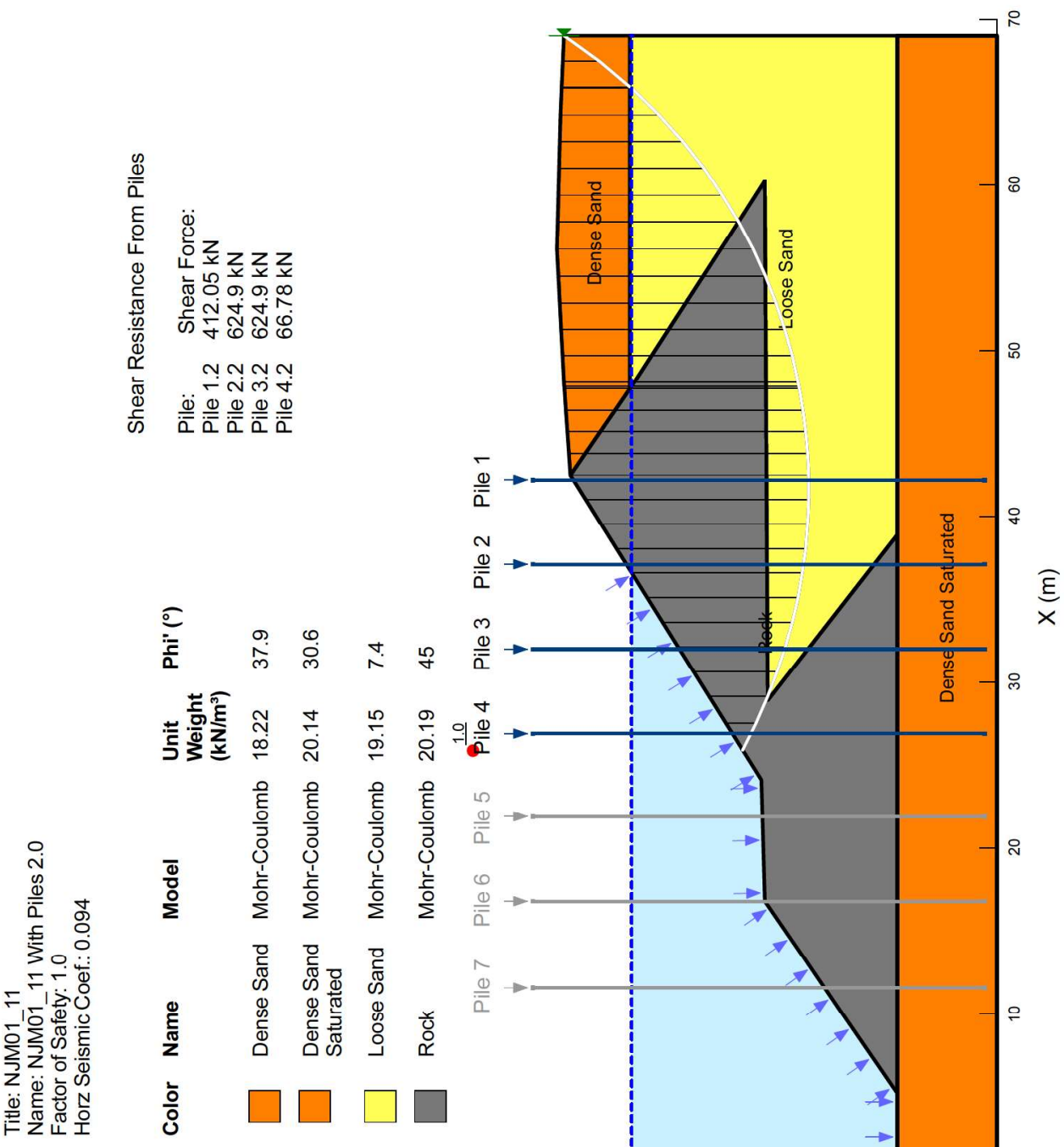

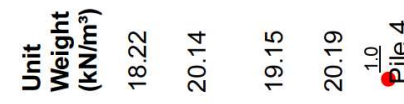

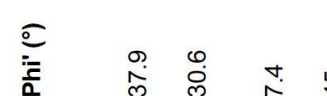

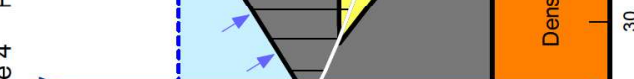

이

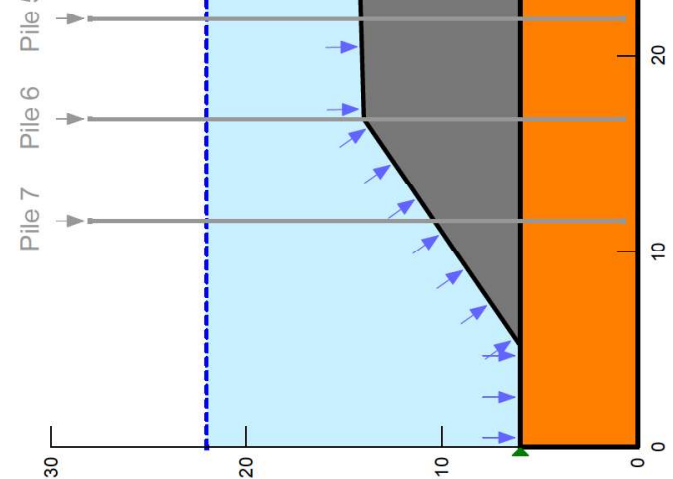

(w) Z 



(u) Z 

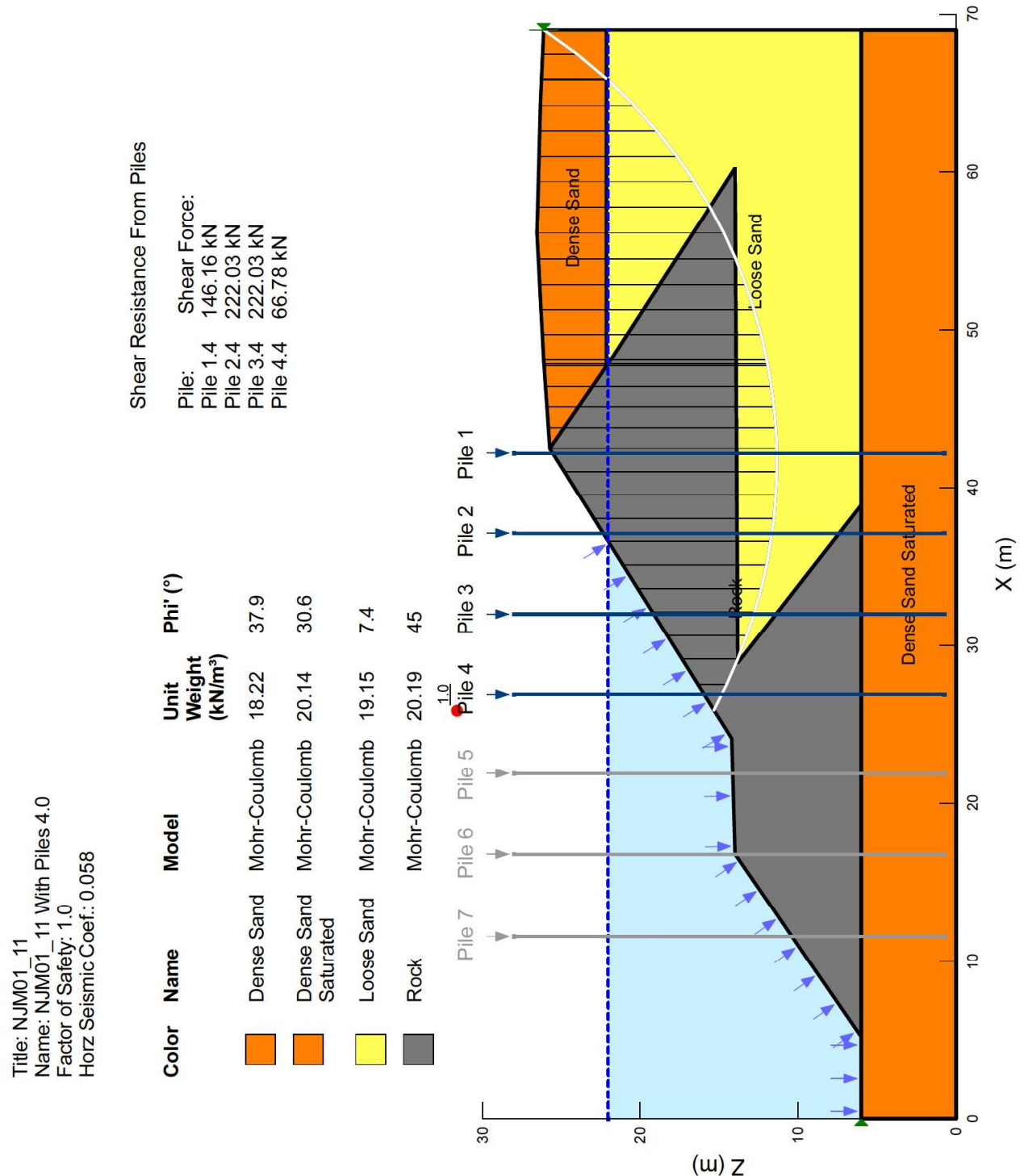

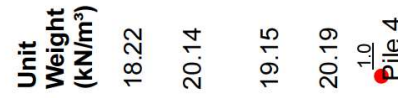

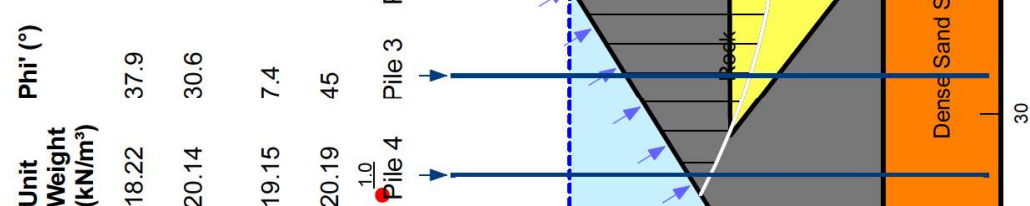

$\underset{x}{\widehat{\xi}}$ 



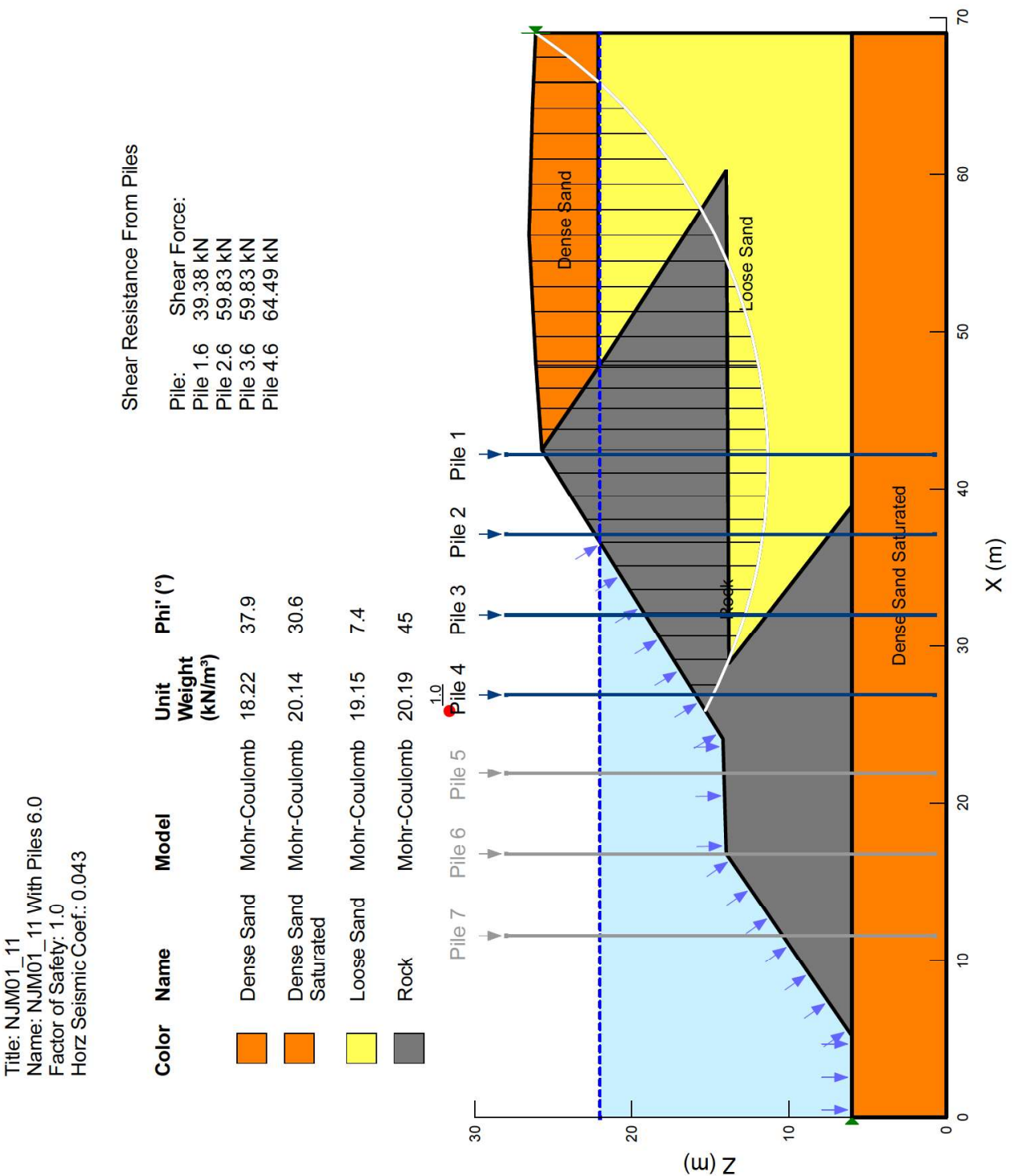

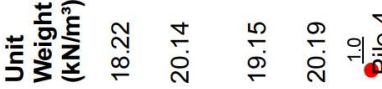



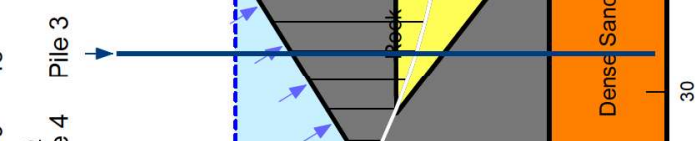

$\times$ 

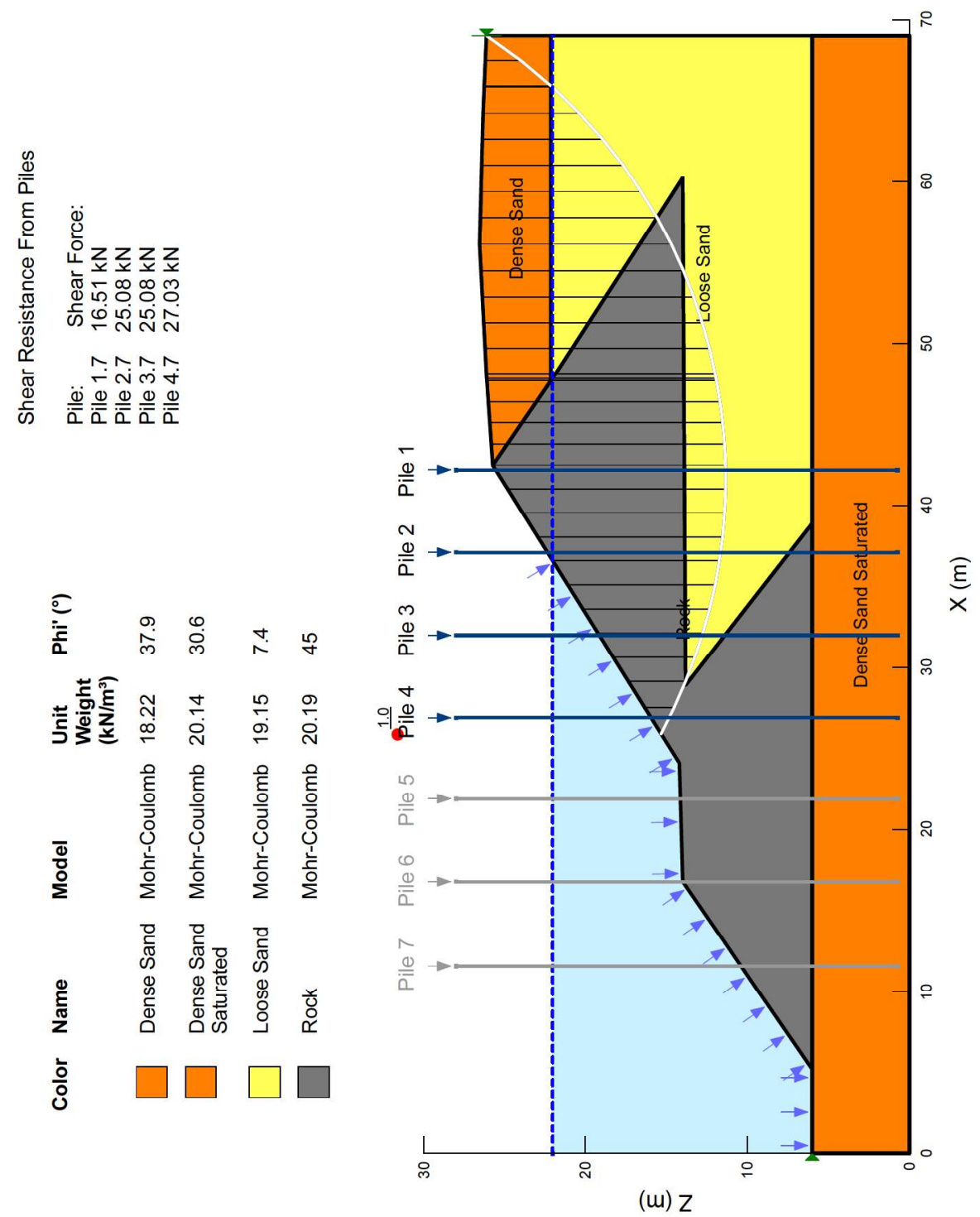

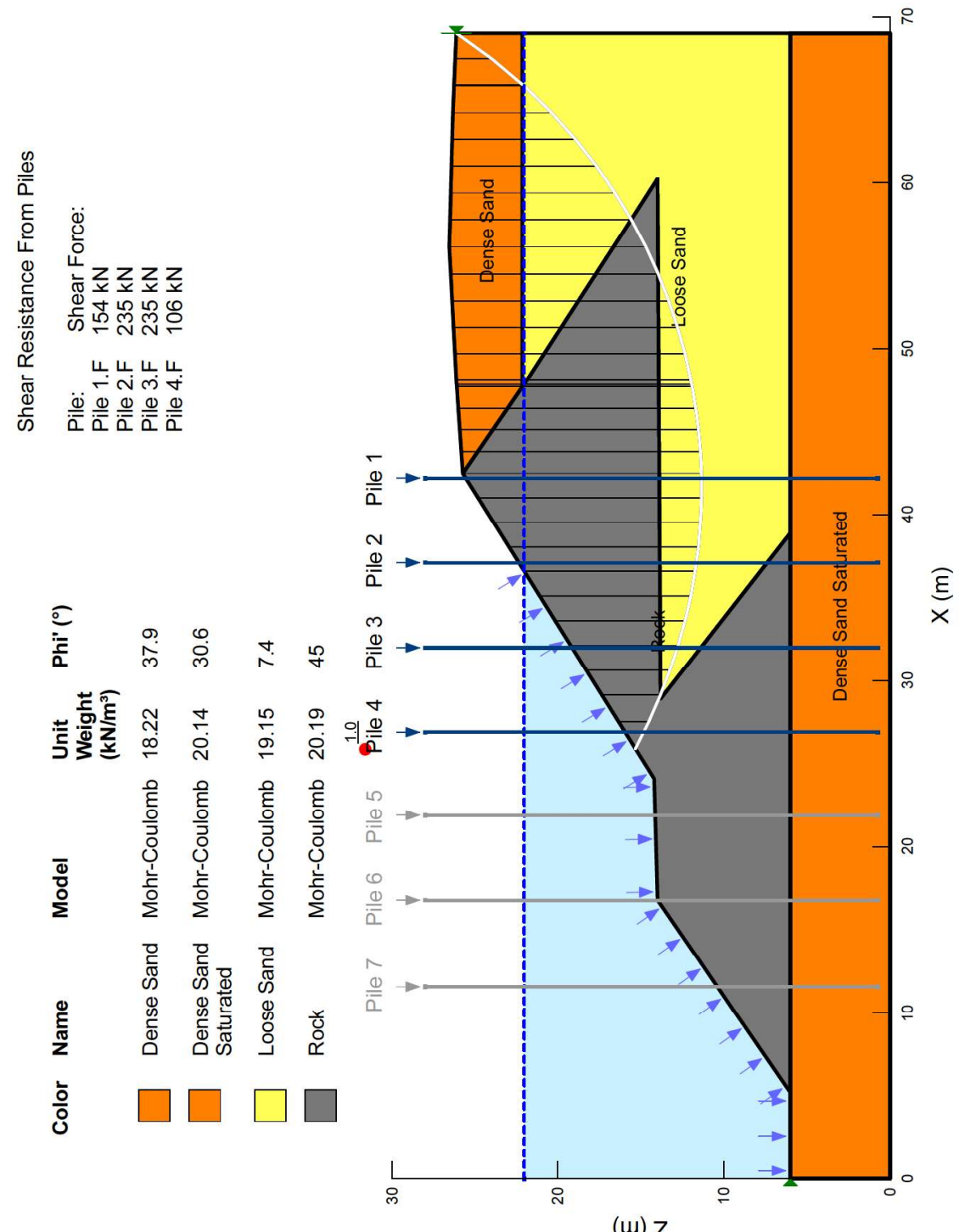


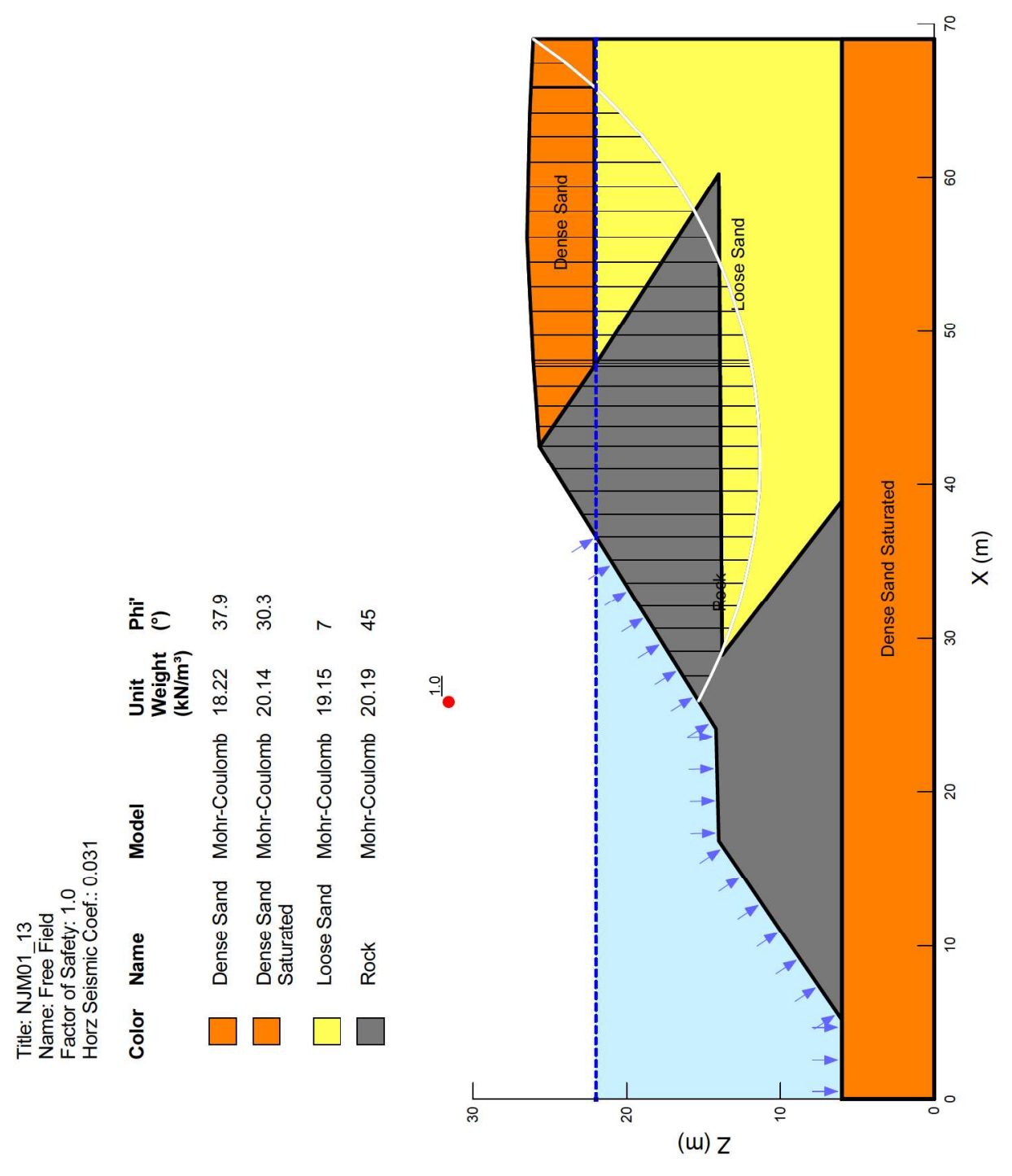





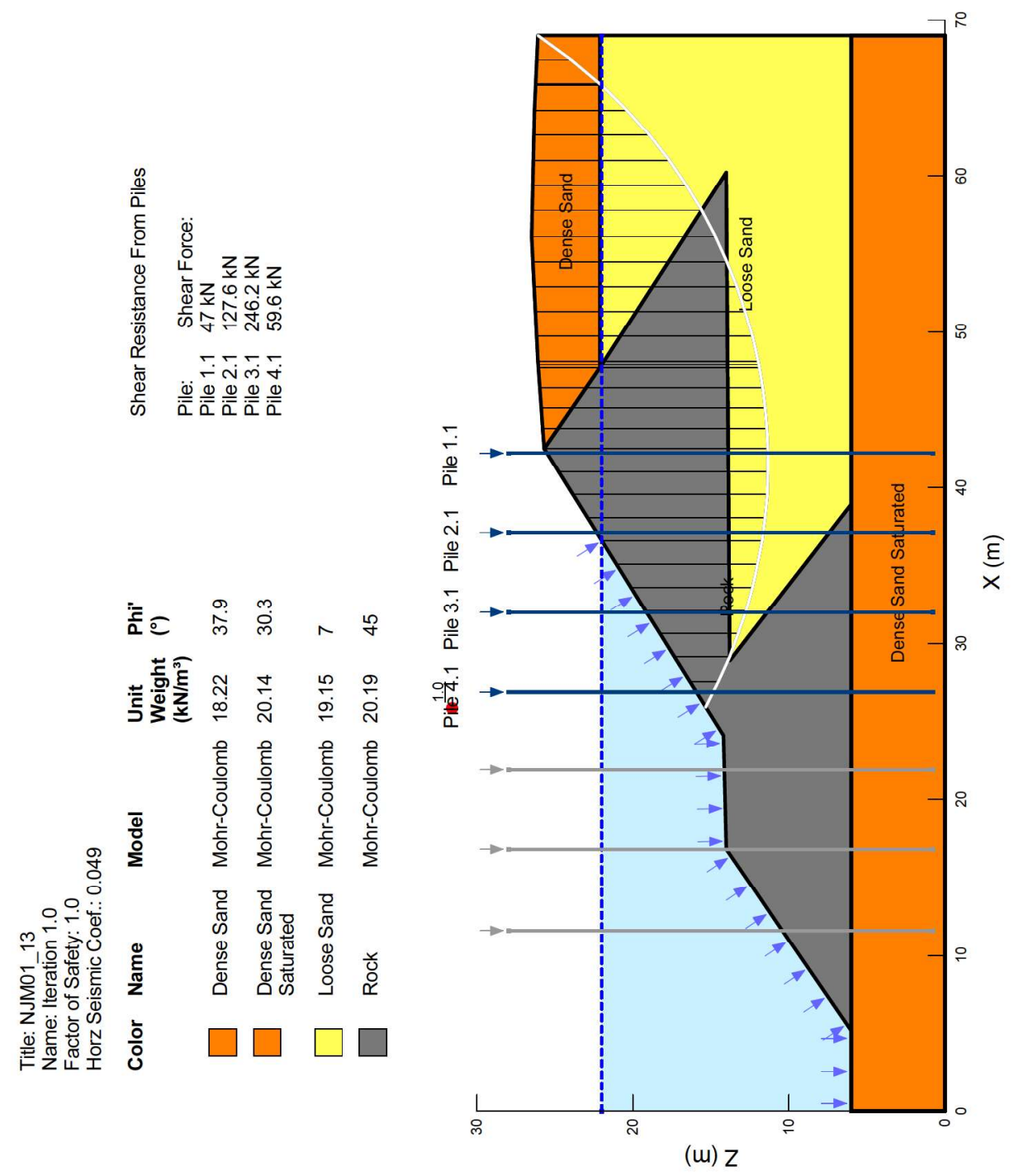

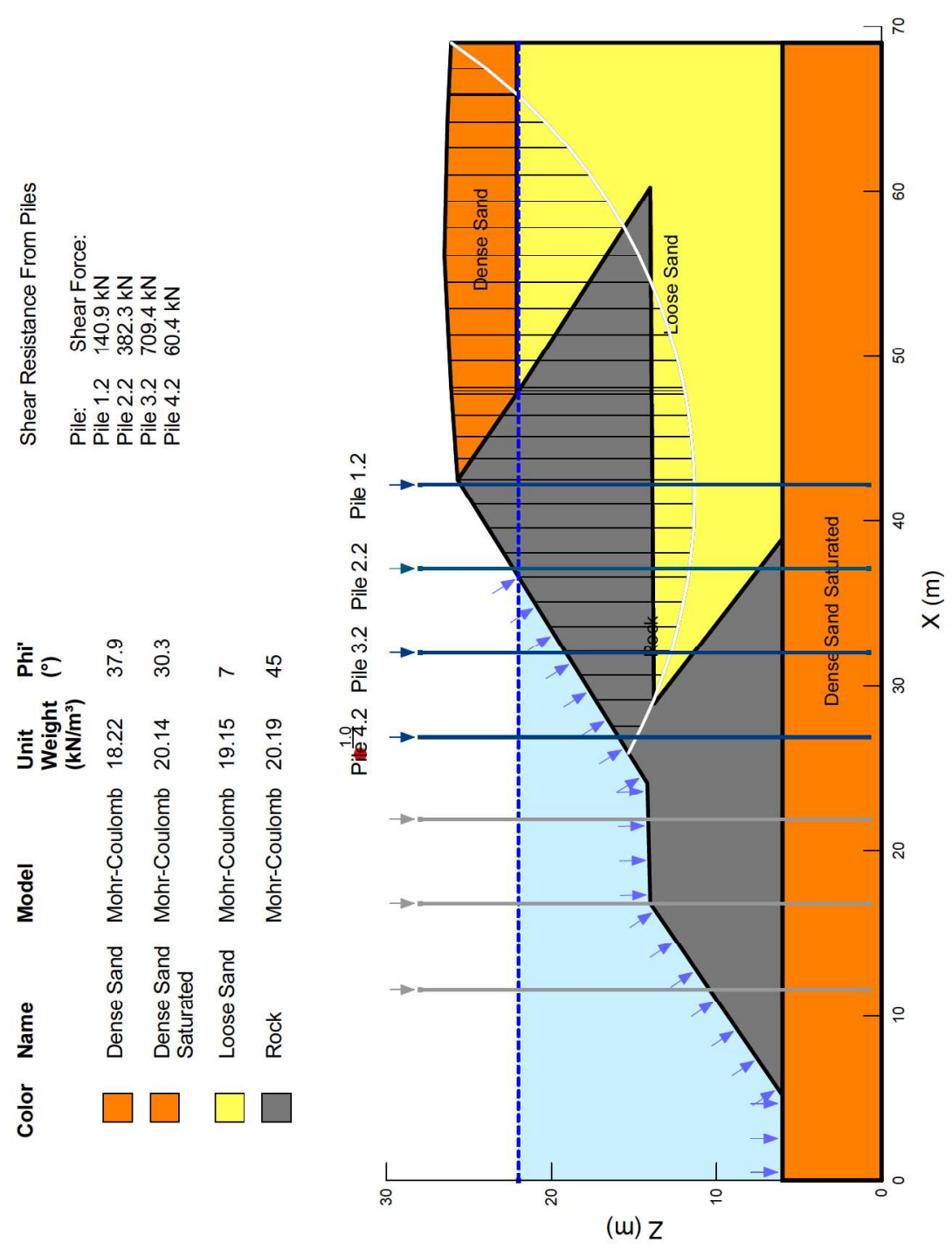

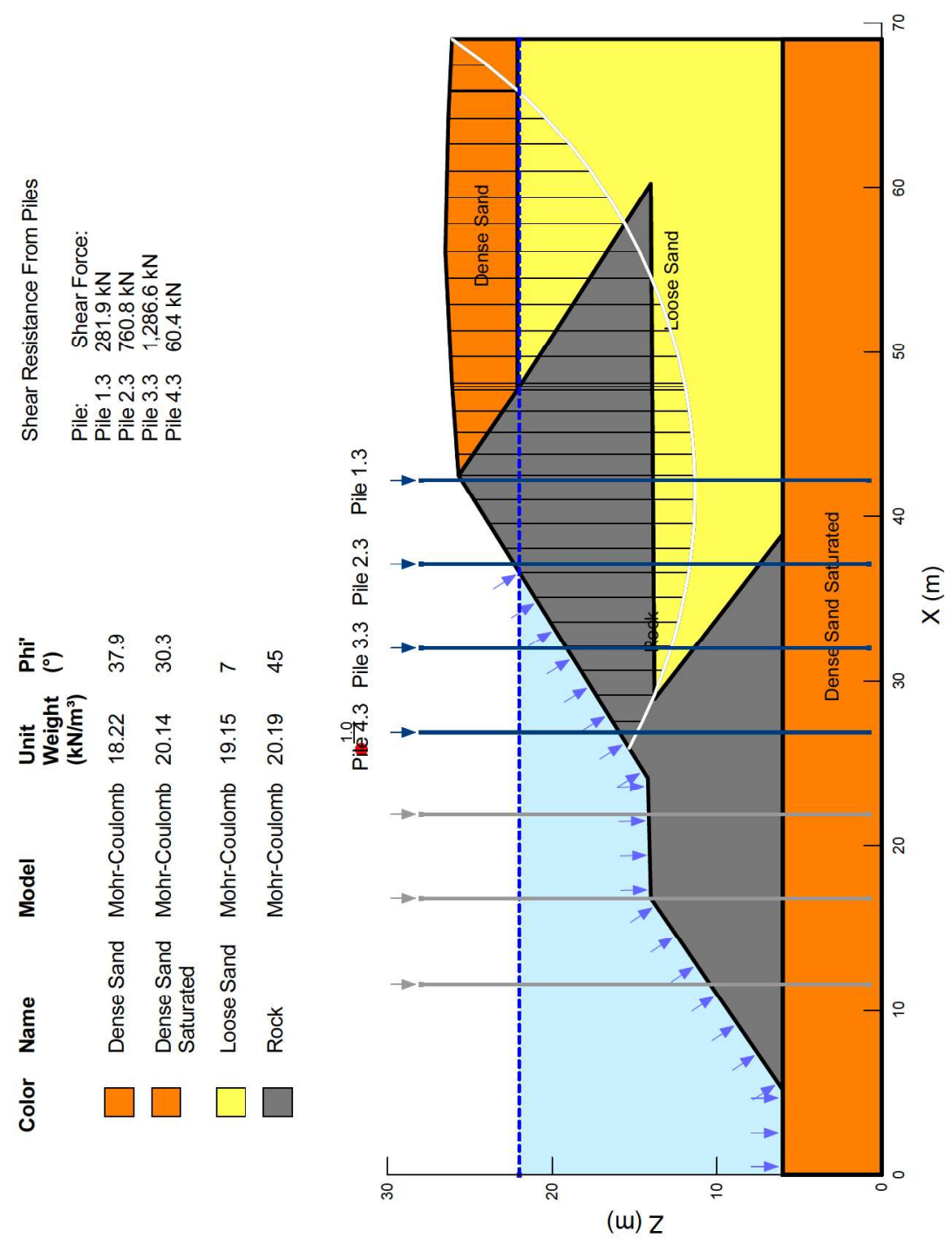

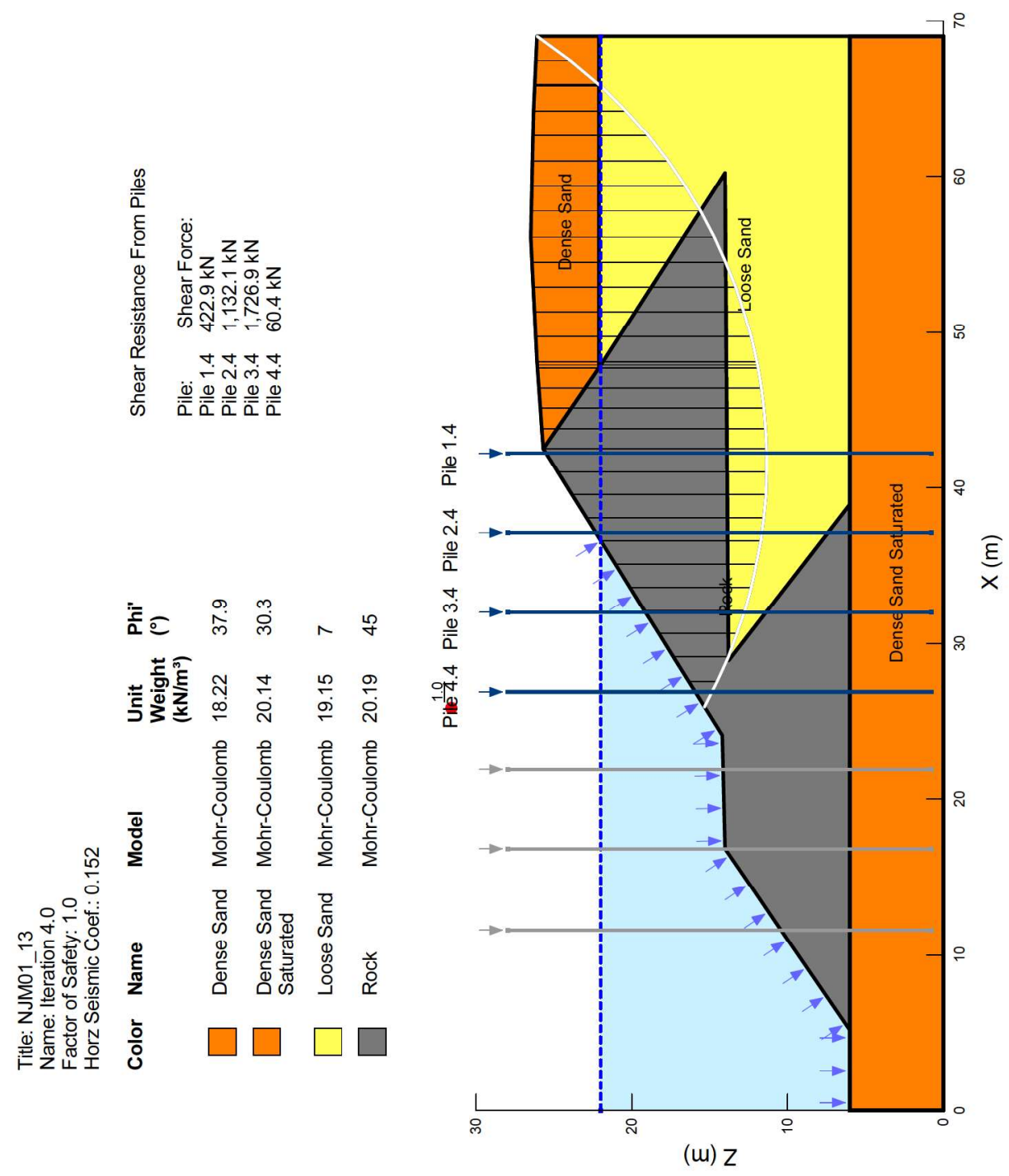

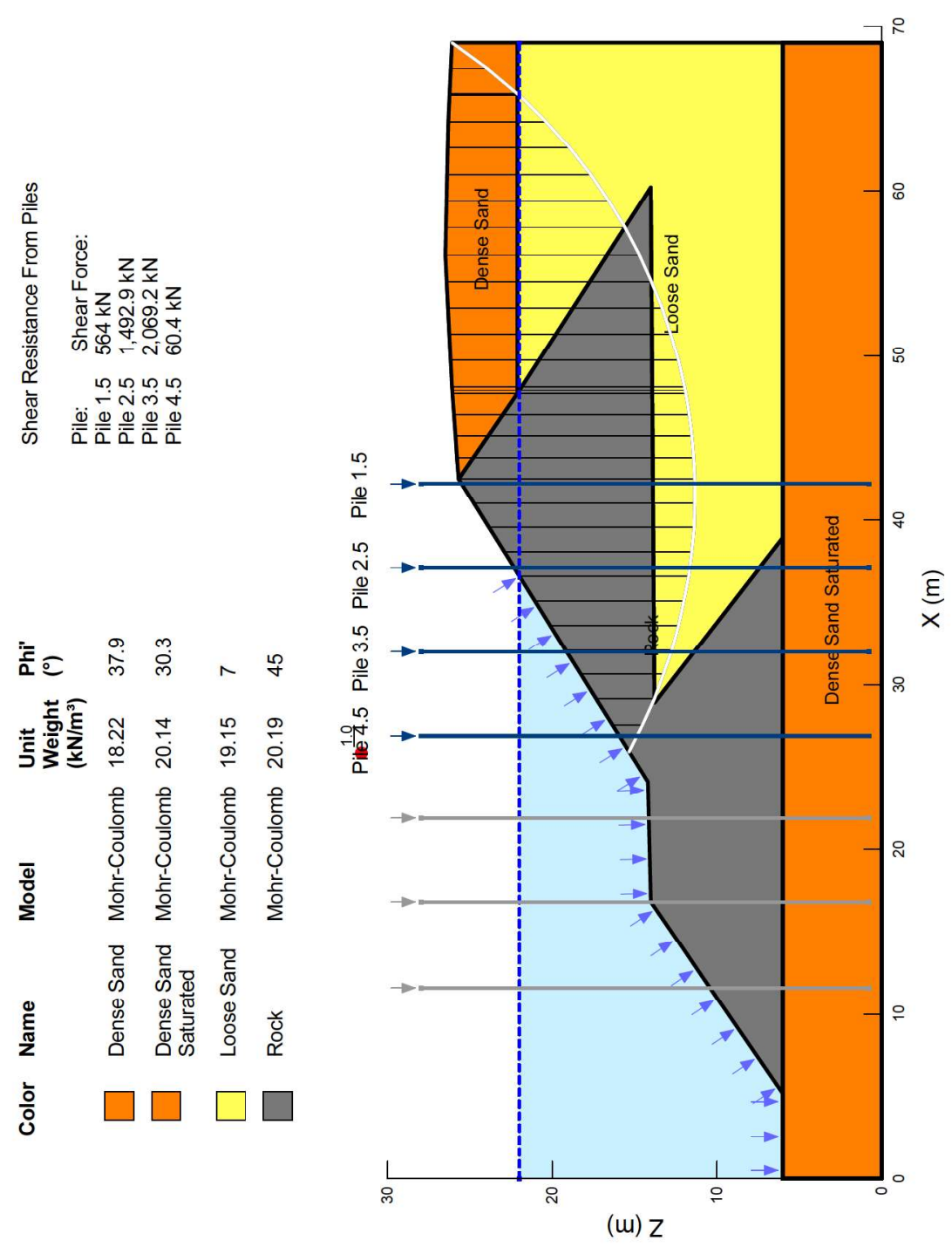

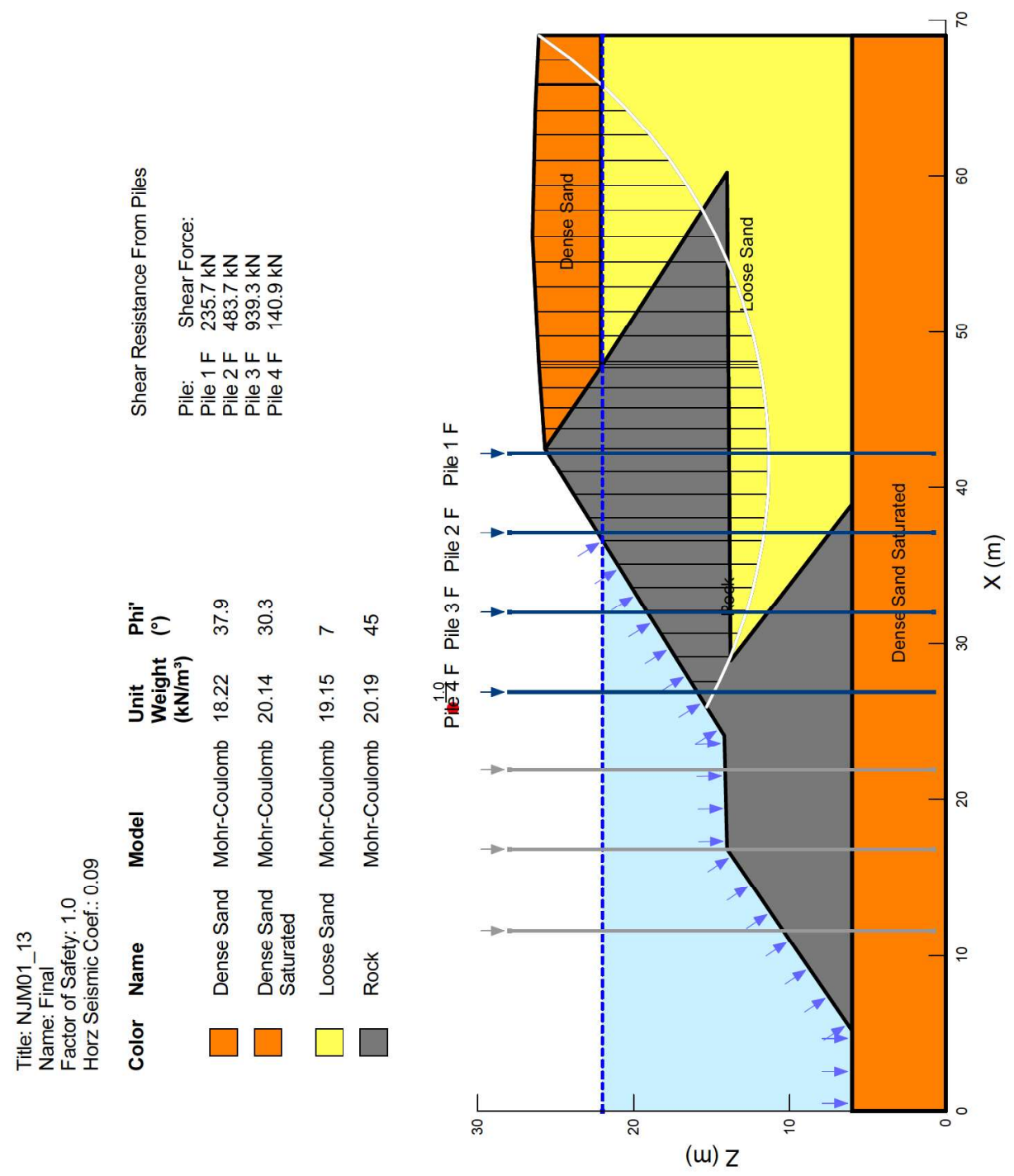


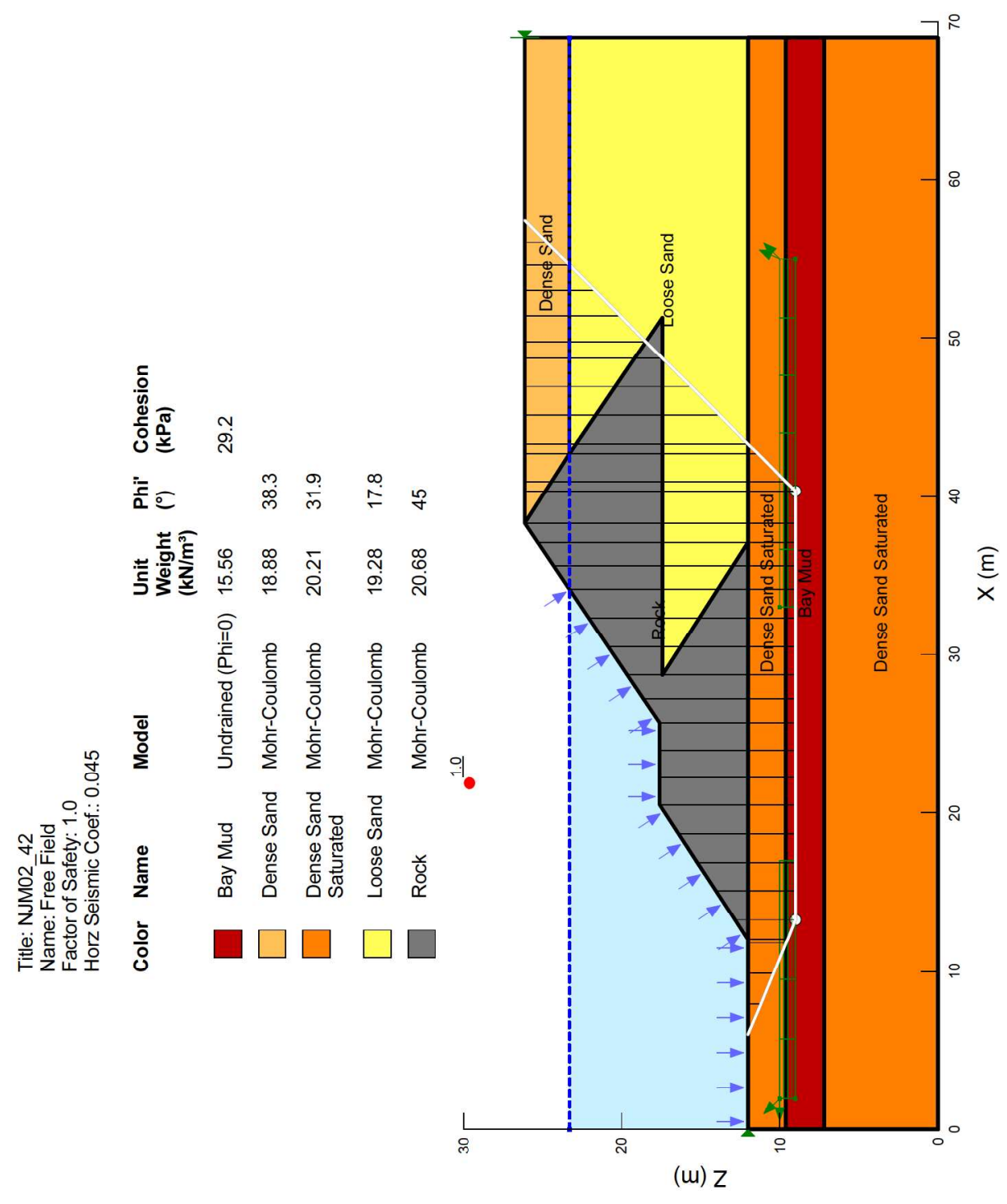



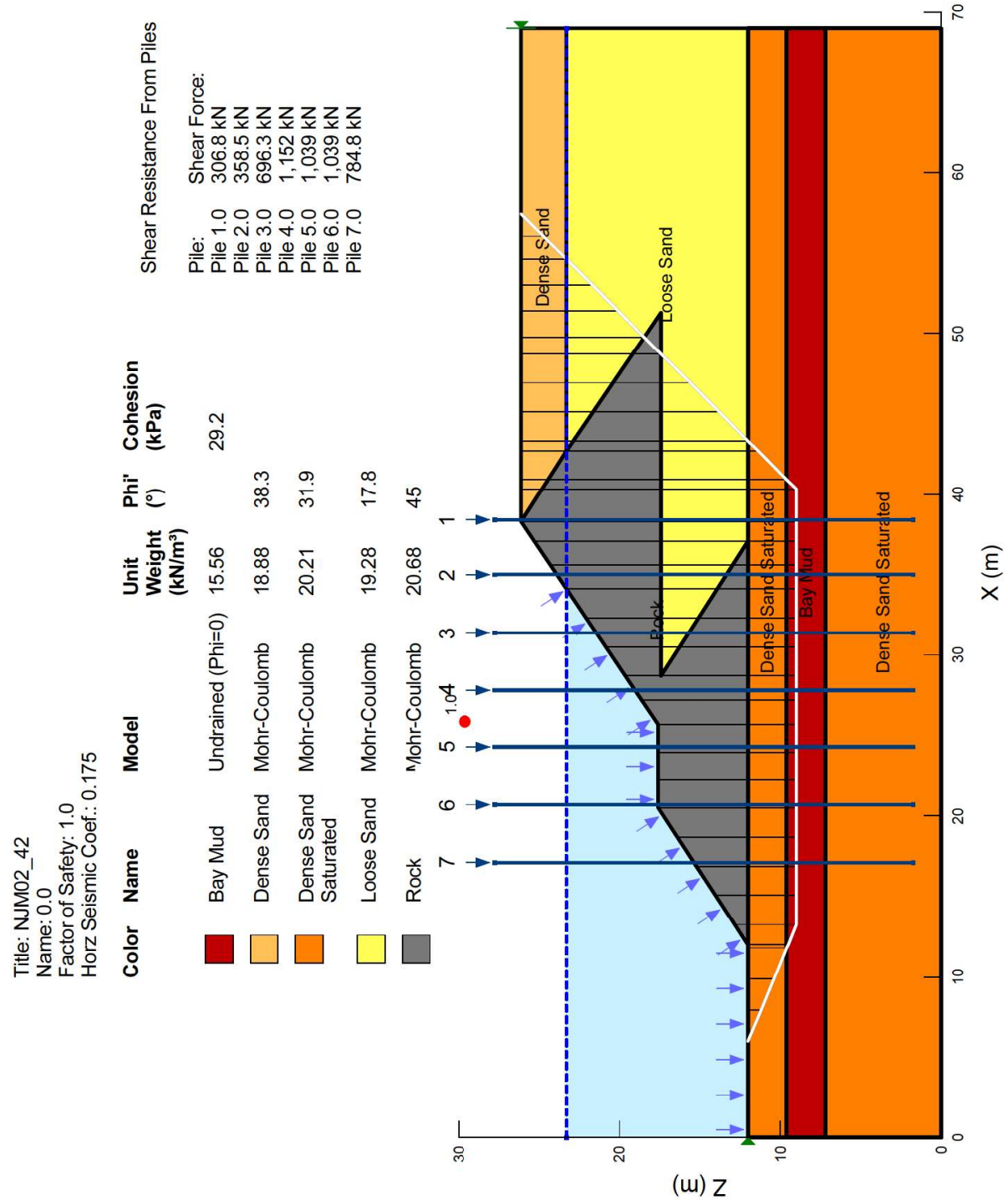

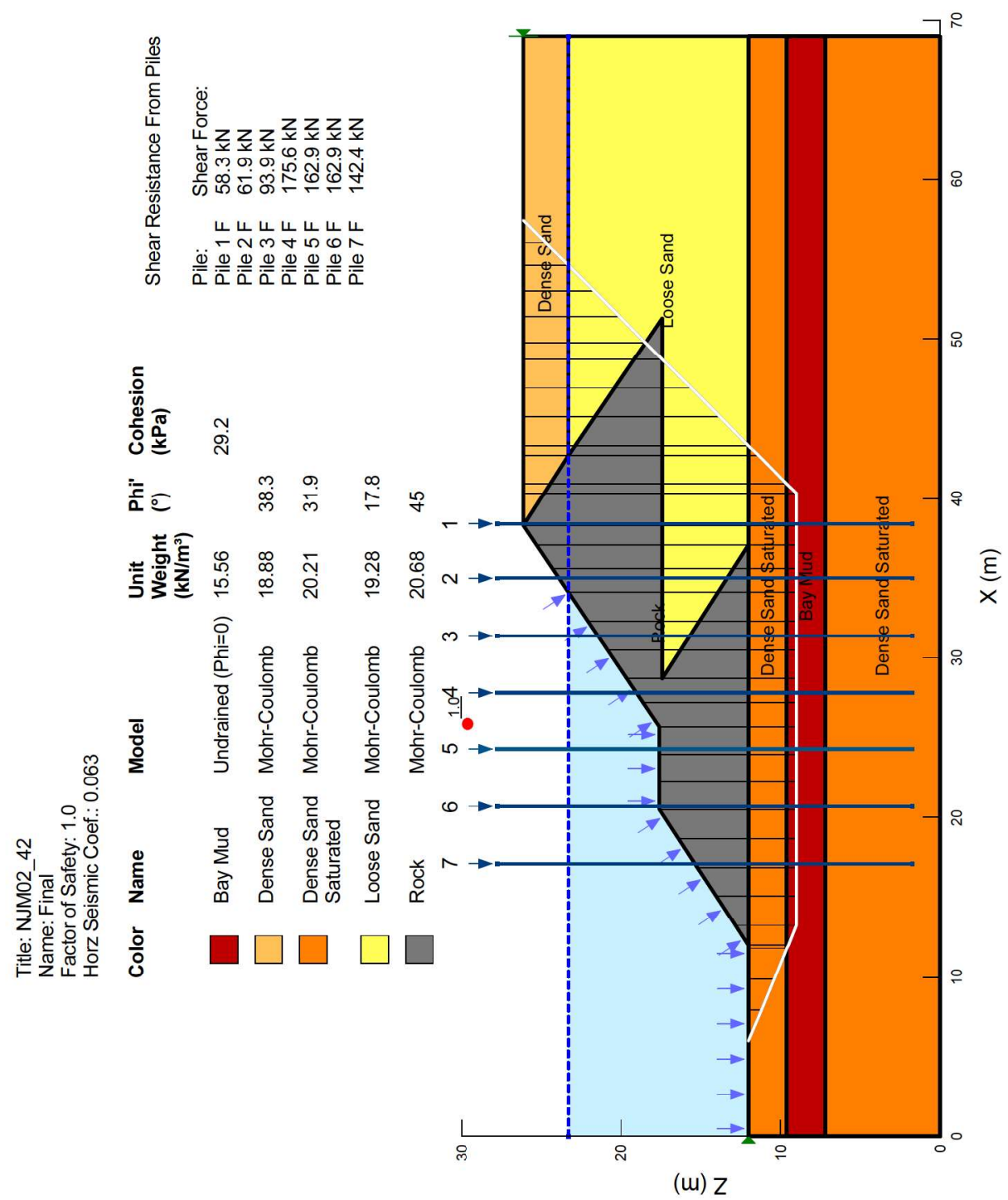

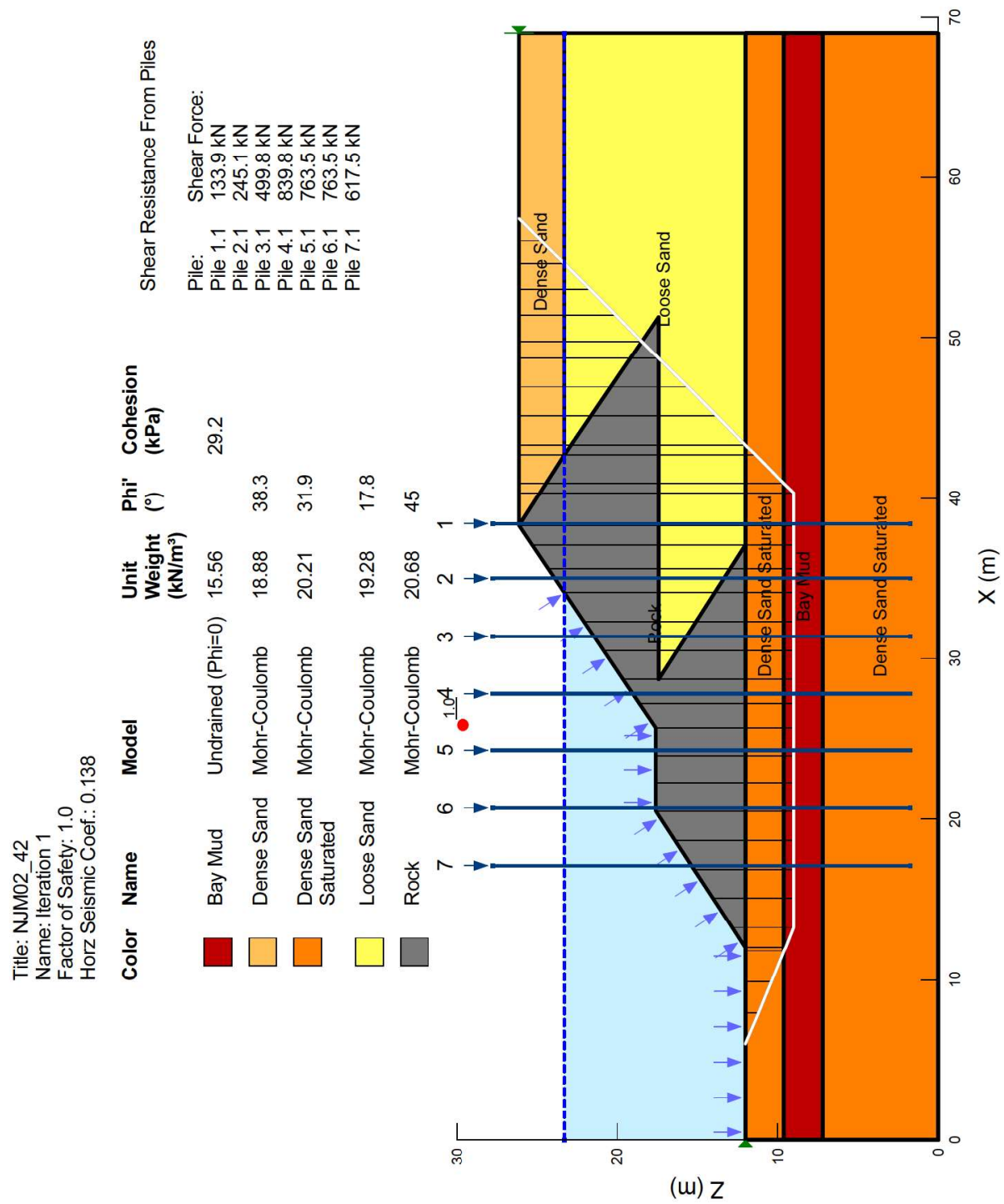

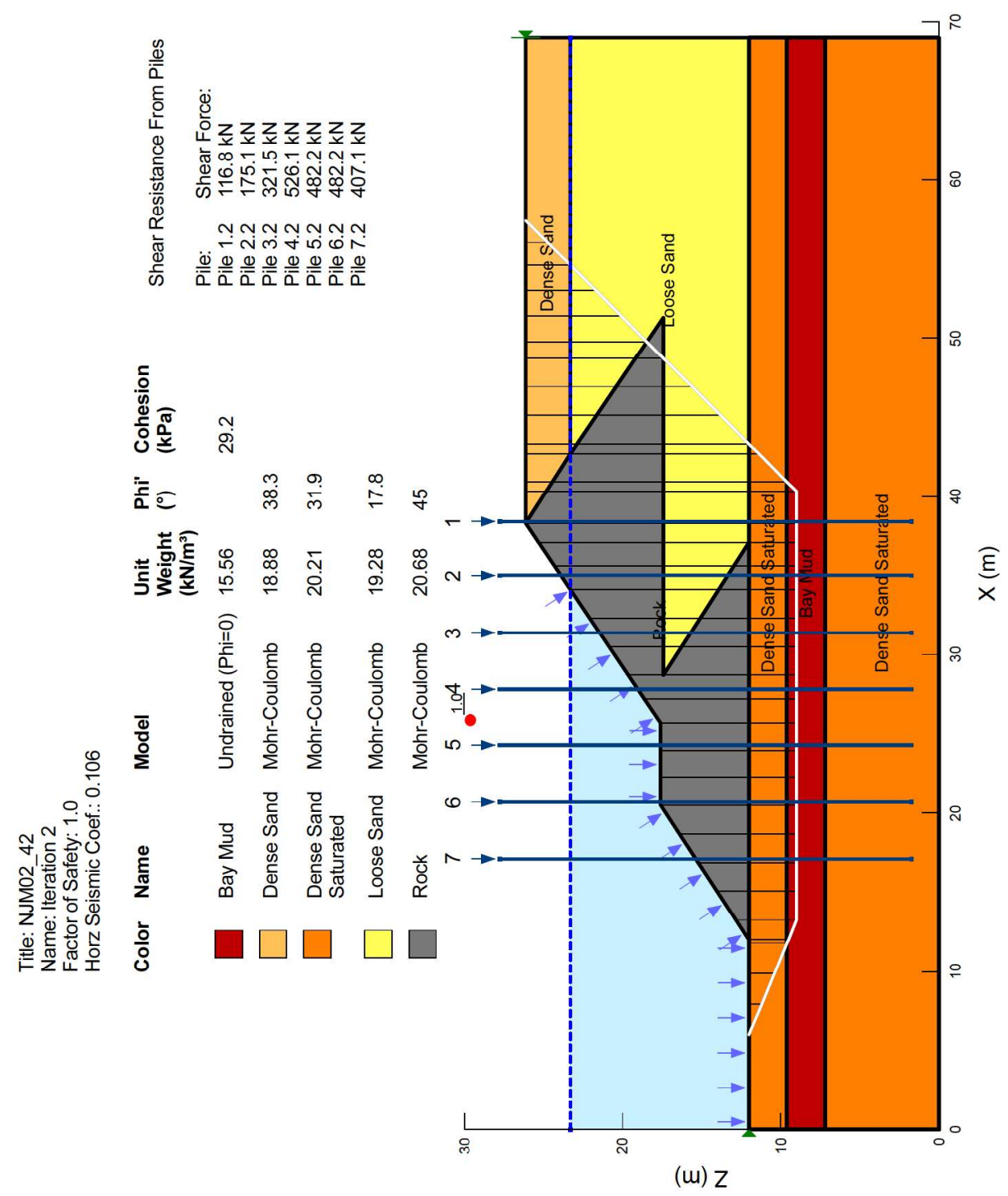

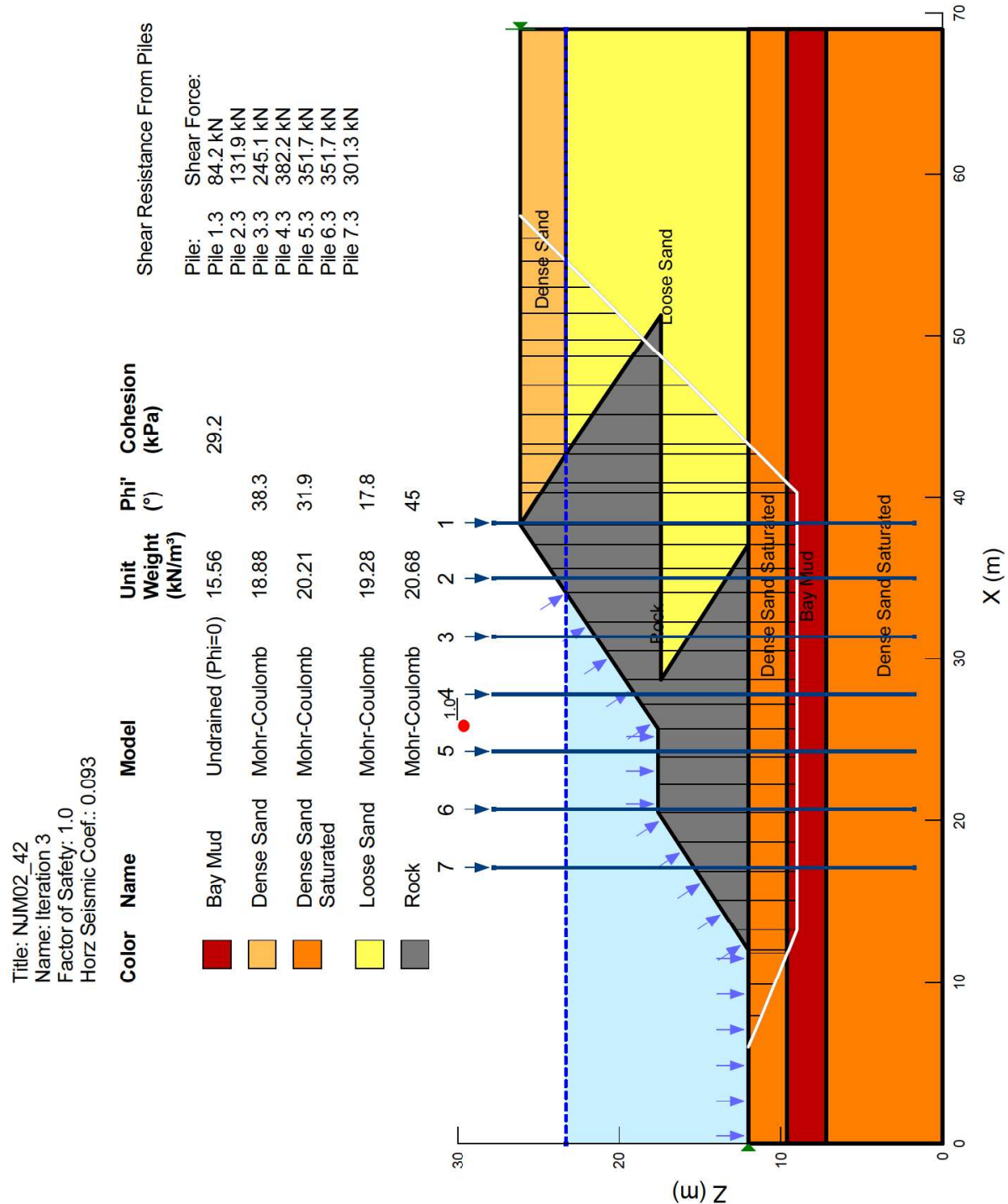



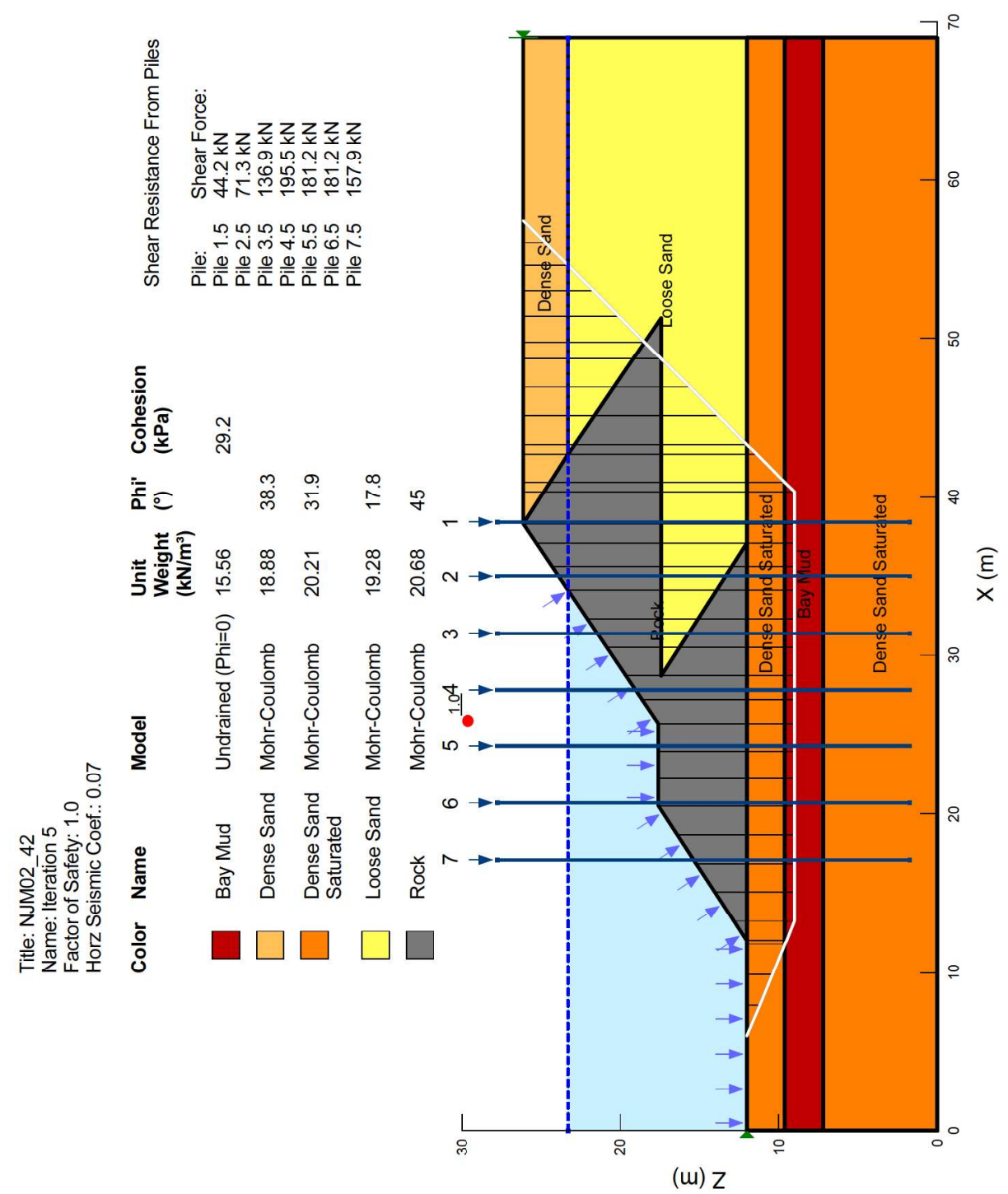




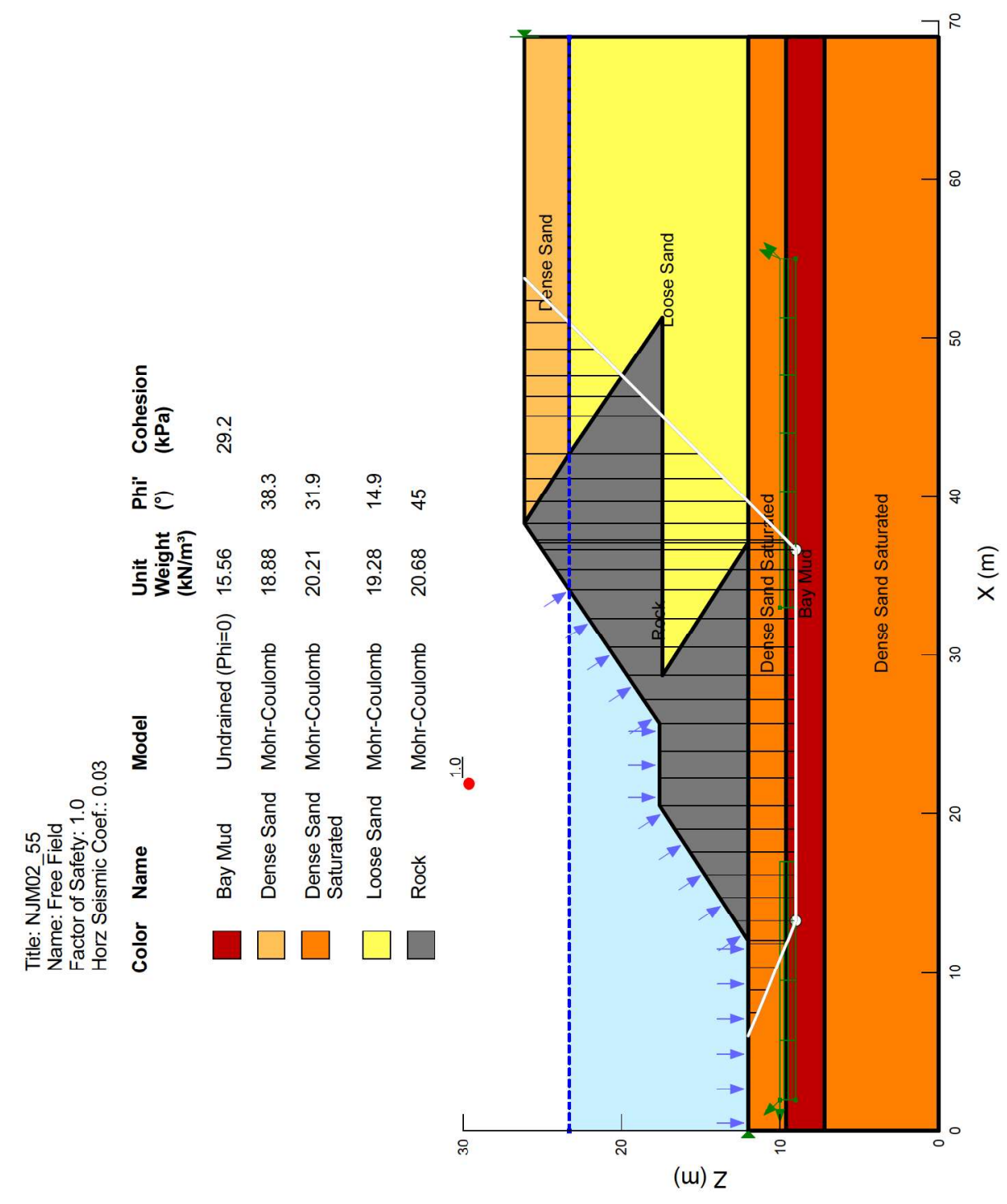



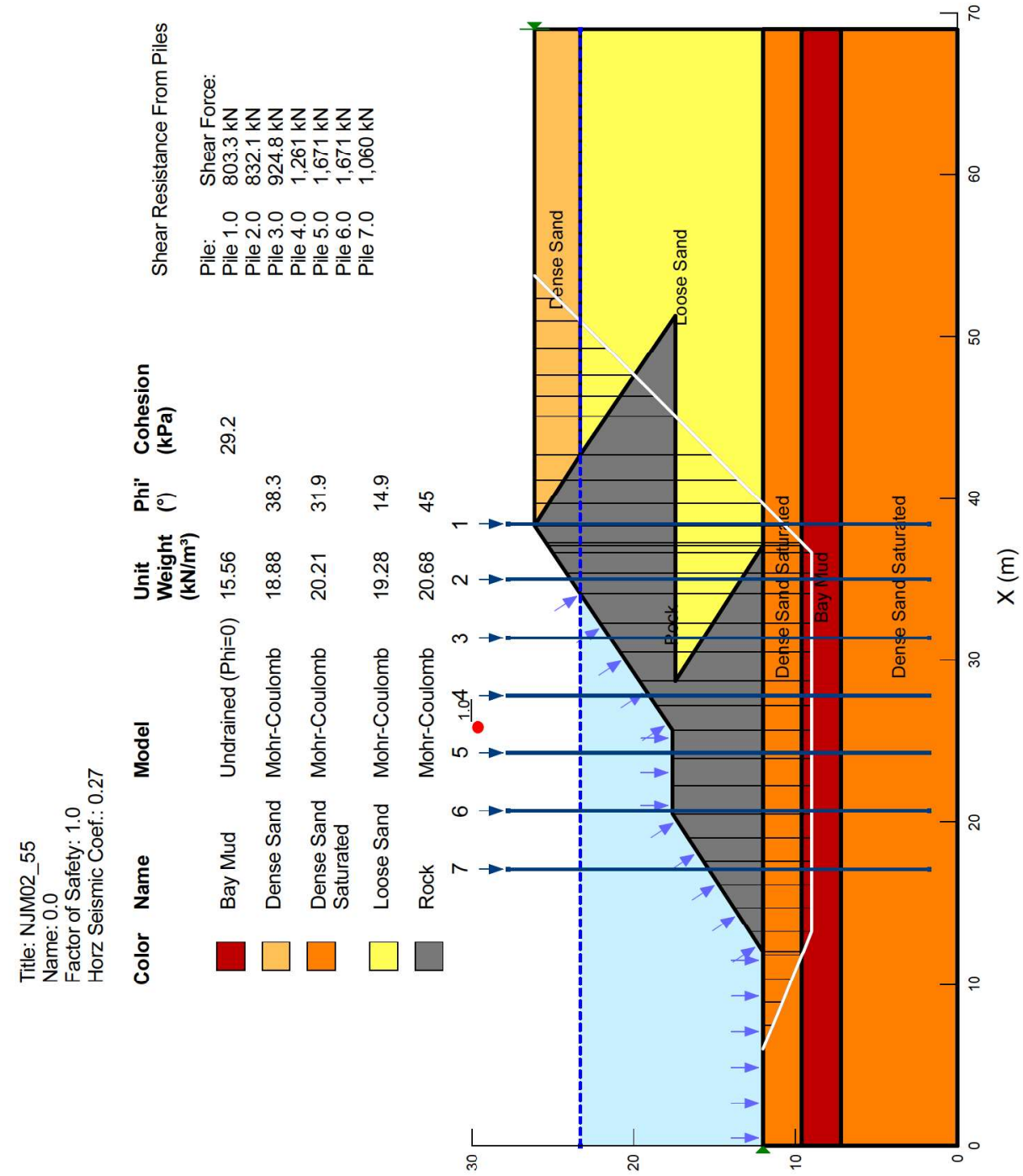

(u) Z 

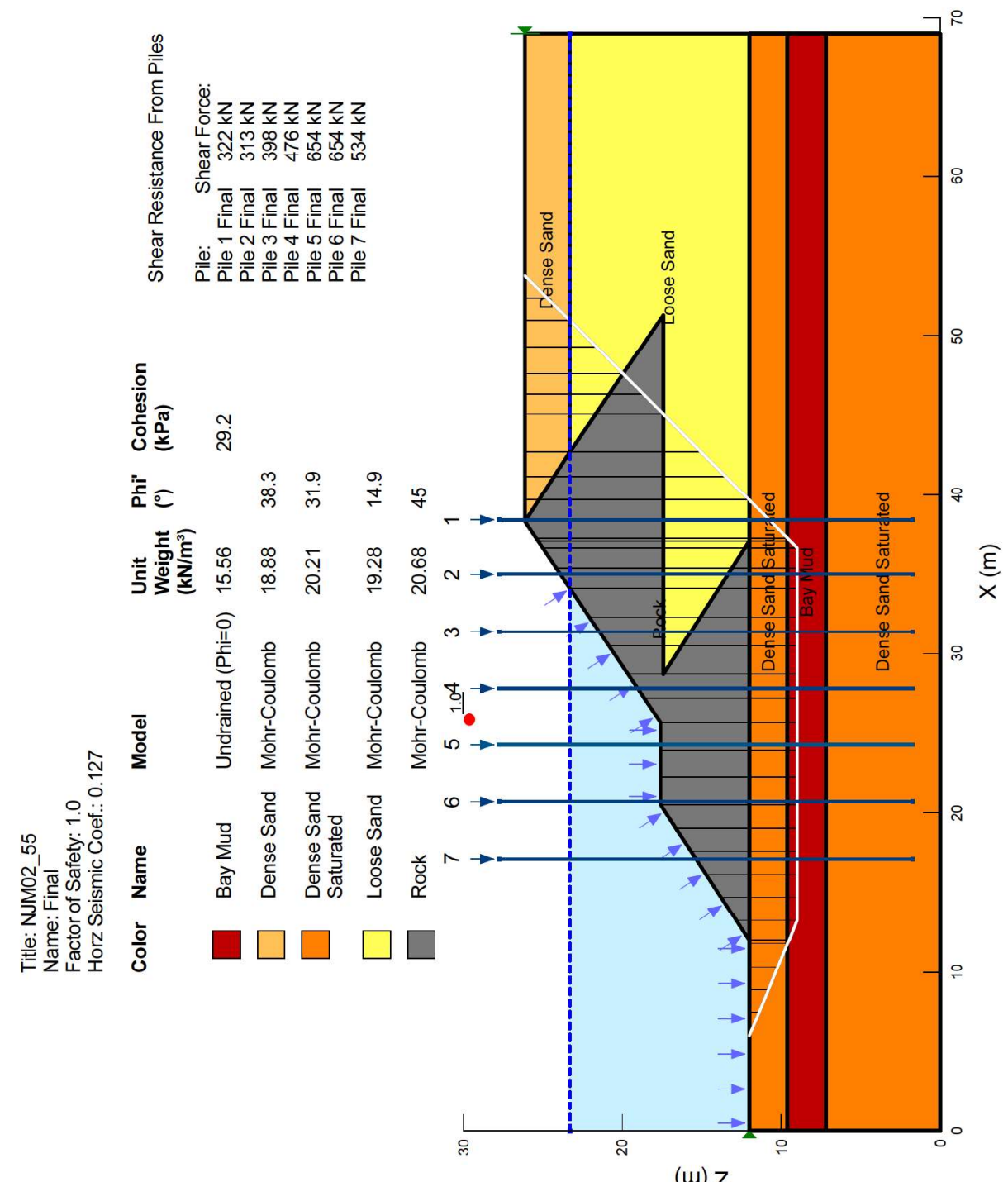

(u) Z 


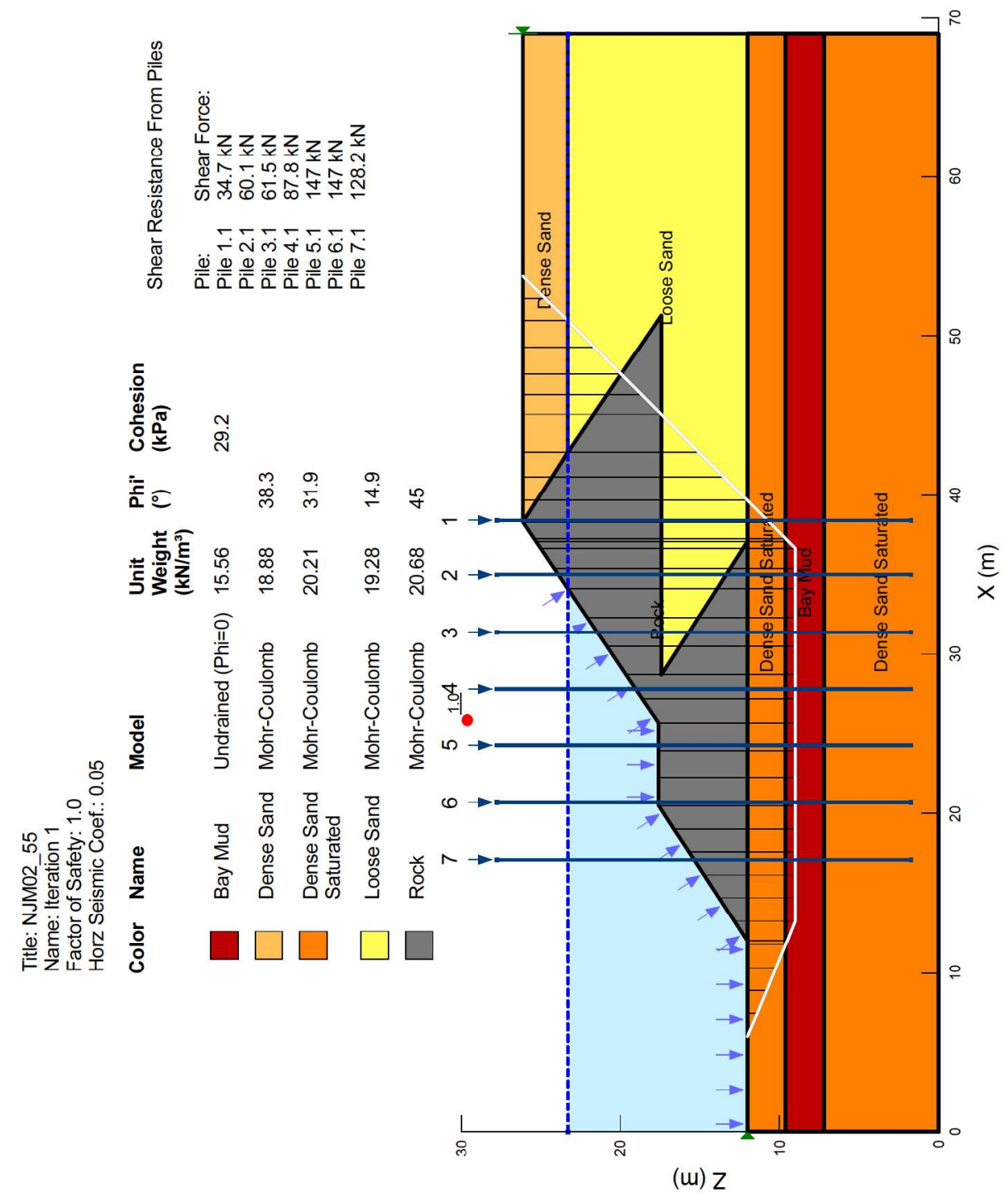



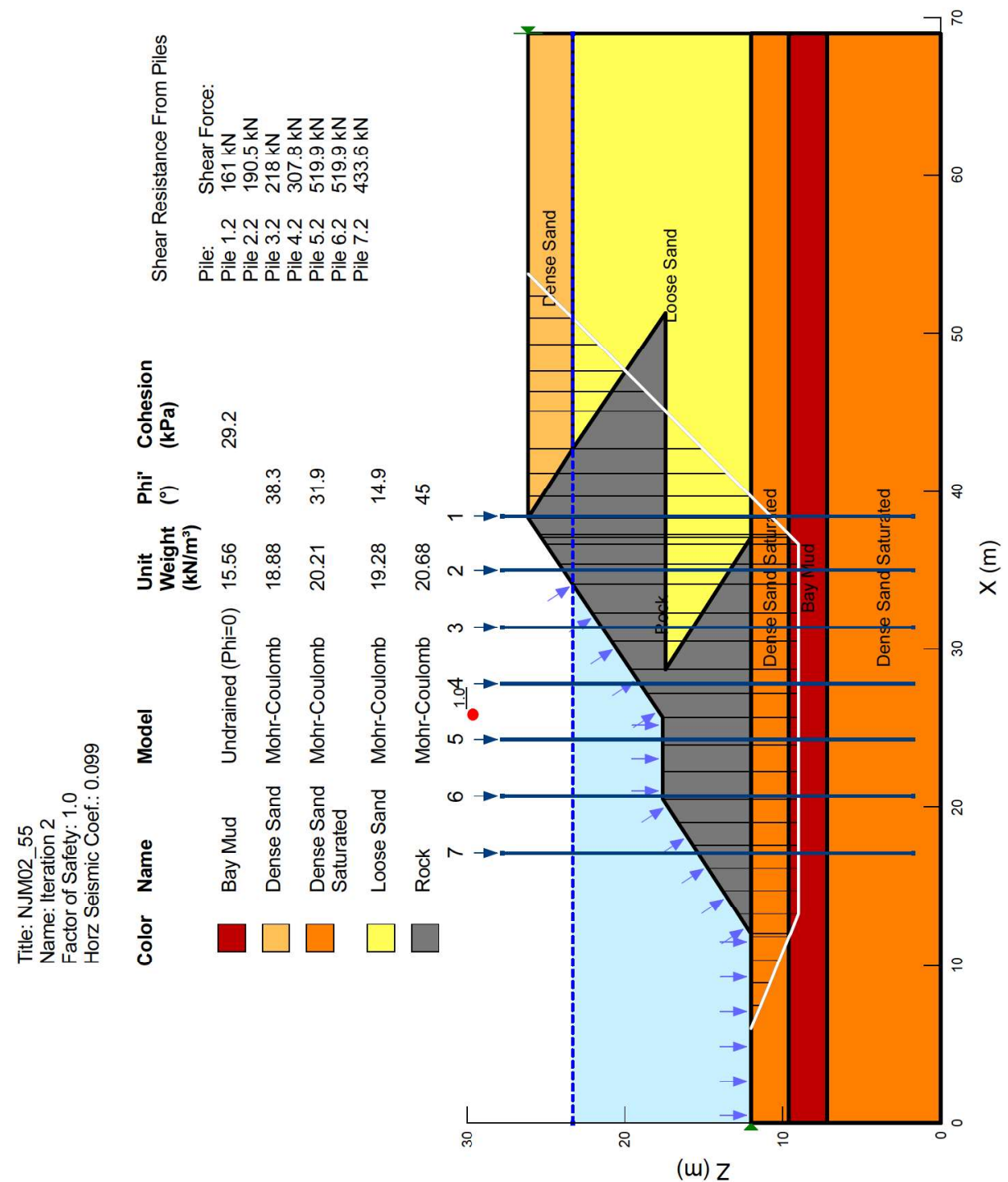



(u) Z 

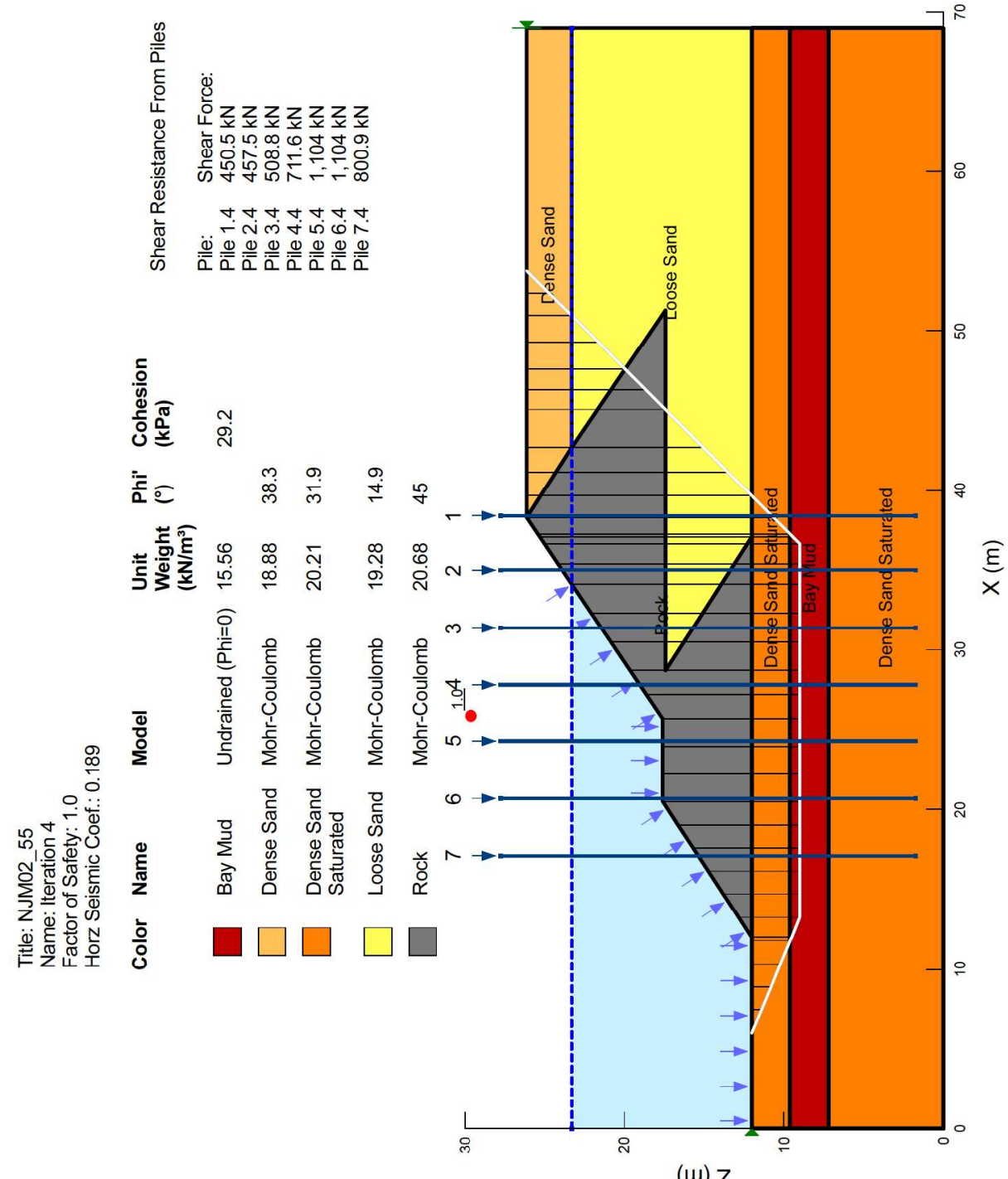

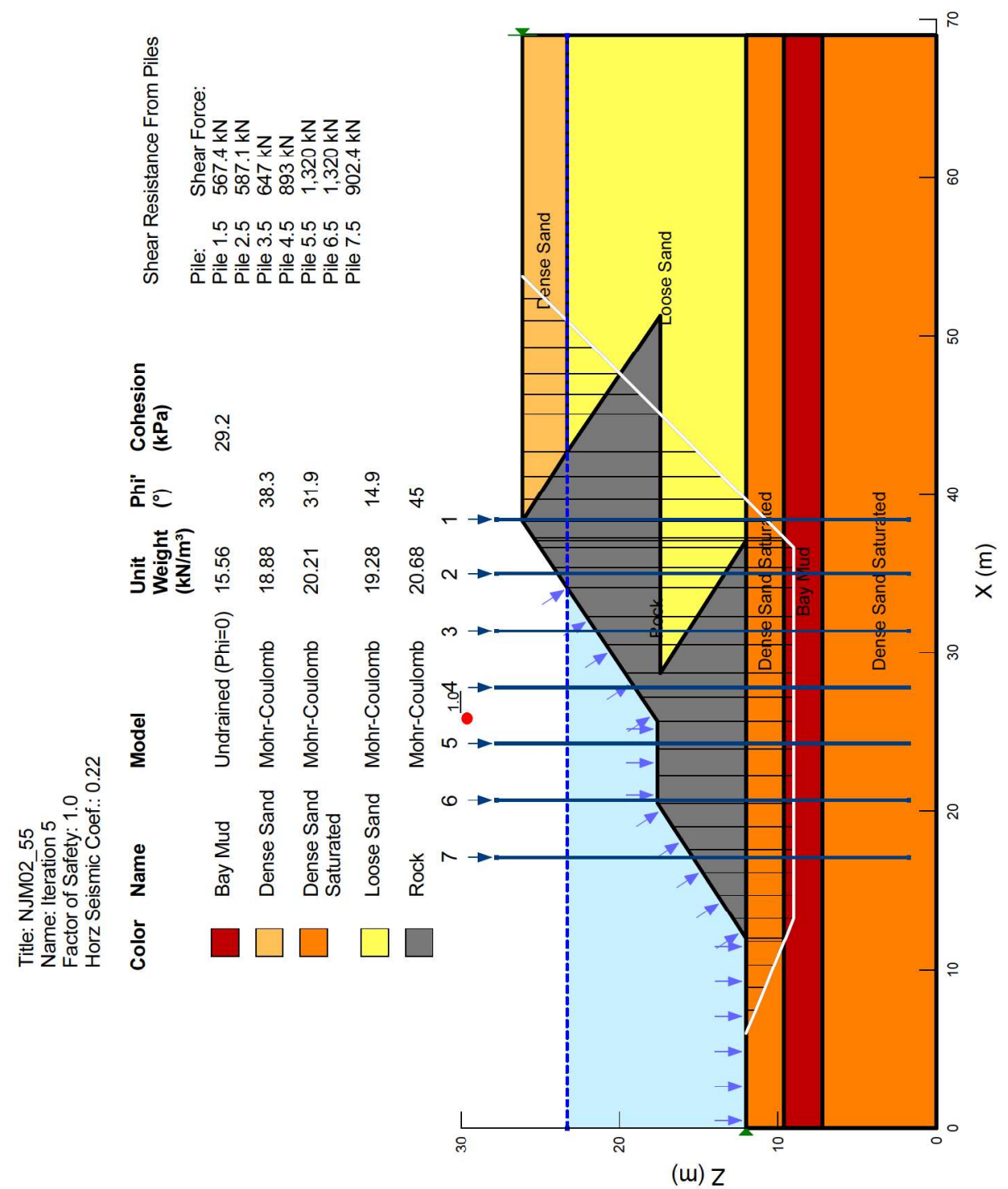


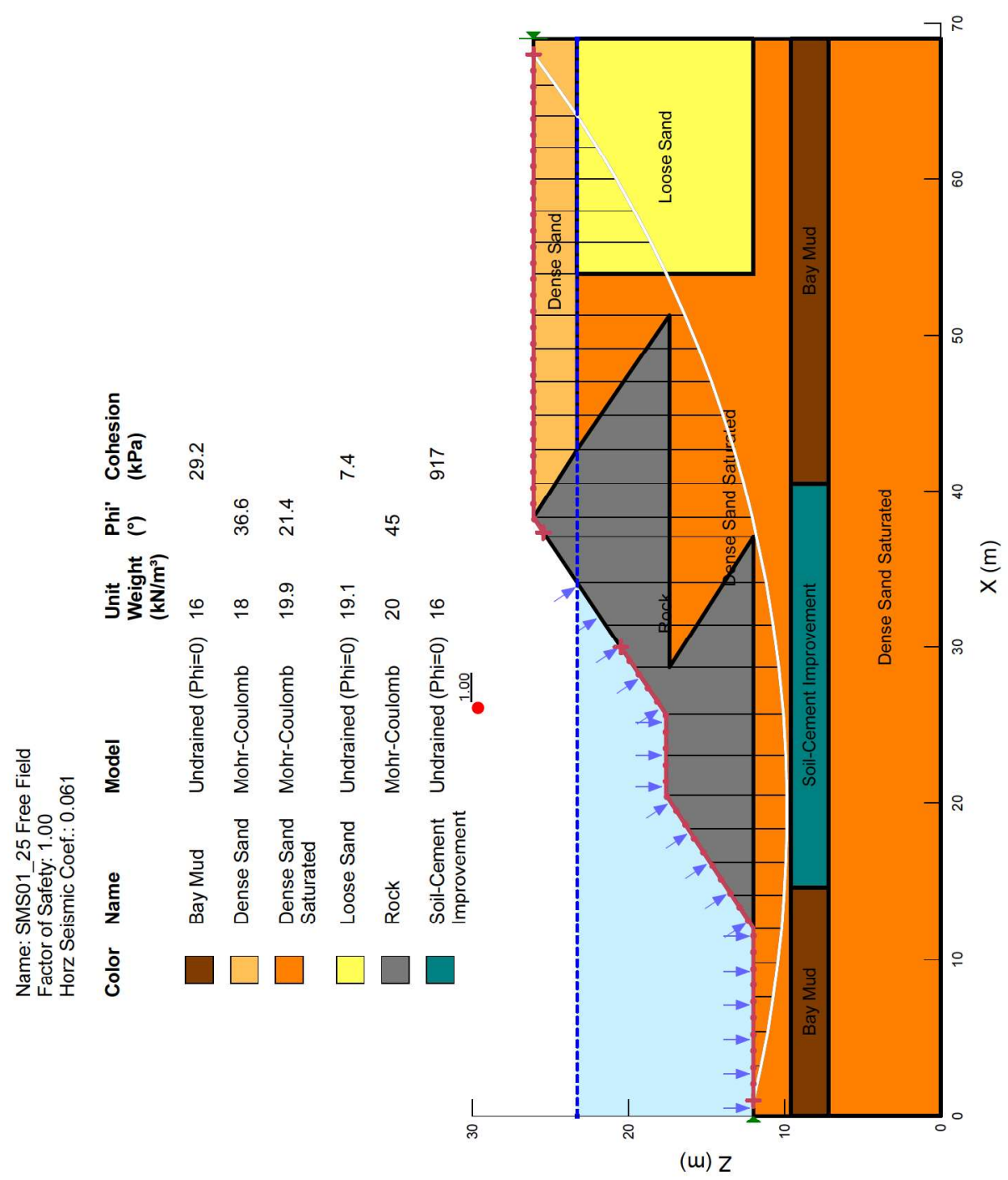




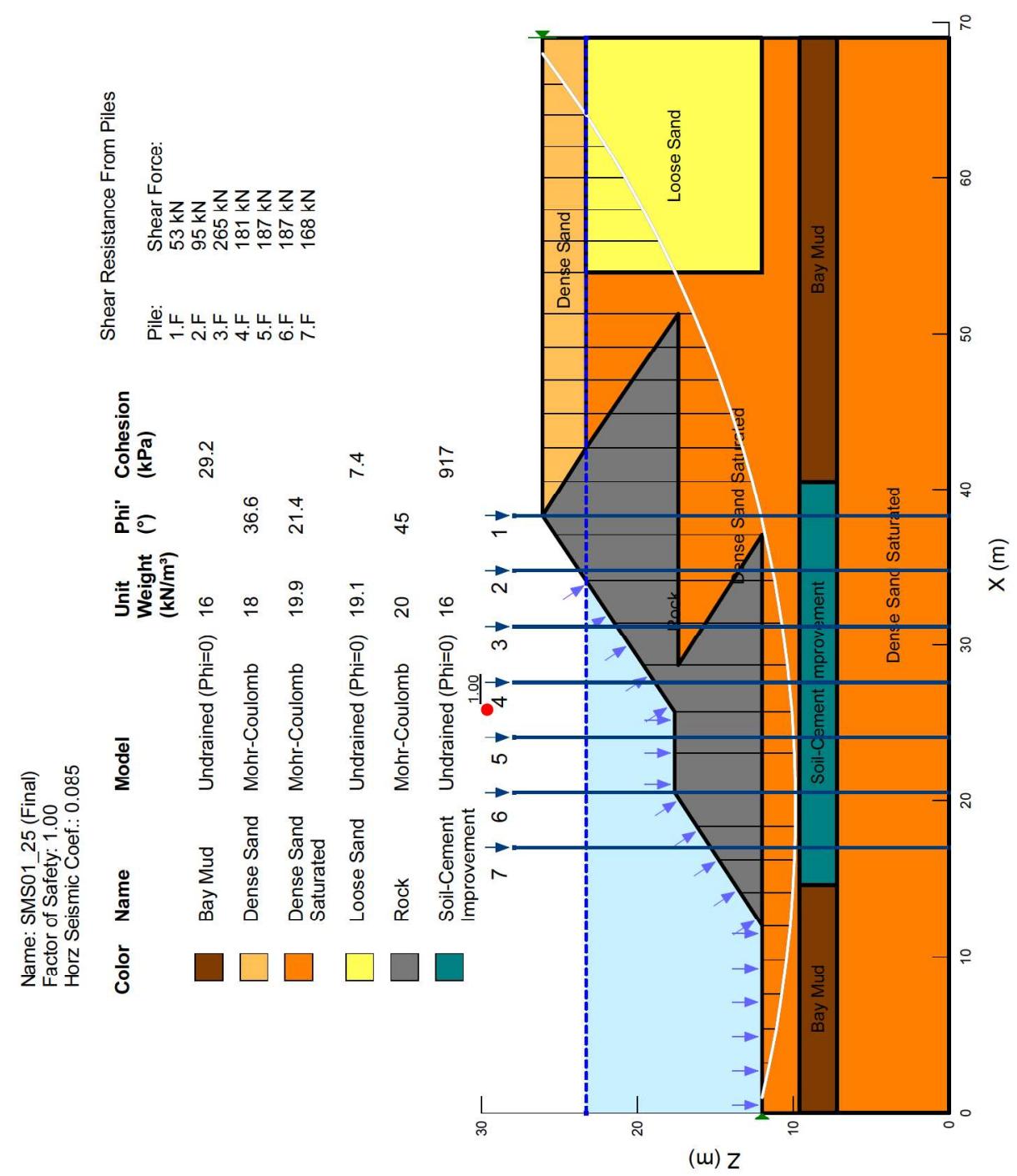




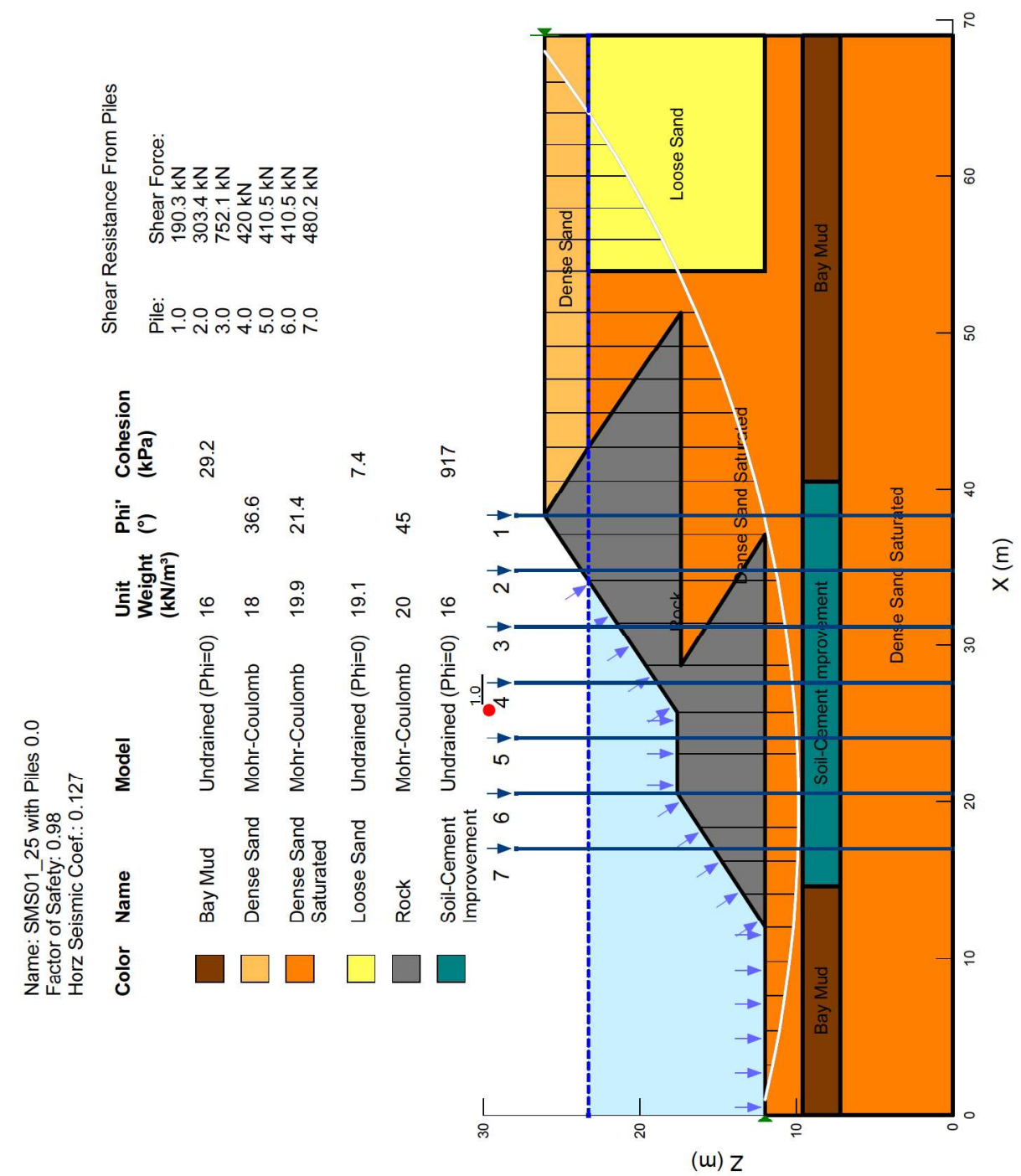





(u) Z 


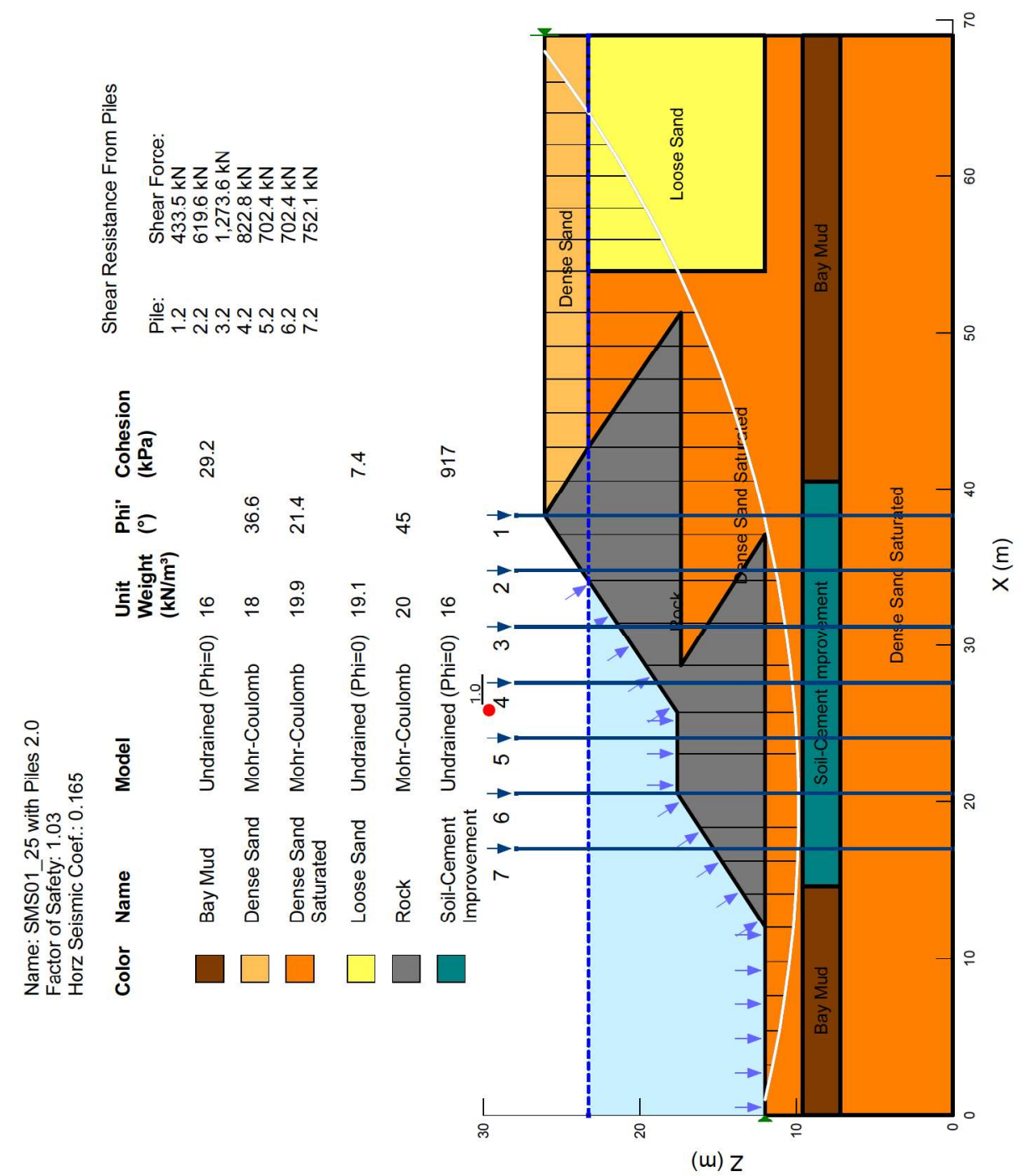



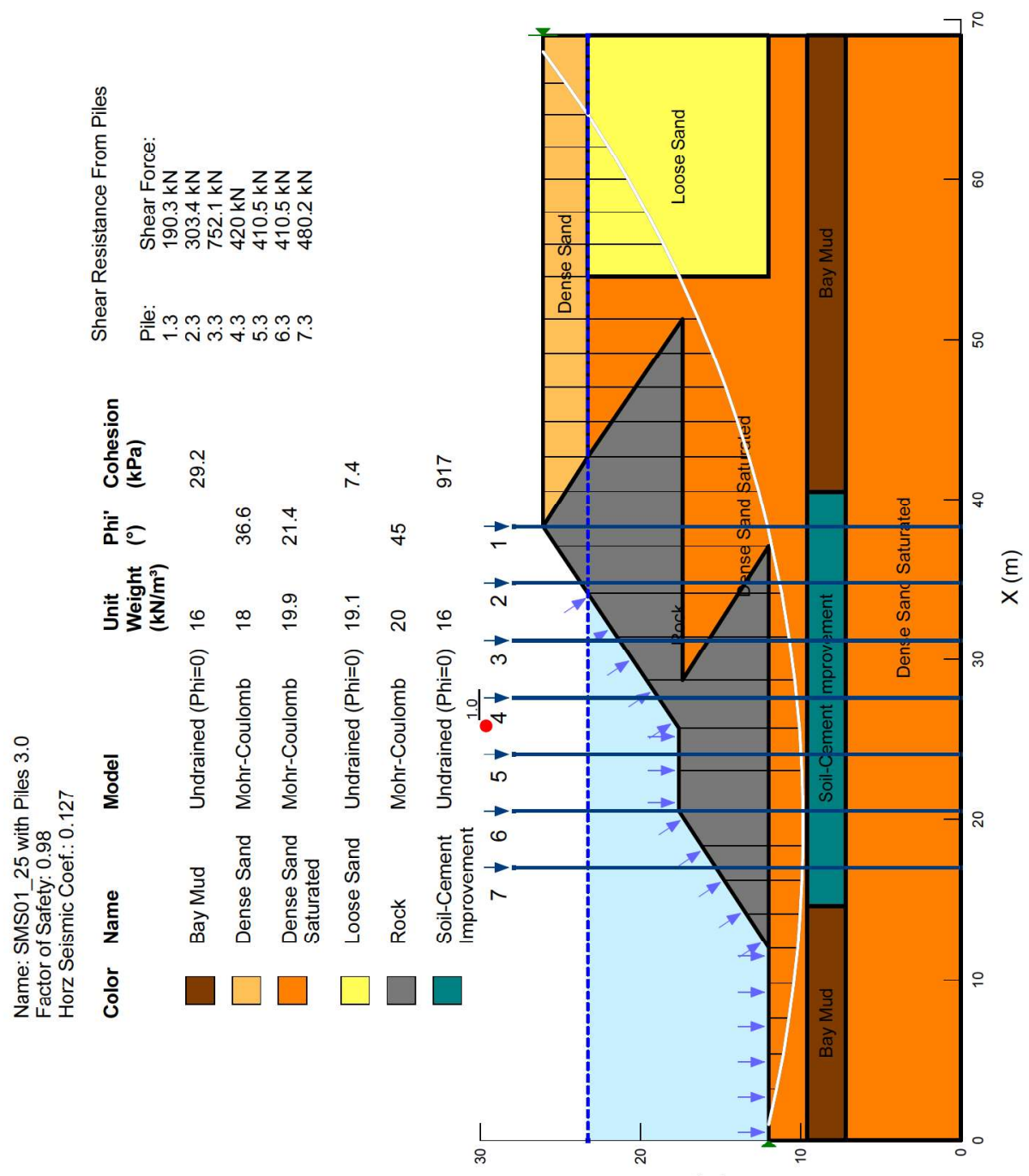

(u) Z 
边

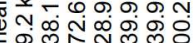

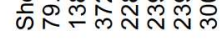

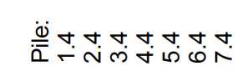

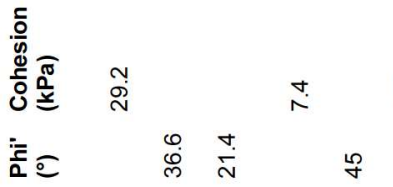

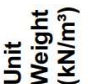



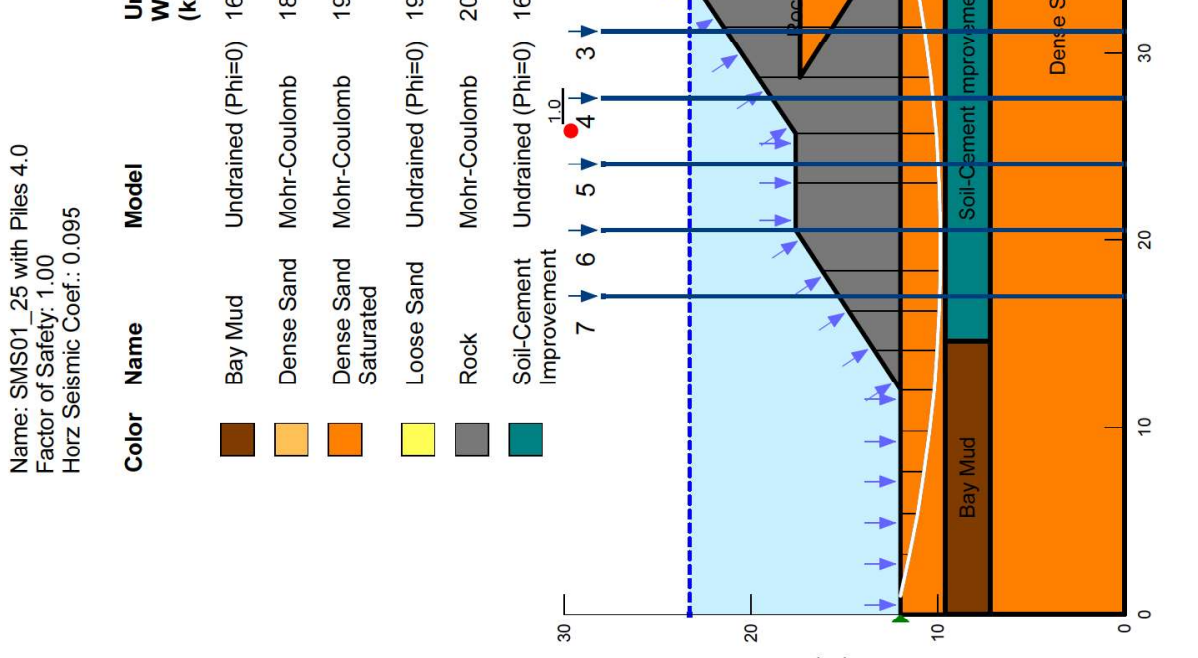

(u) Z 



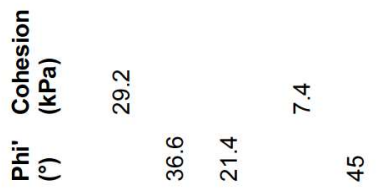

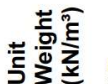

$\leftarrow \stackrel{\circ}{\circ} \stackrel{\circ}{\circ} \stackrel{\circ}{\circ}$

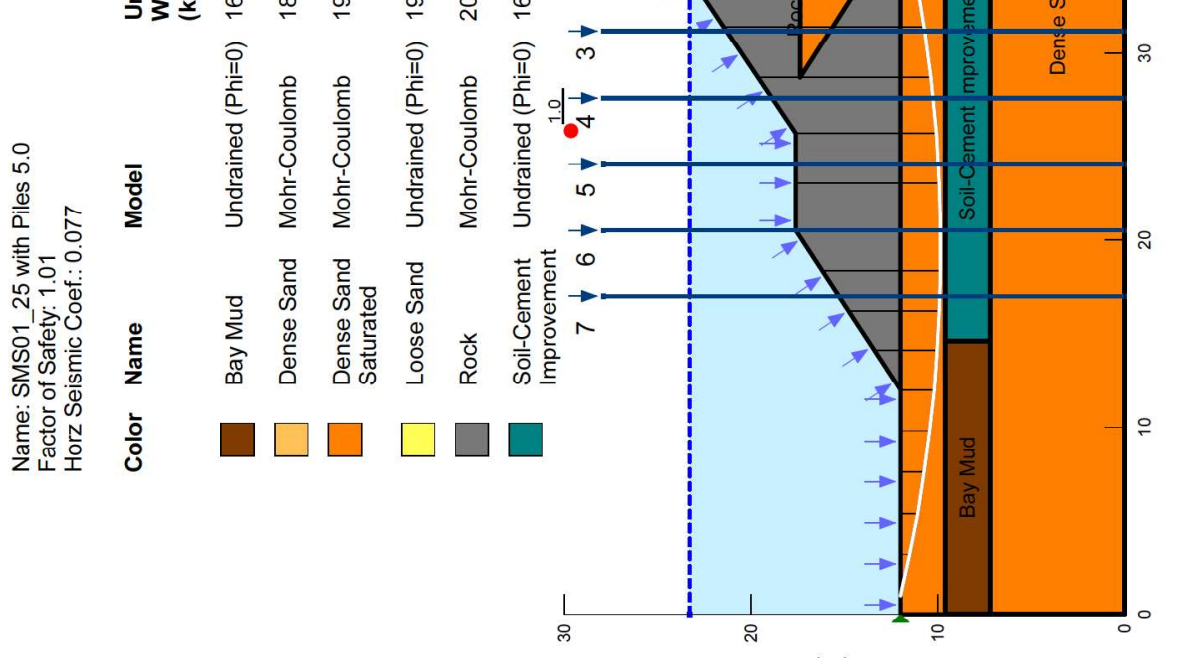

(u) Z 


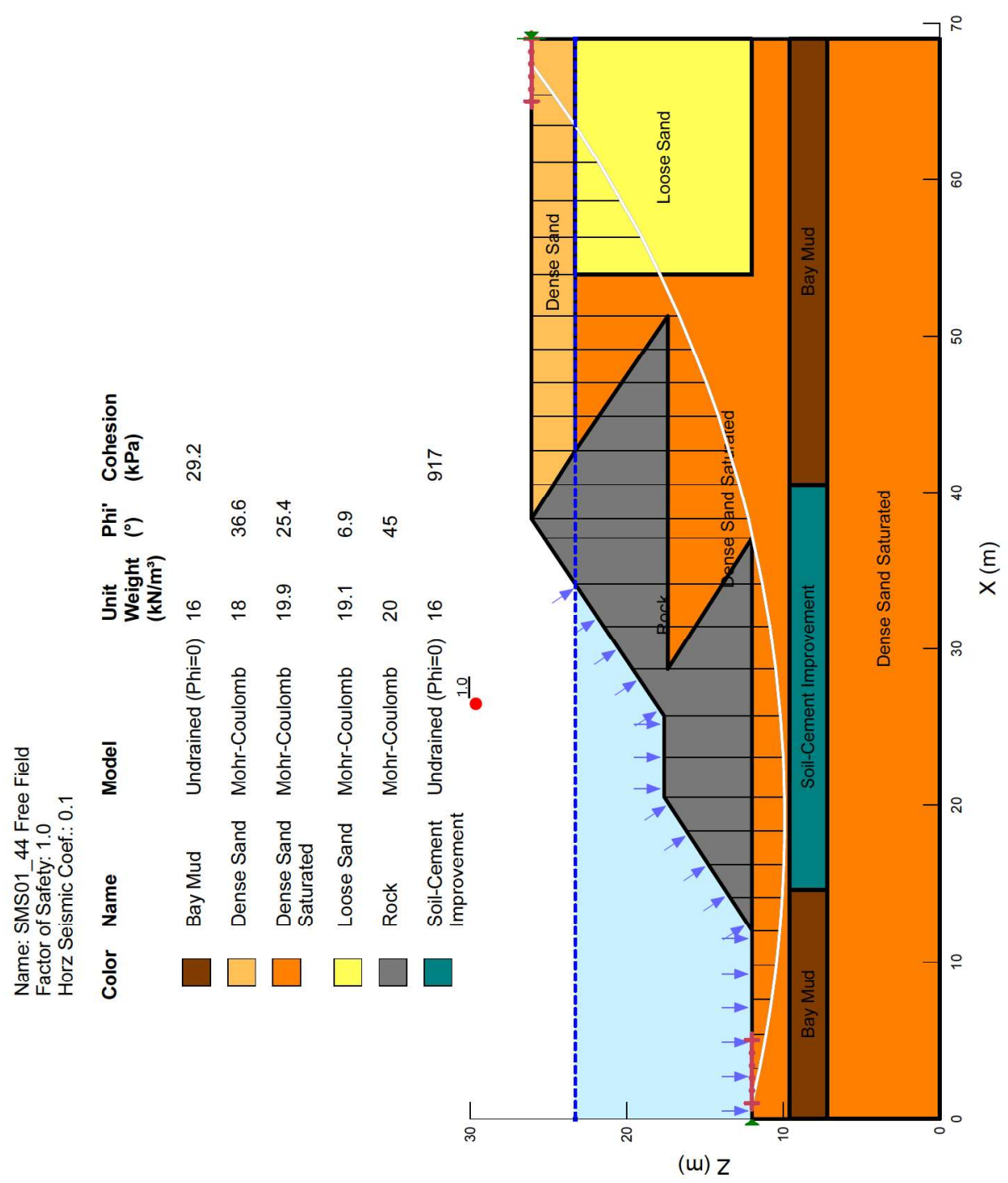



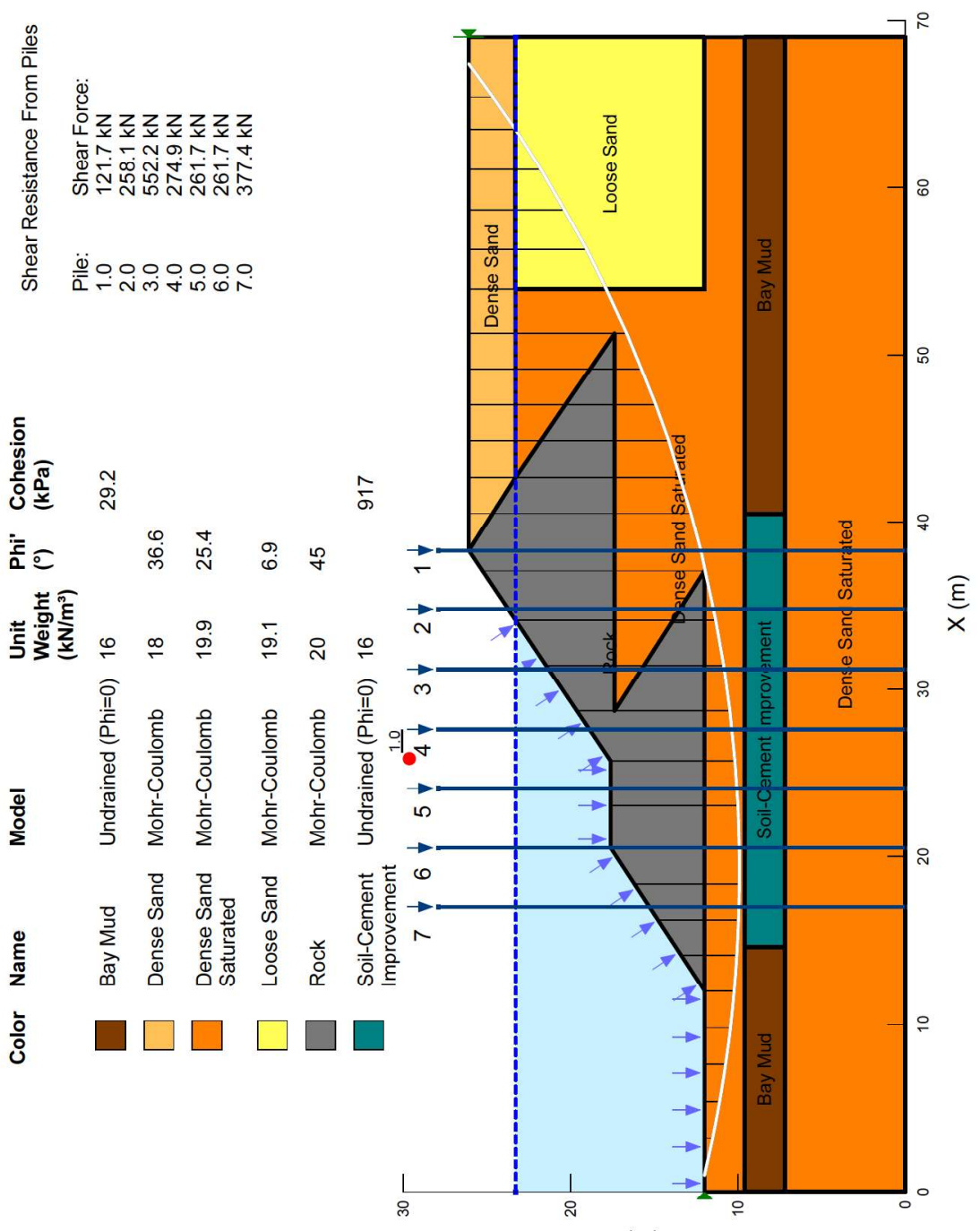

(u) Z 

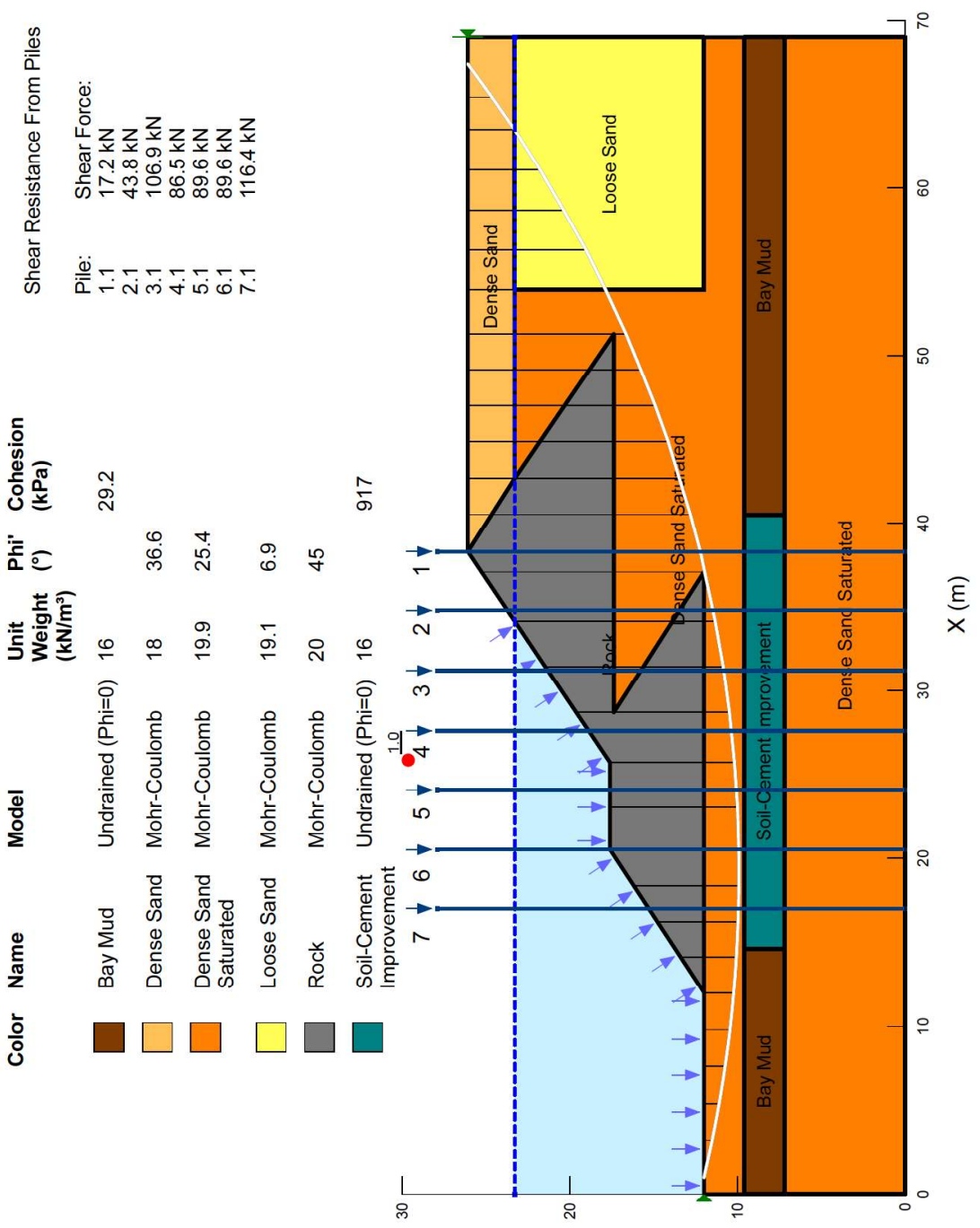

(u) Z 

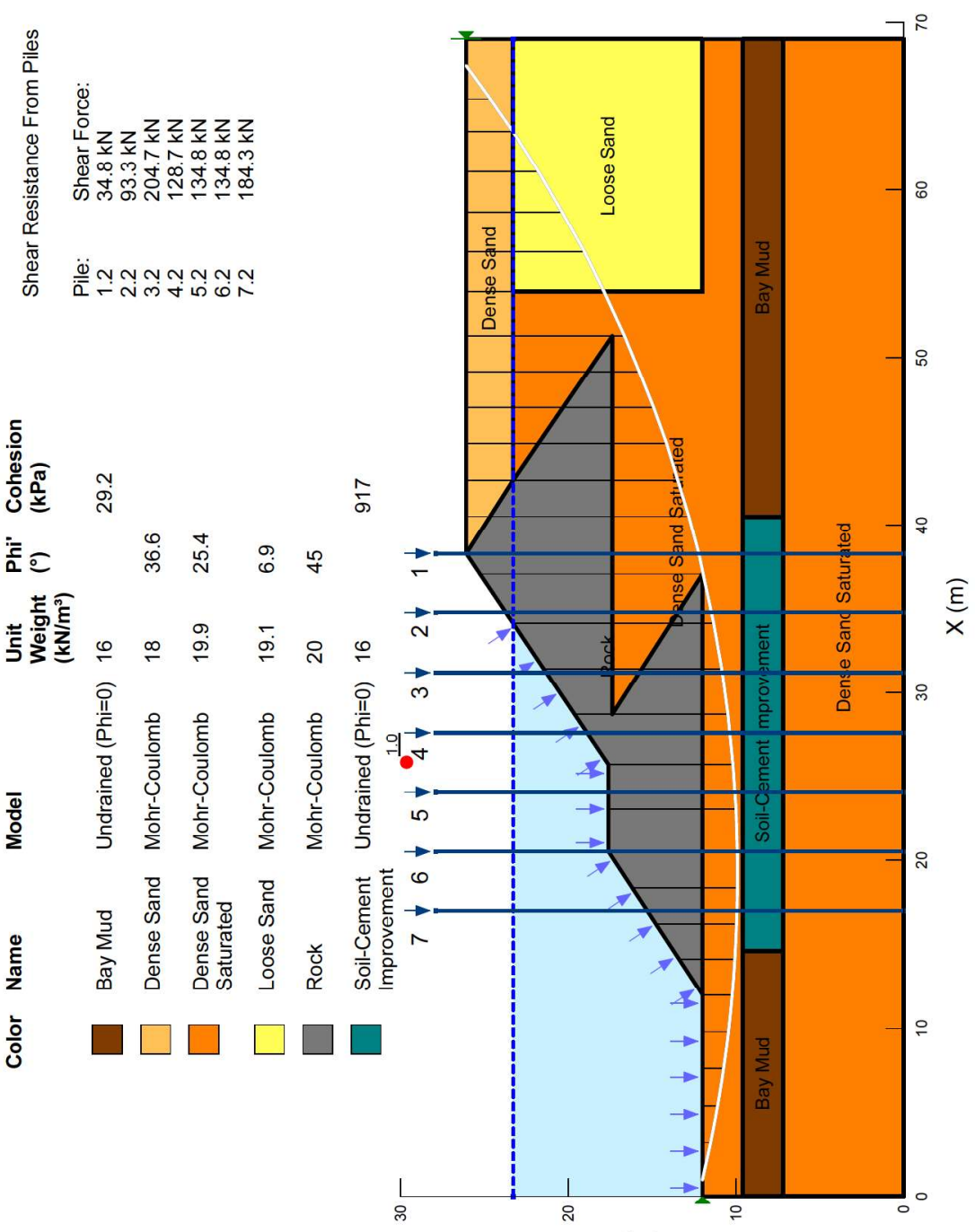

(ui) Z 

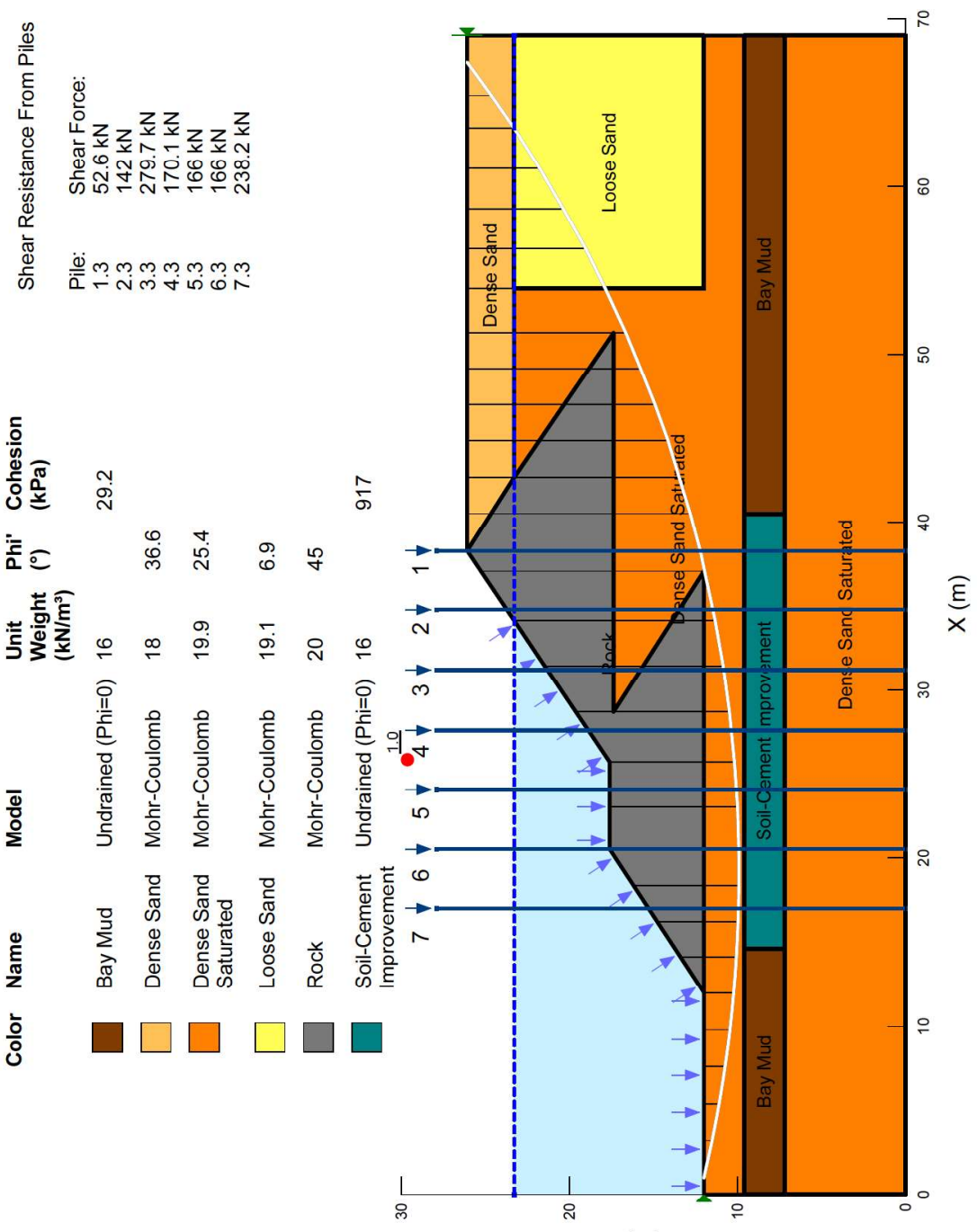

(u) Z 

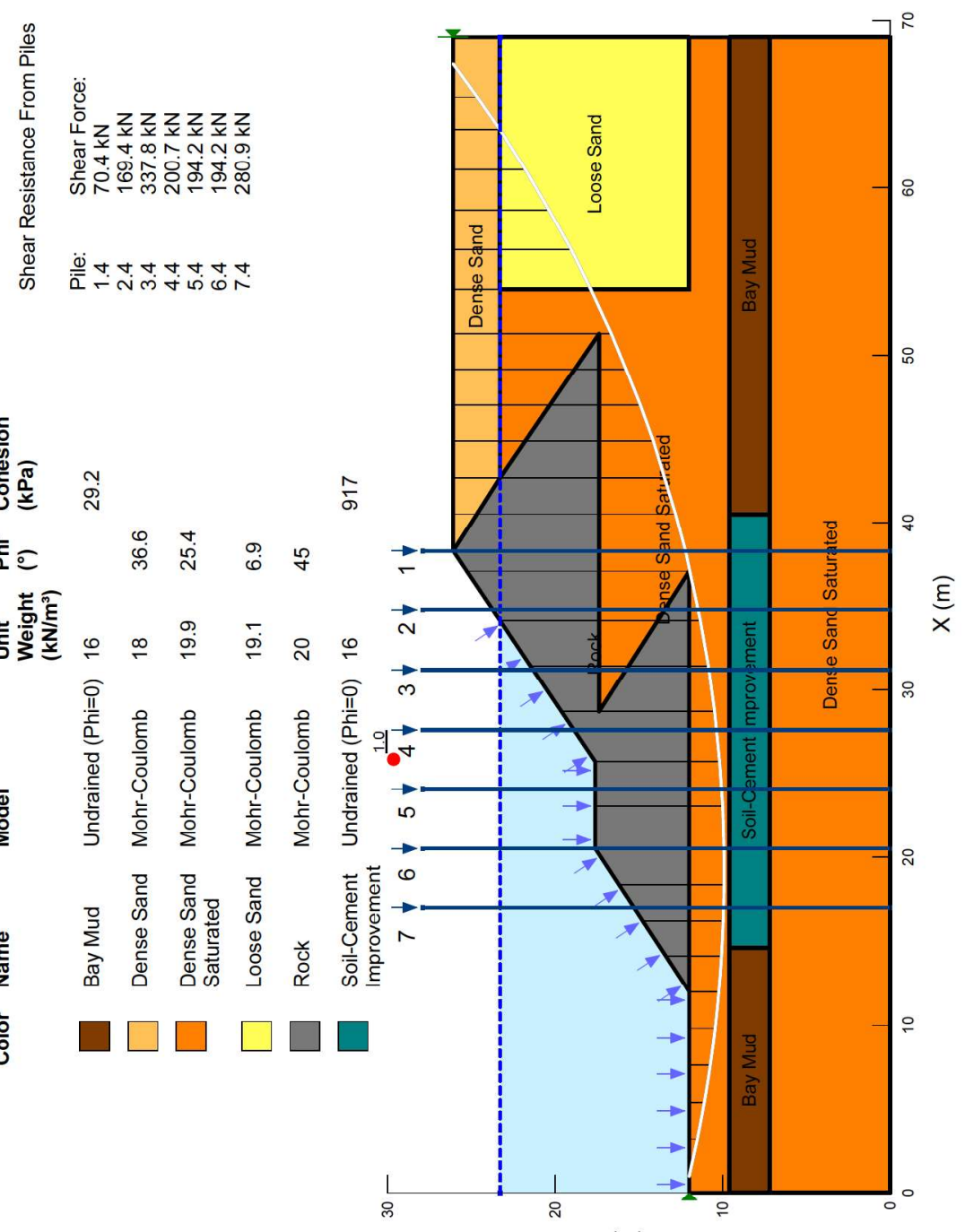

(u) Z 

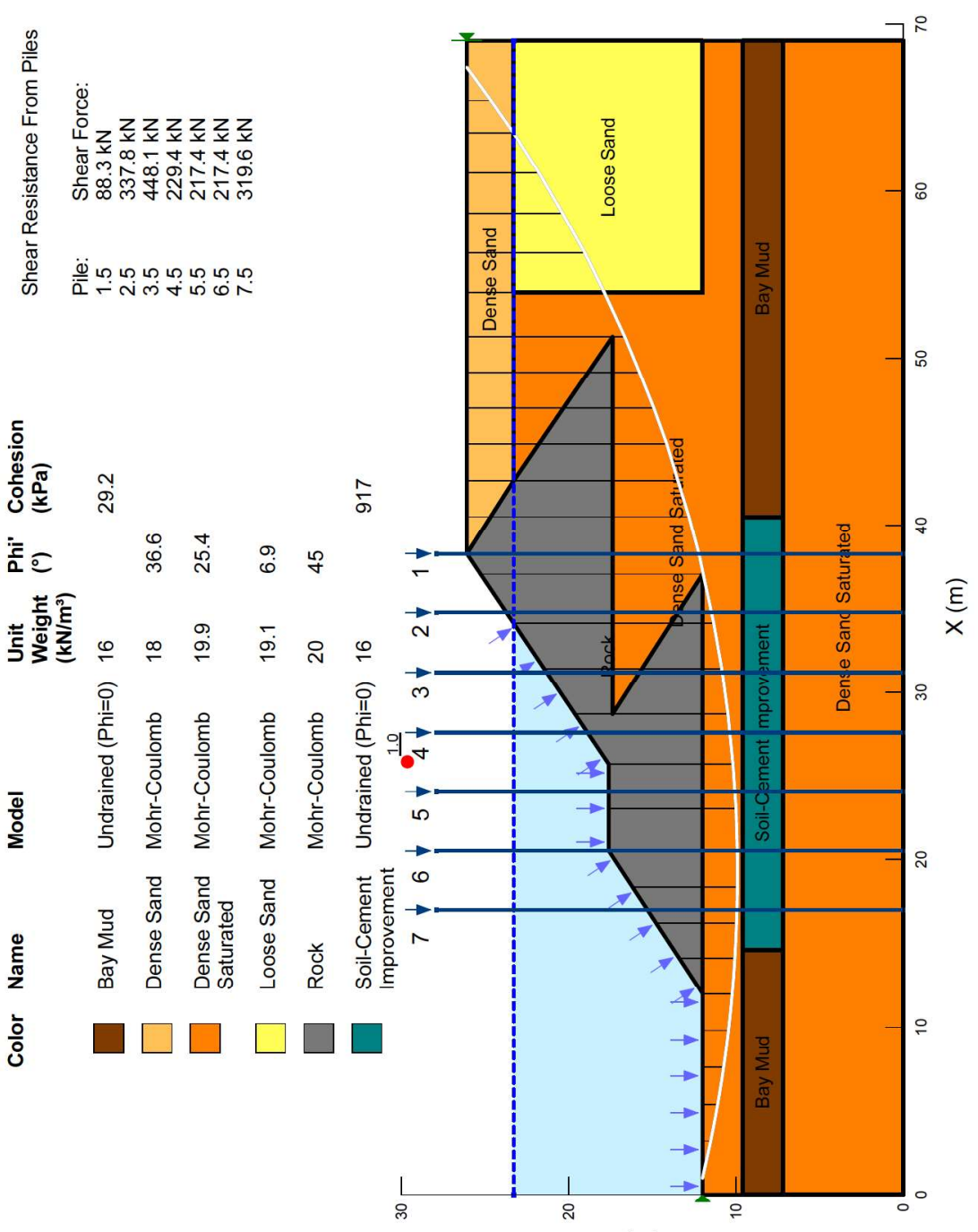

(u) Z 

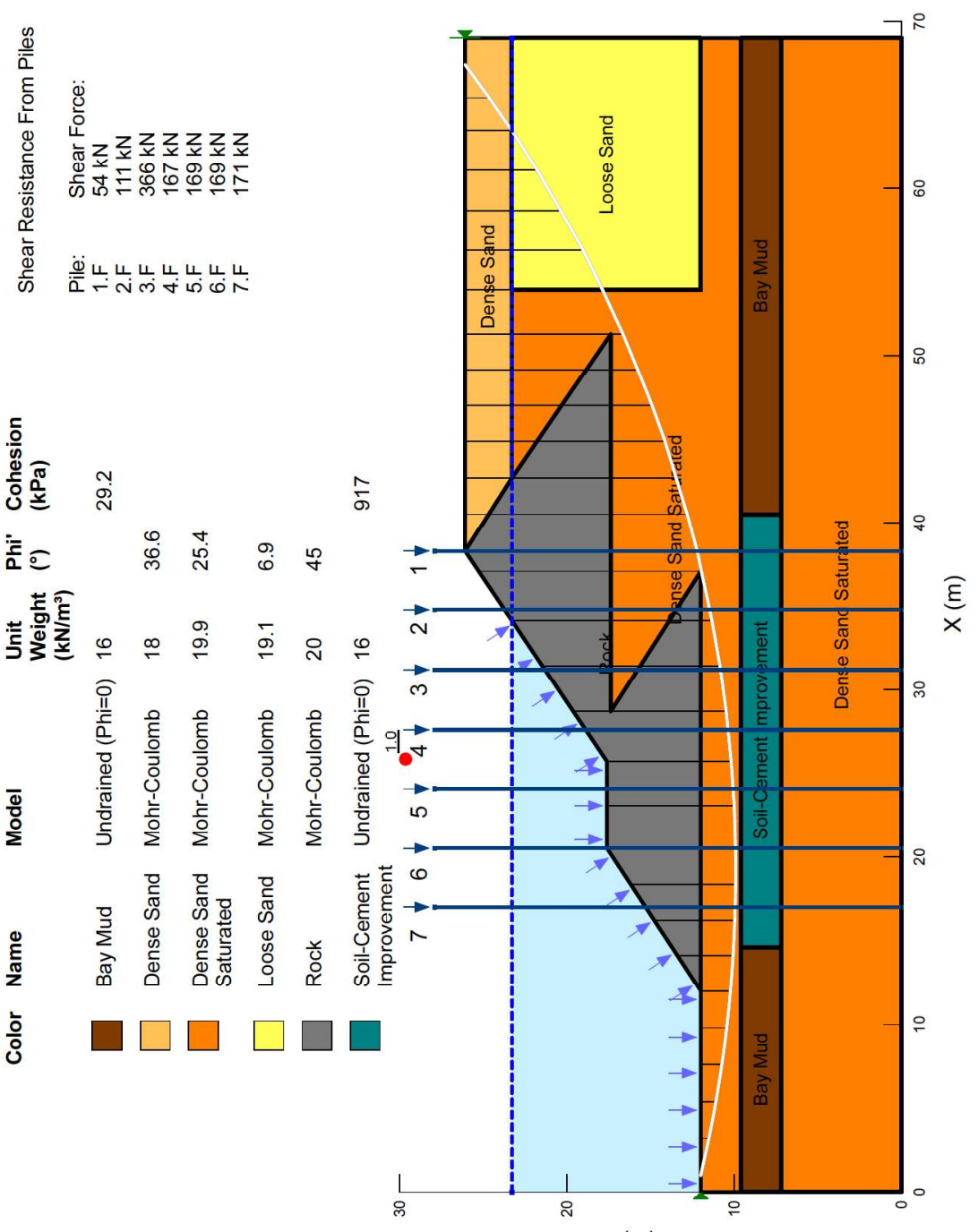

(u) Z 


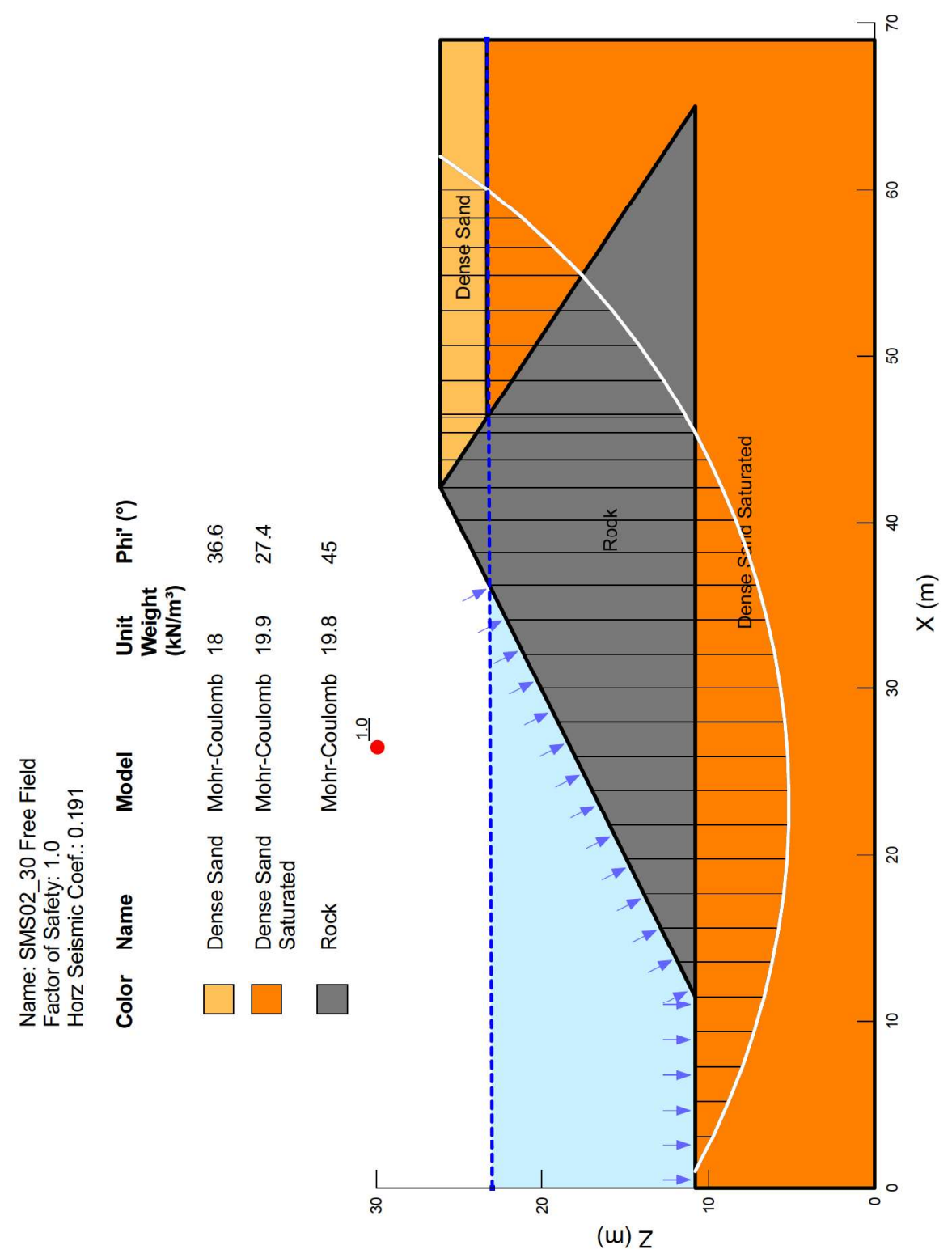




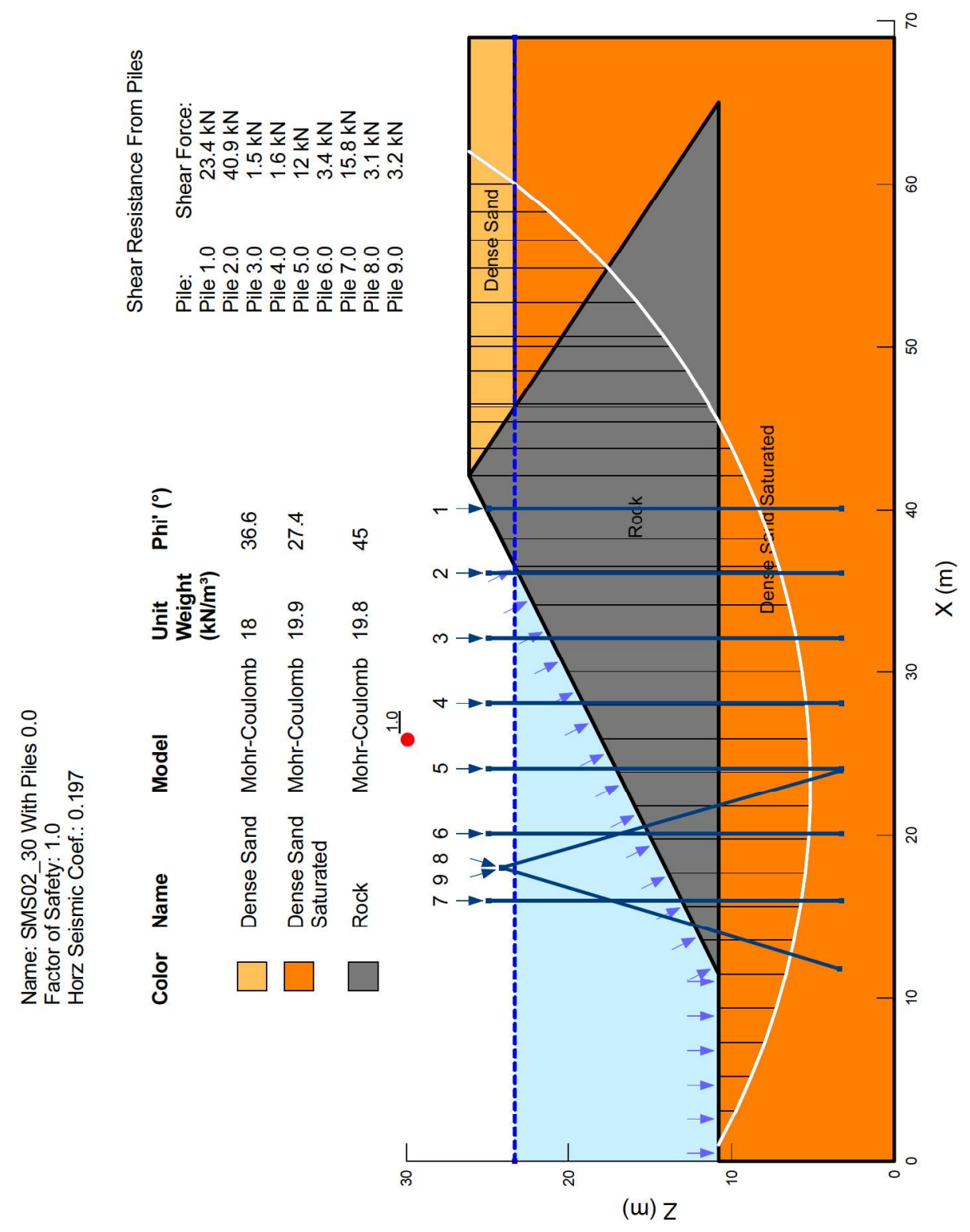









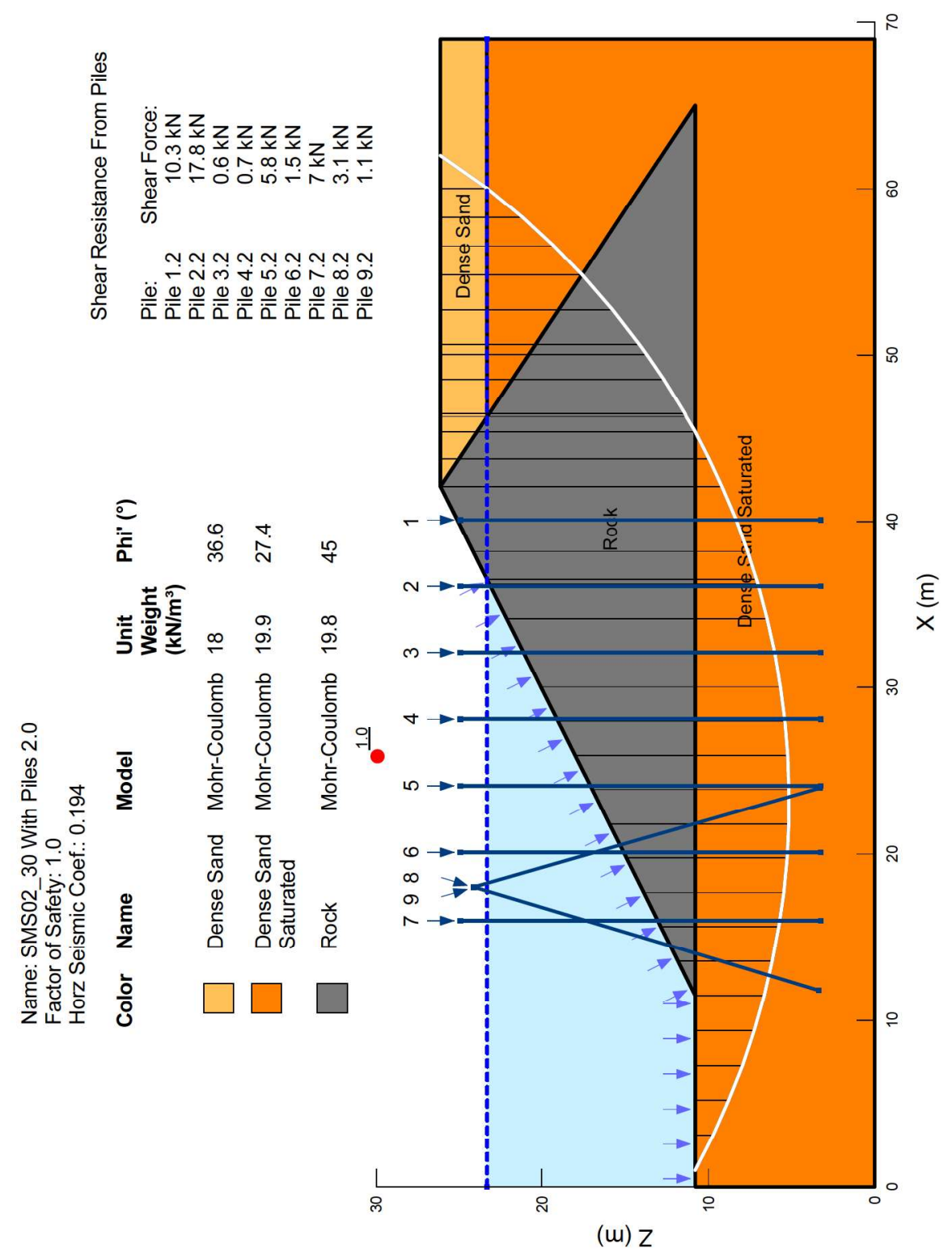




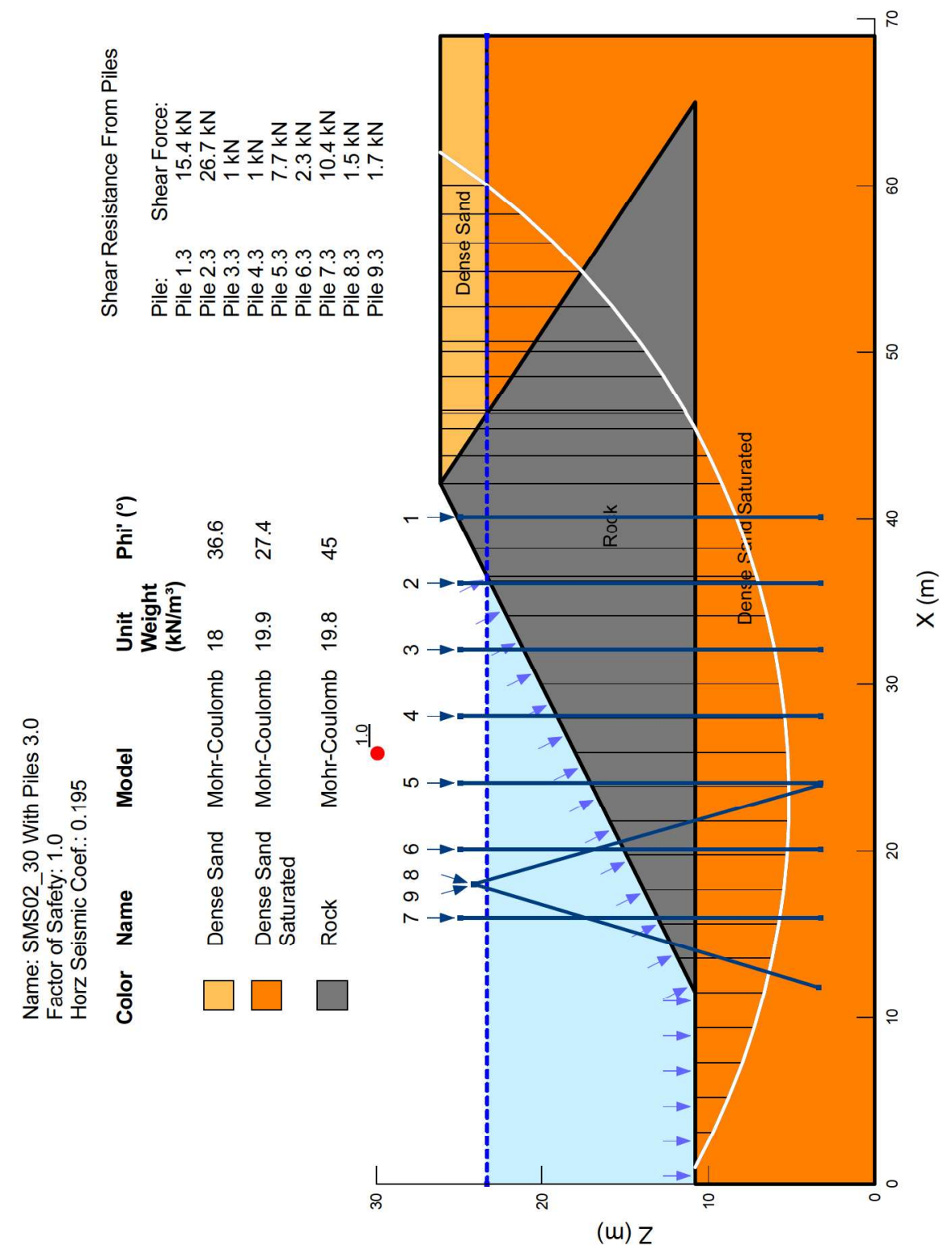




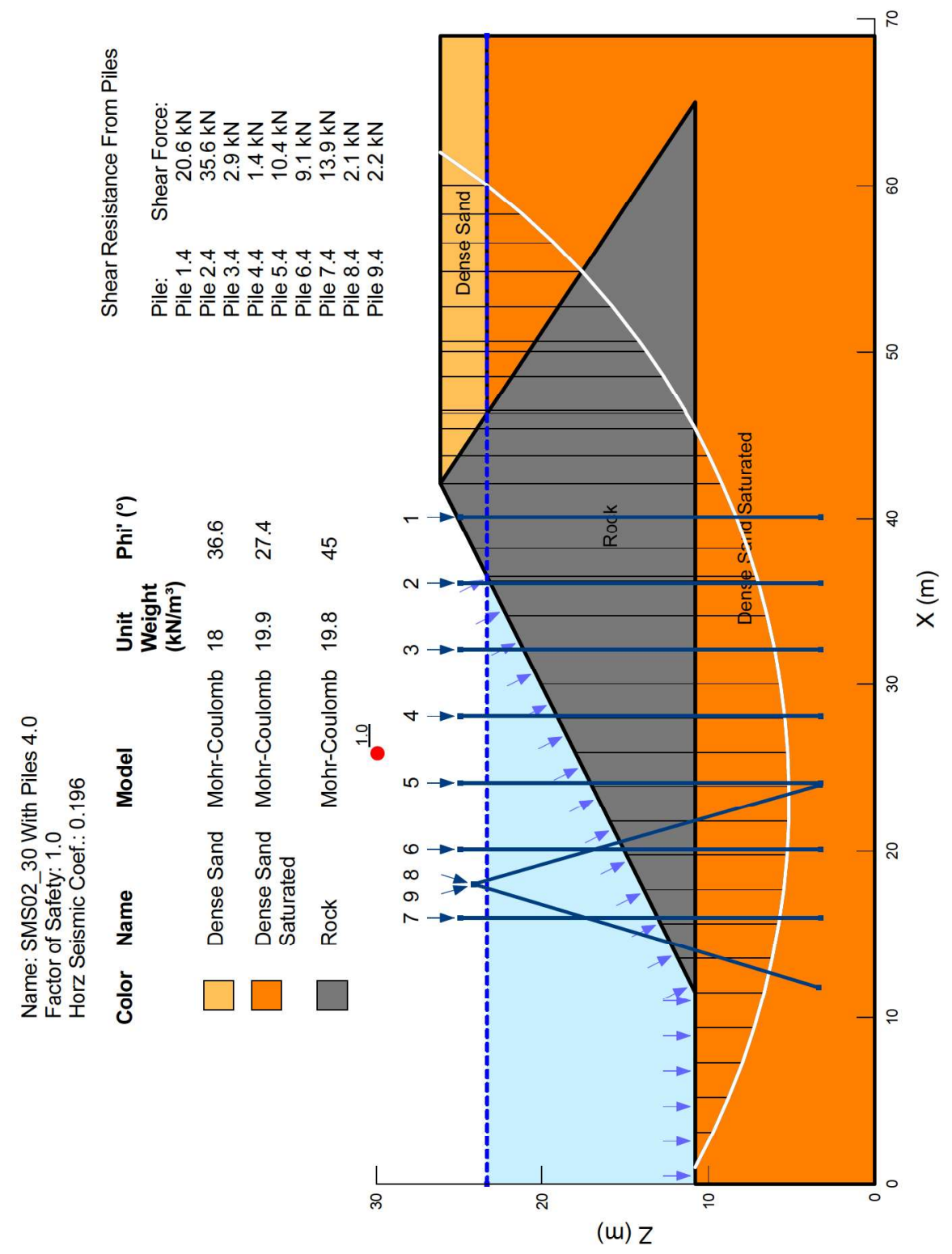



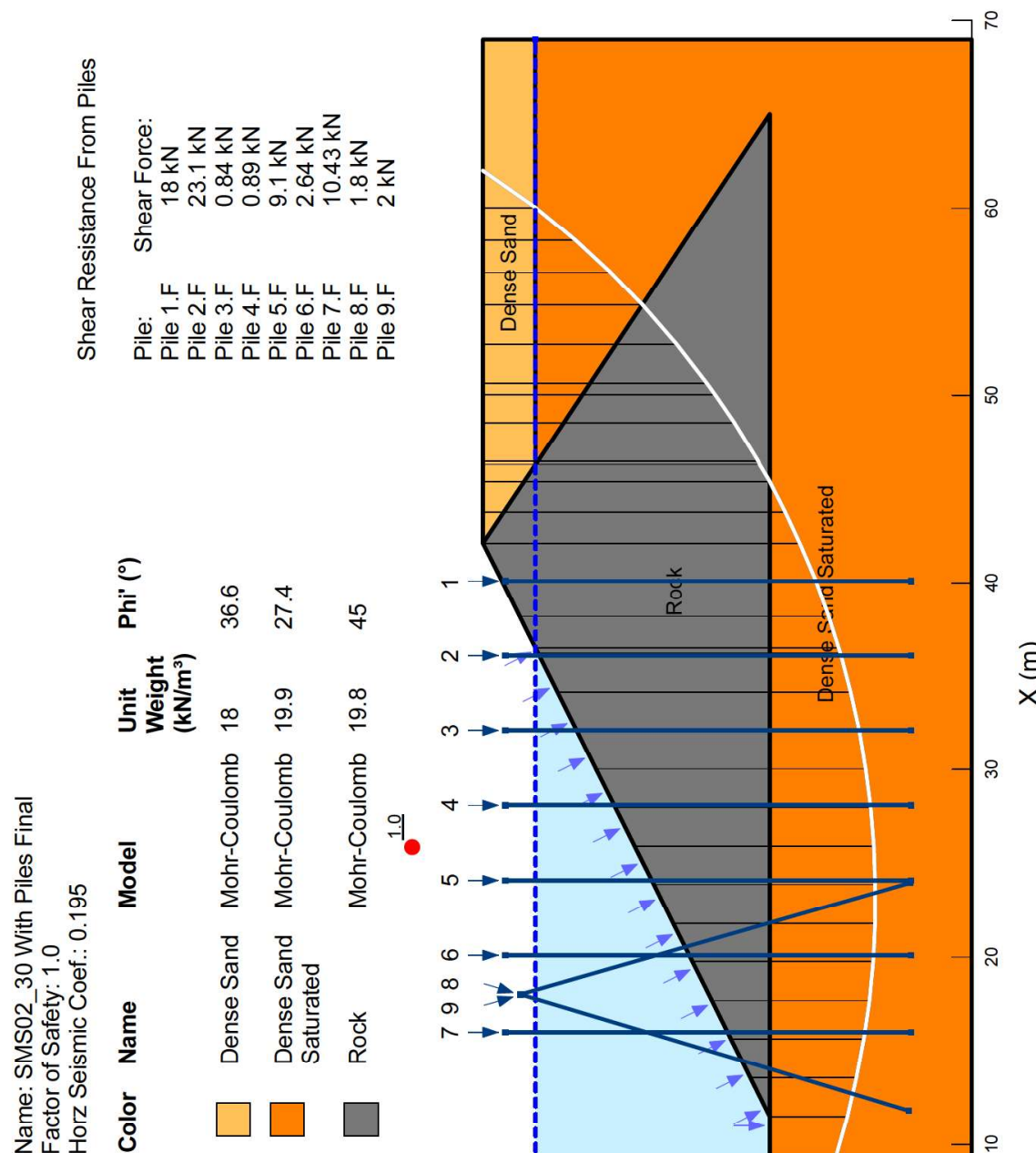

:

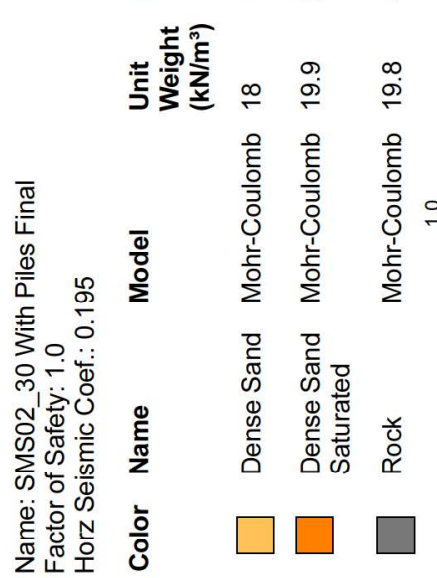
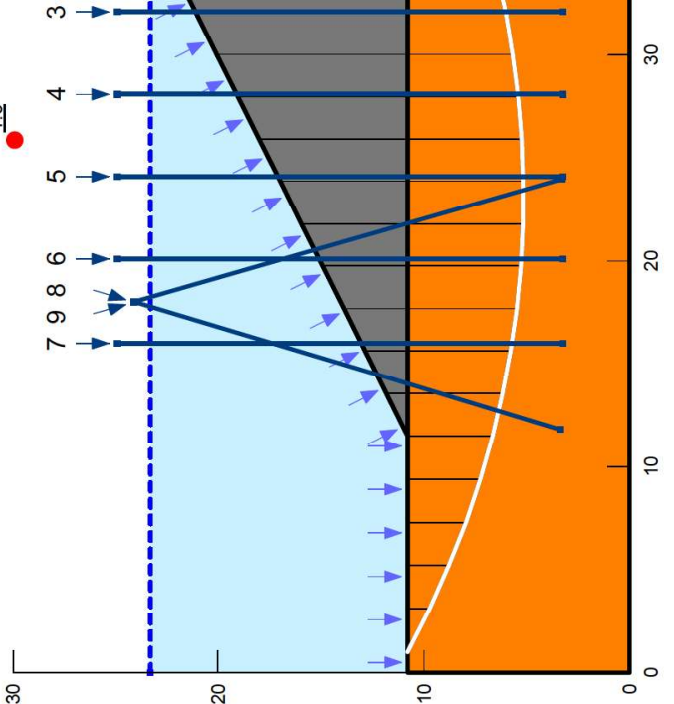

(w) Z 


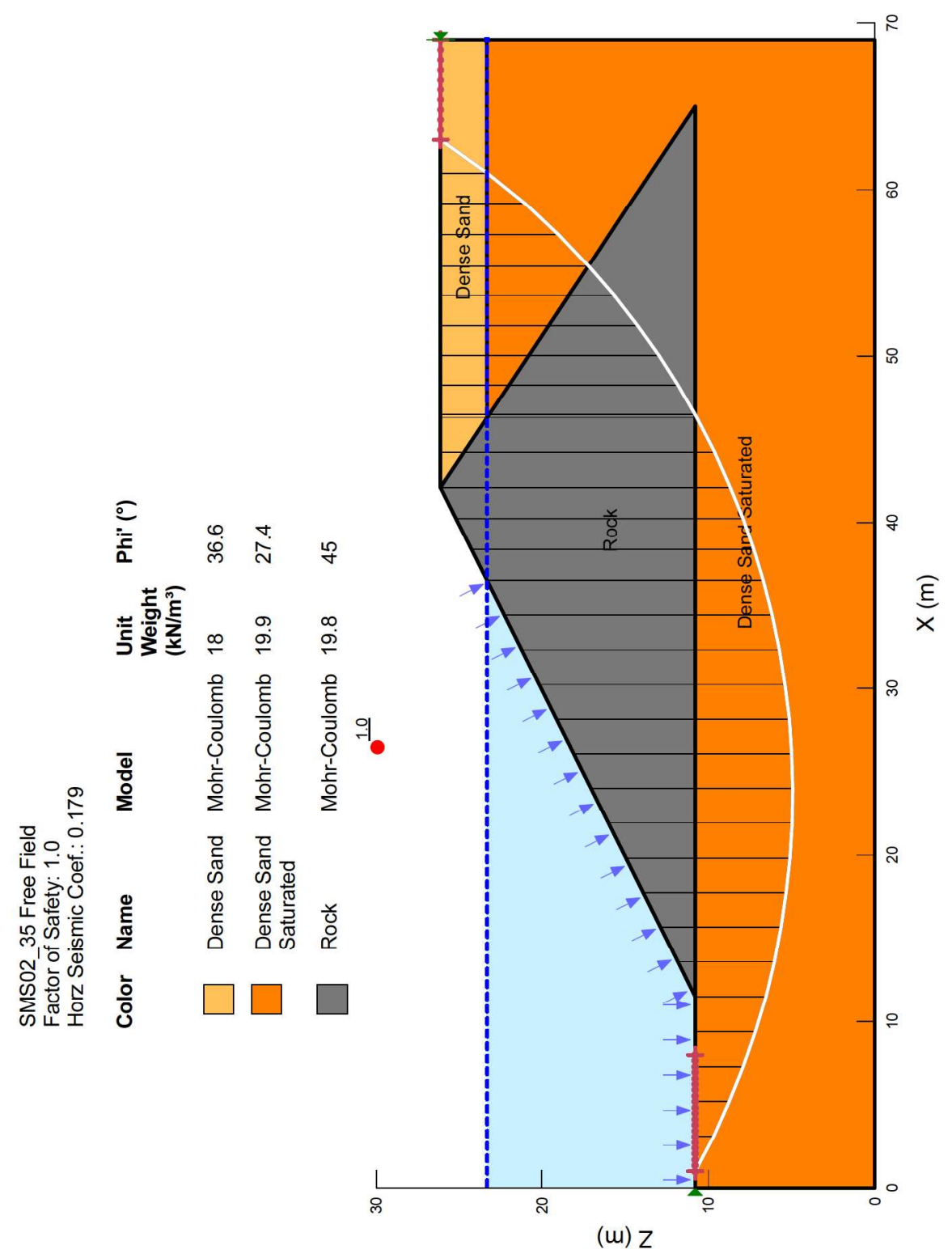




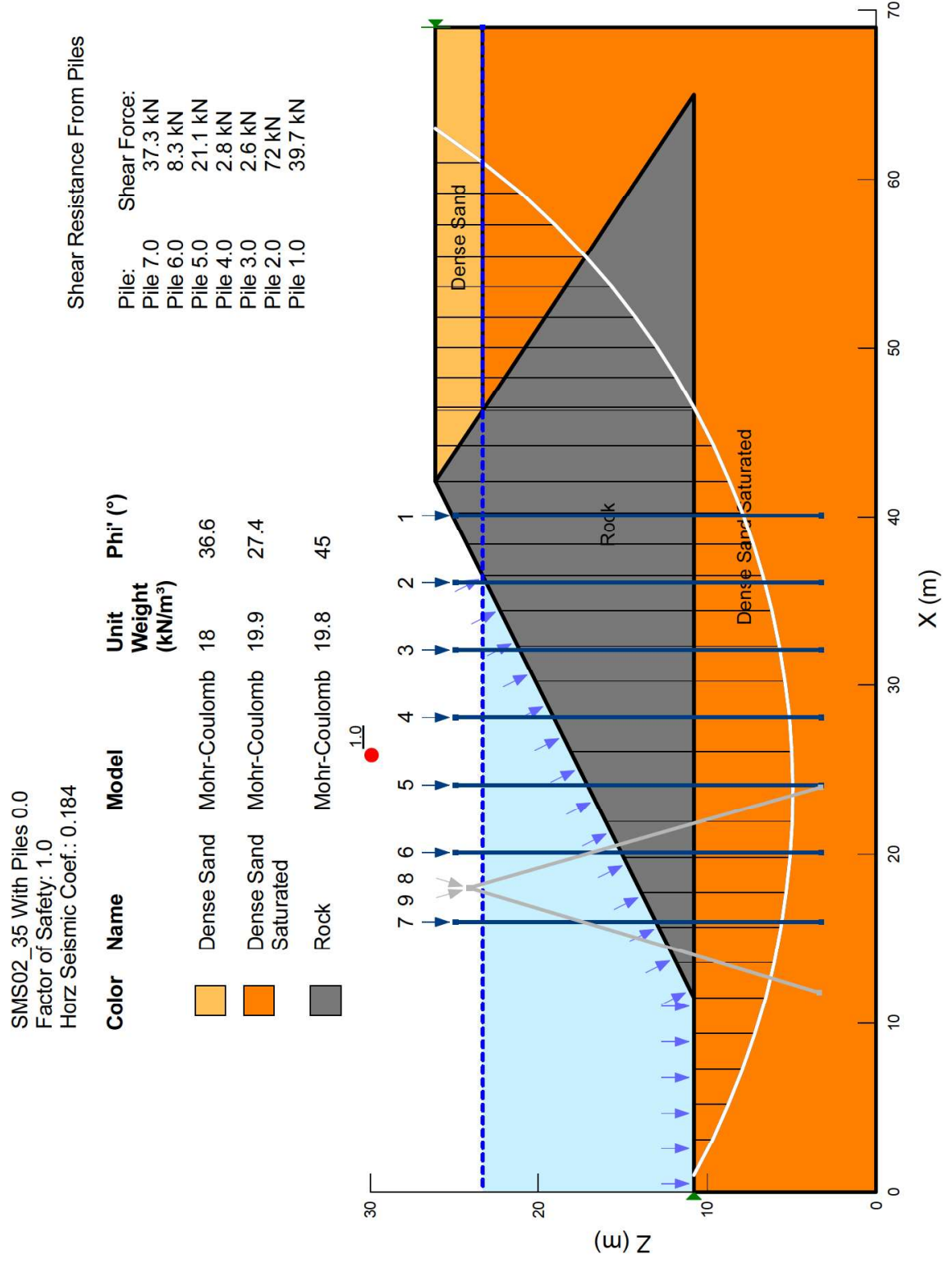




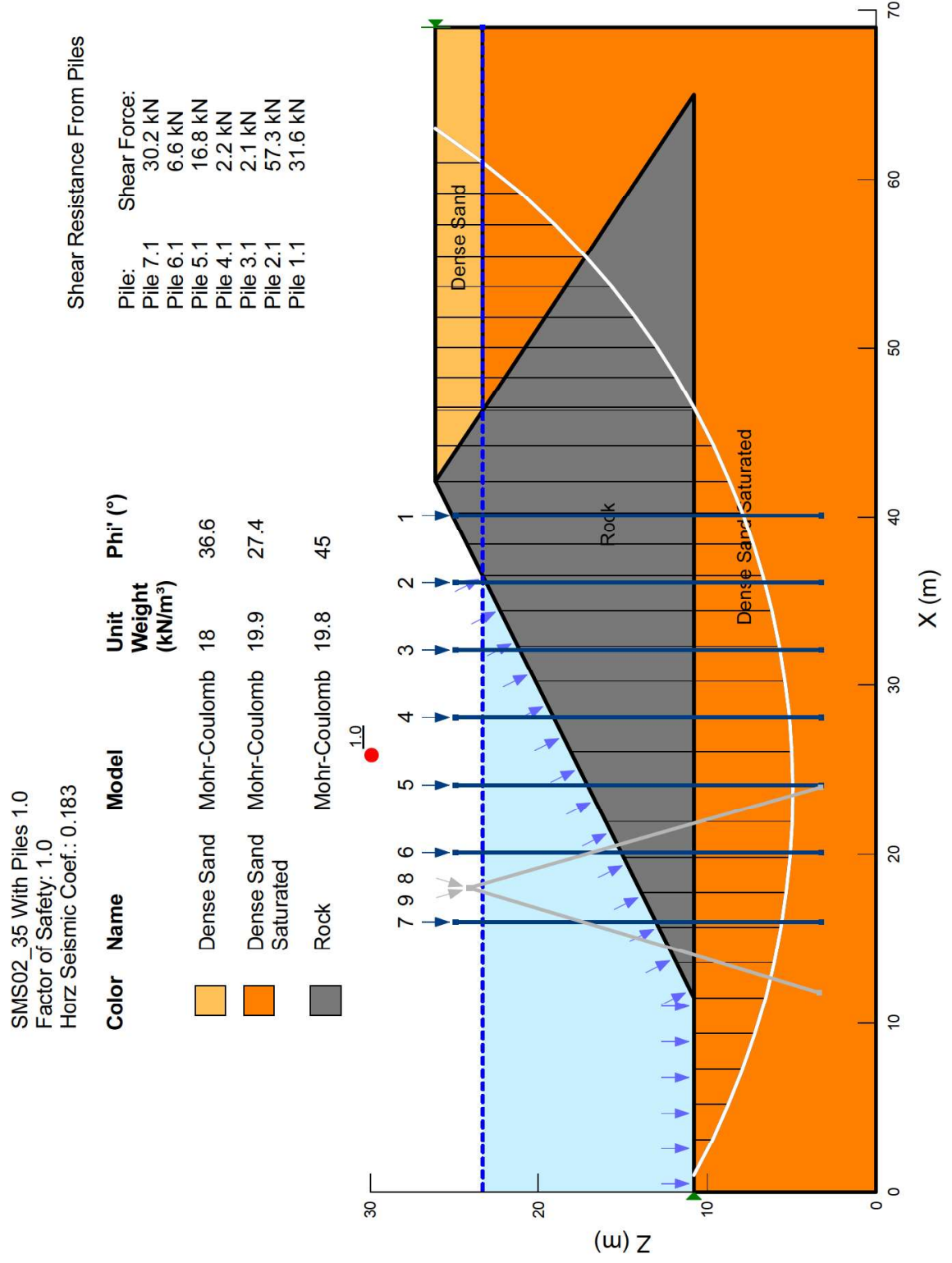




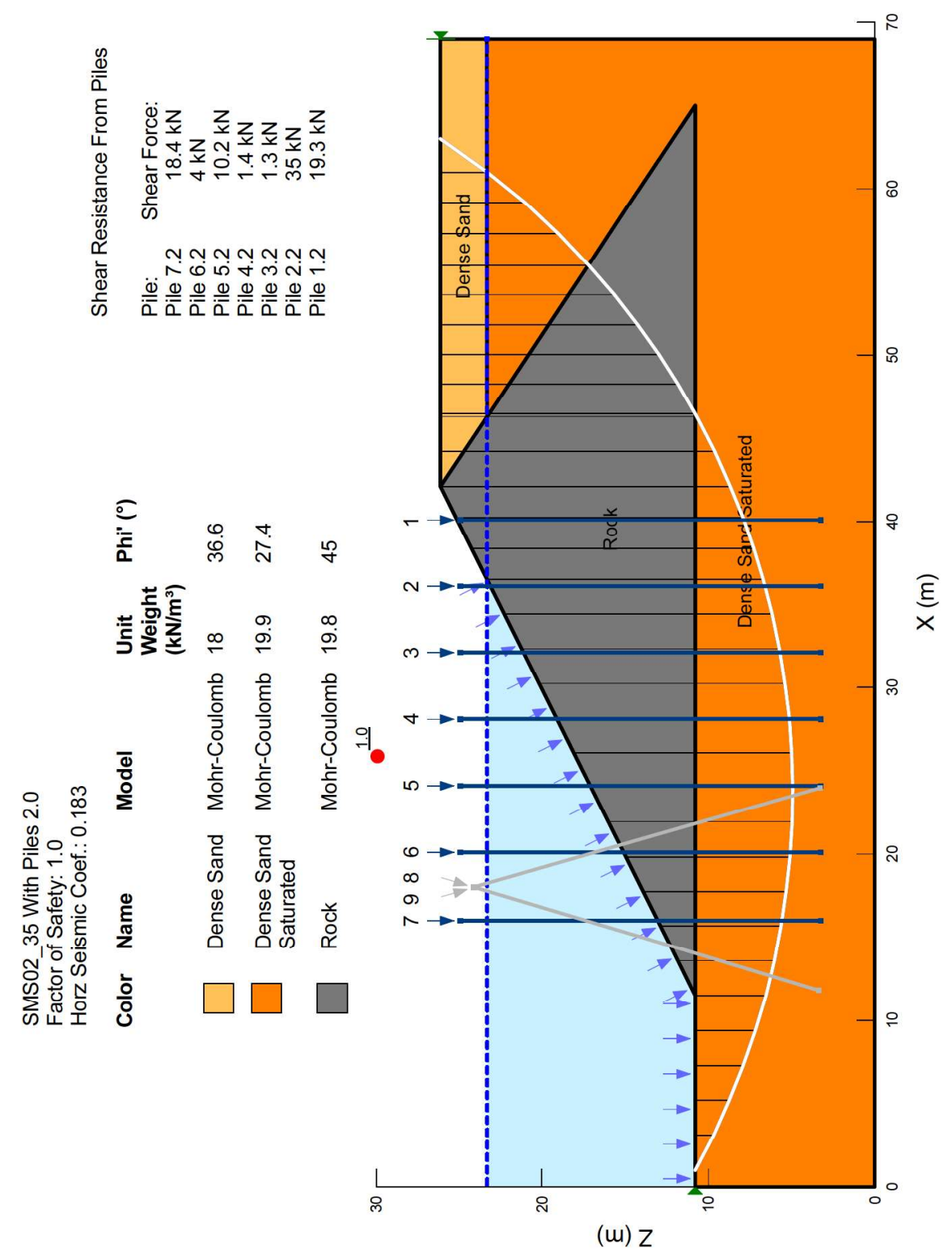




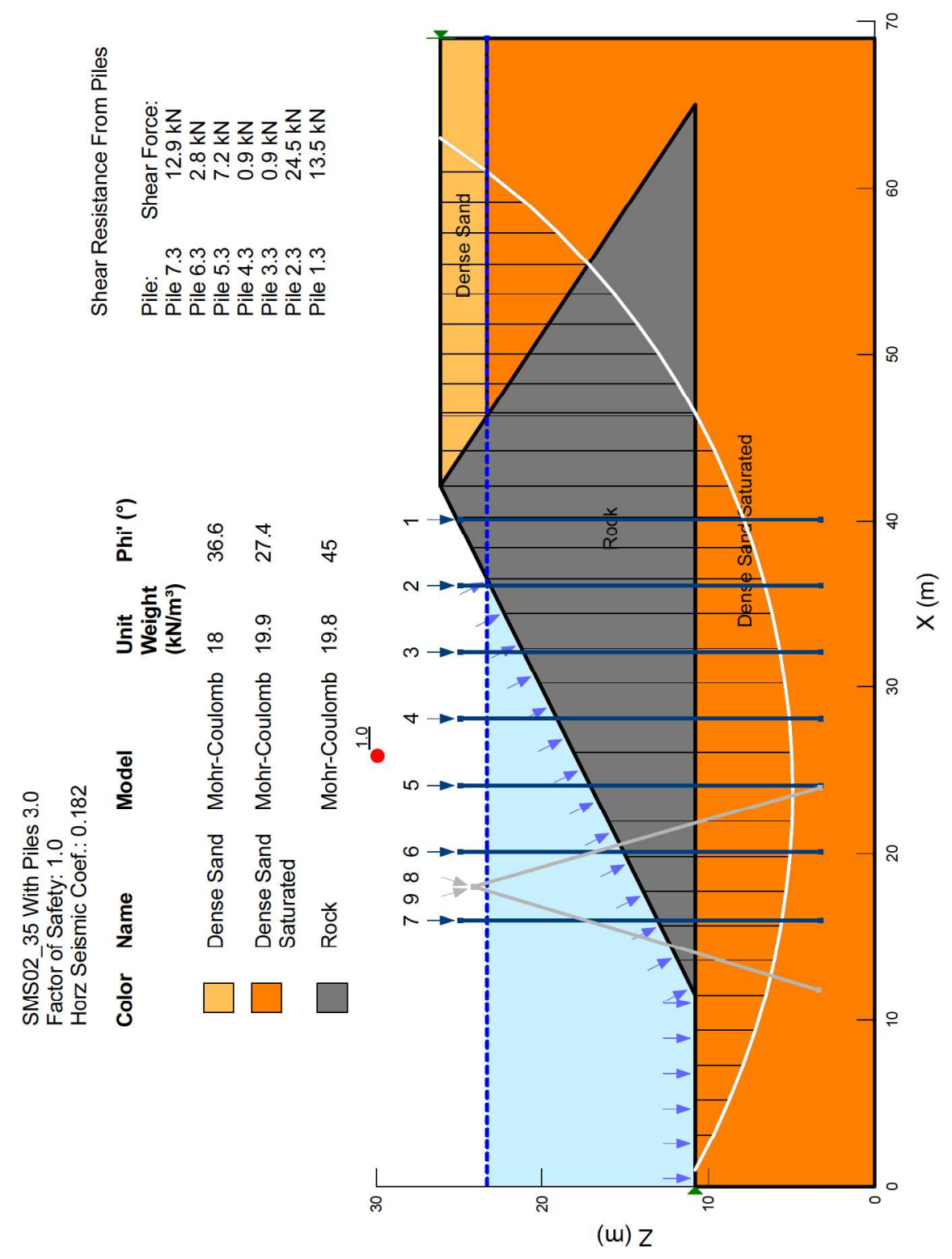




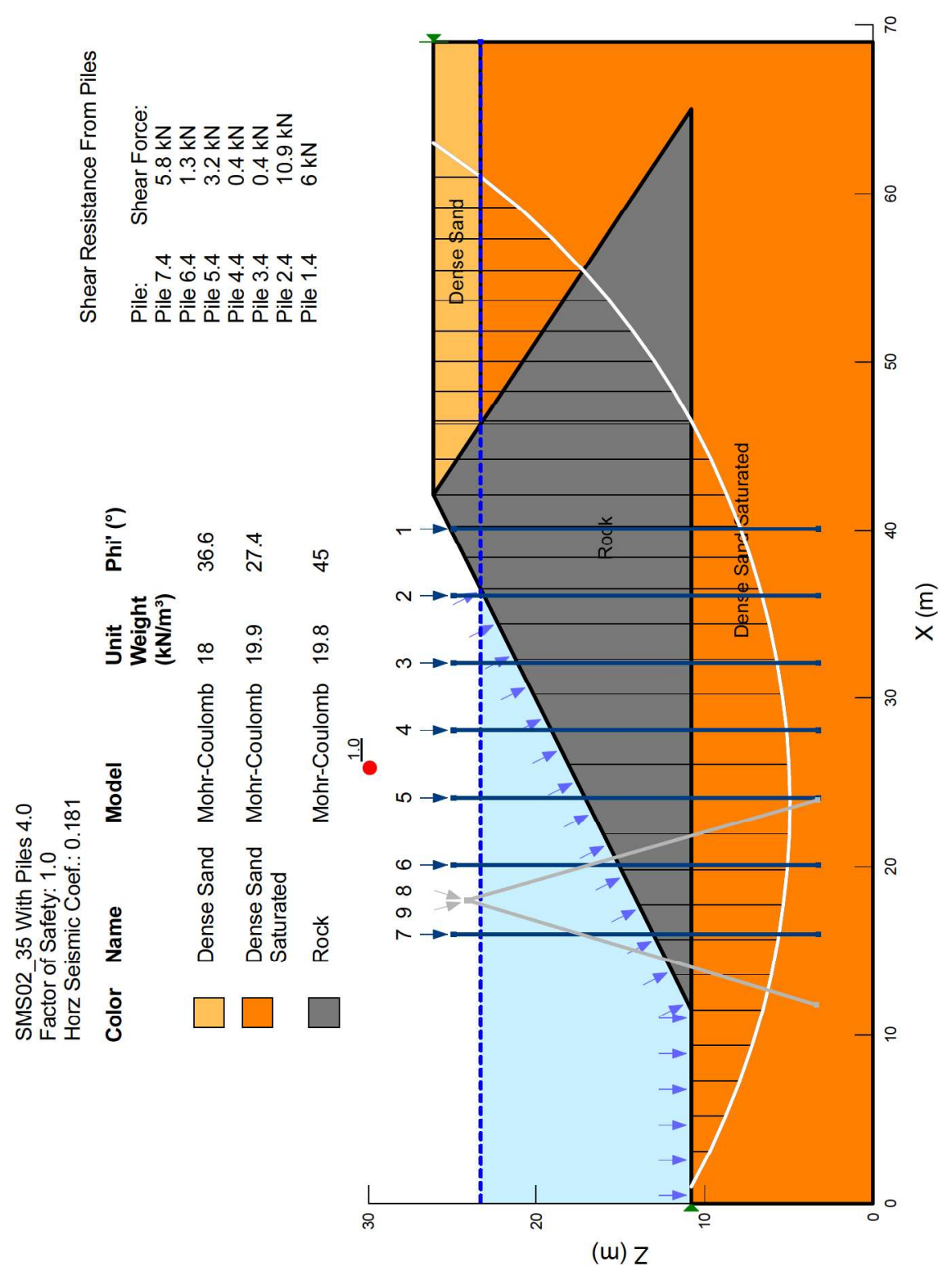




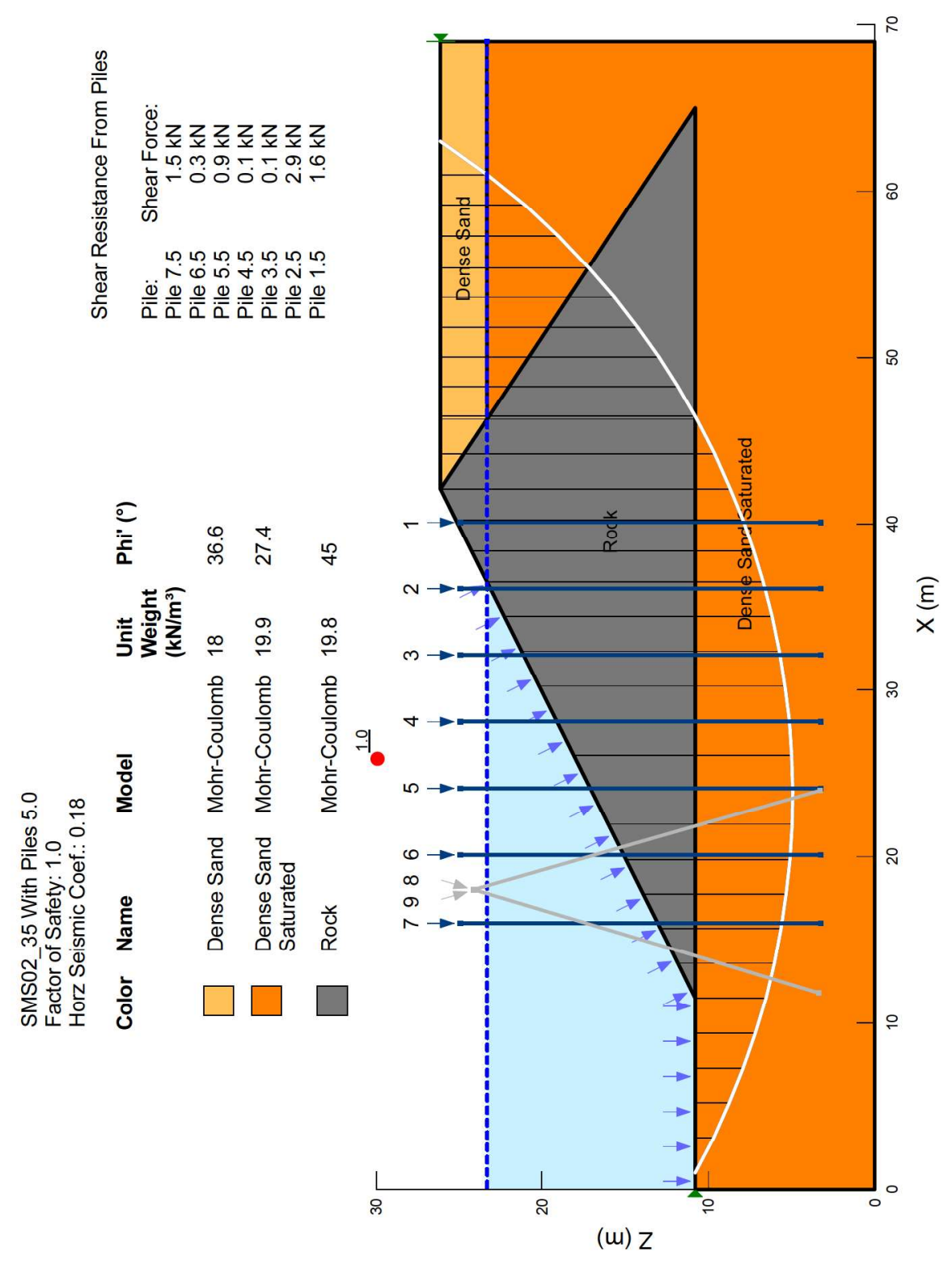




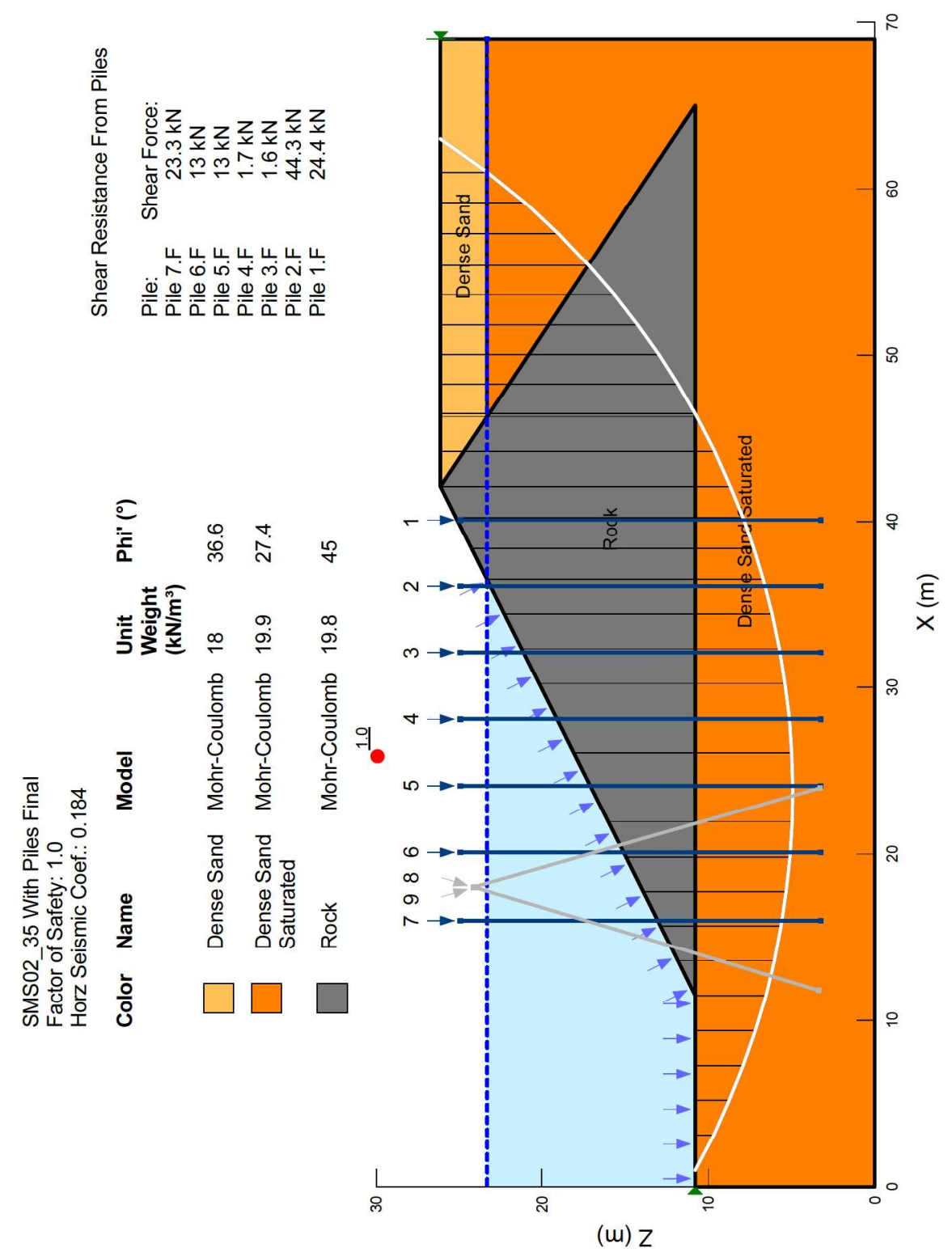




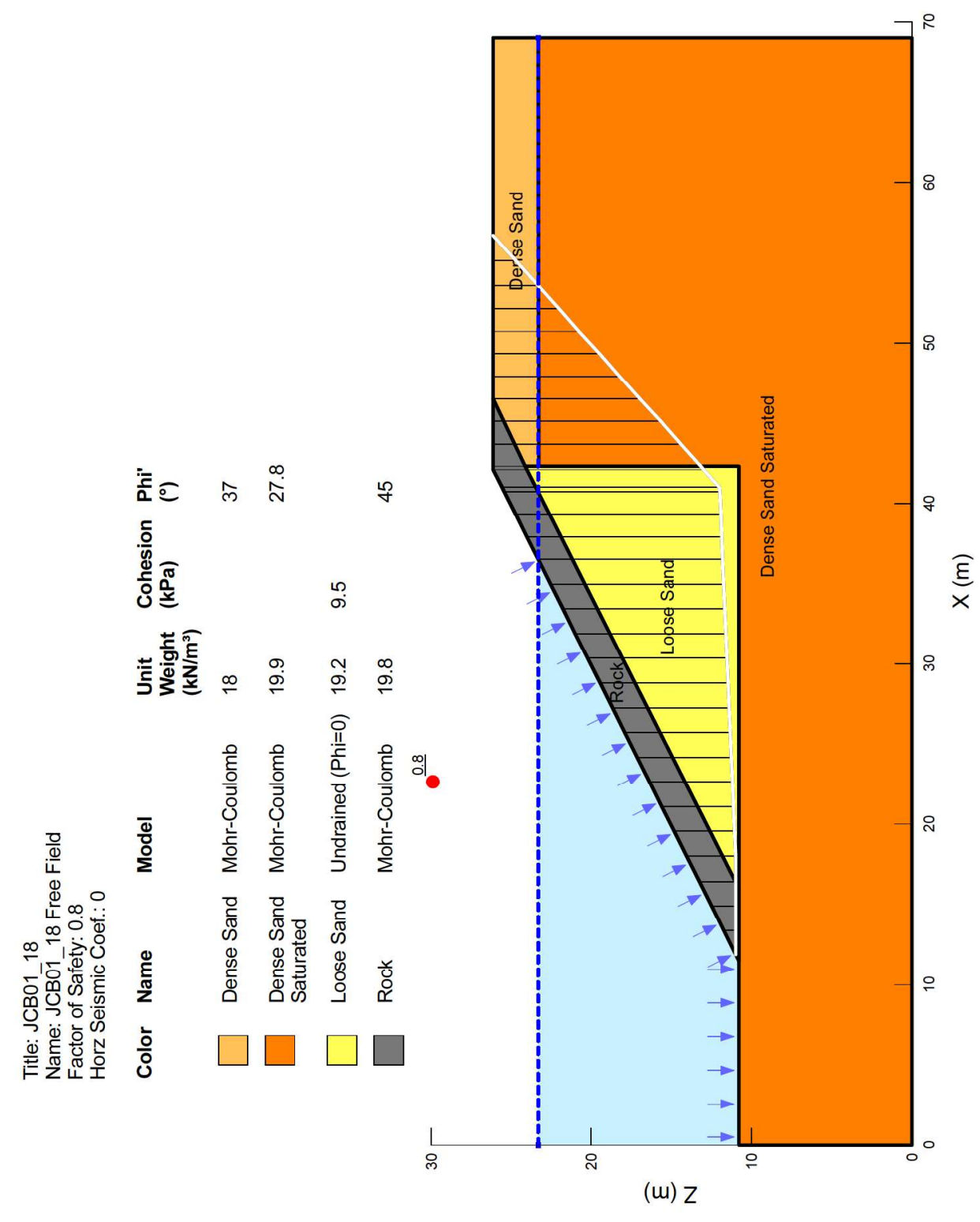




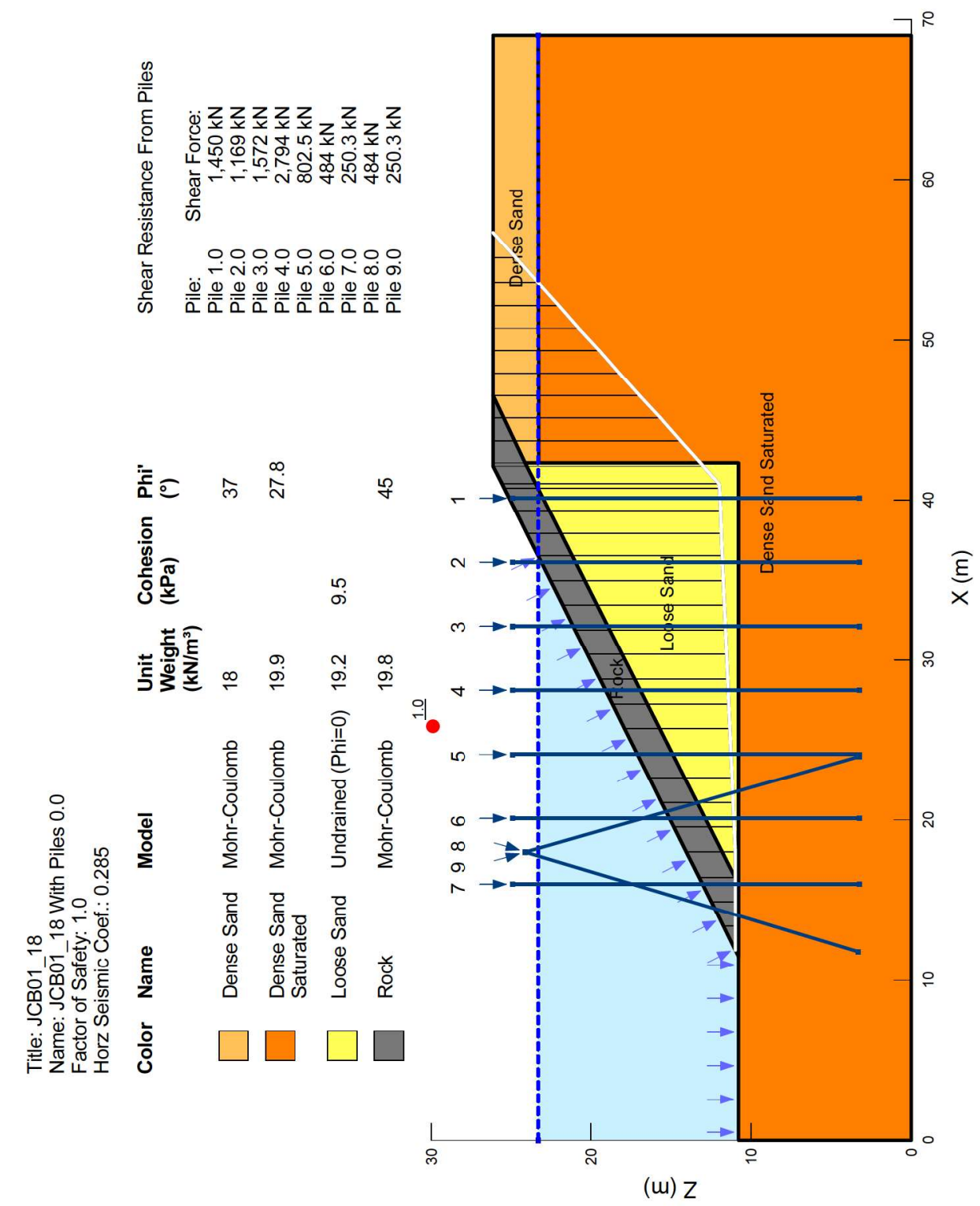




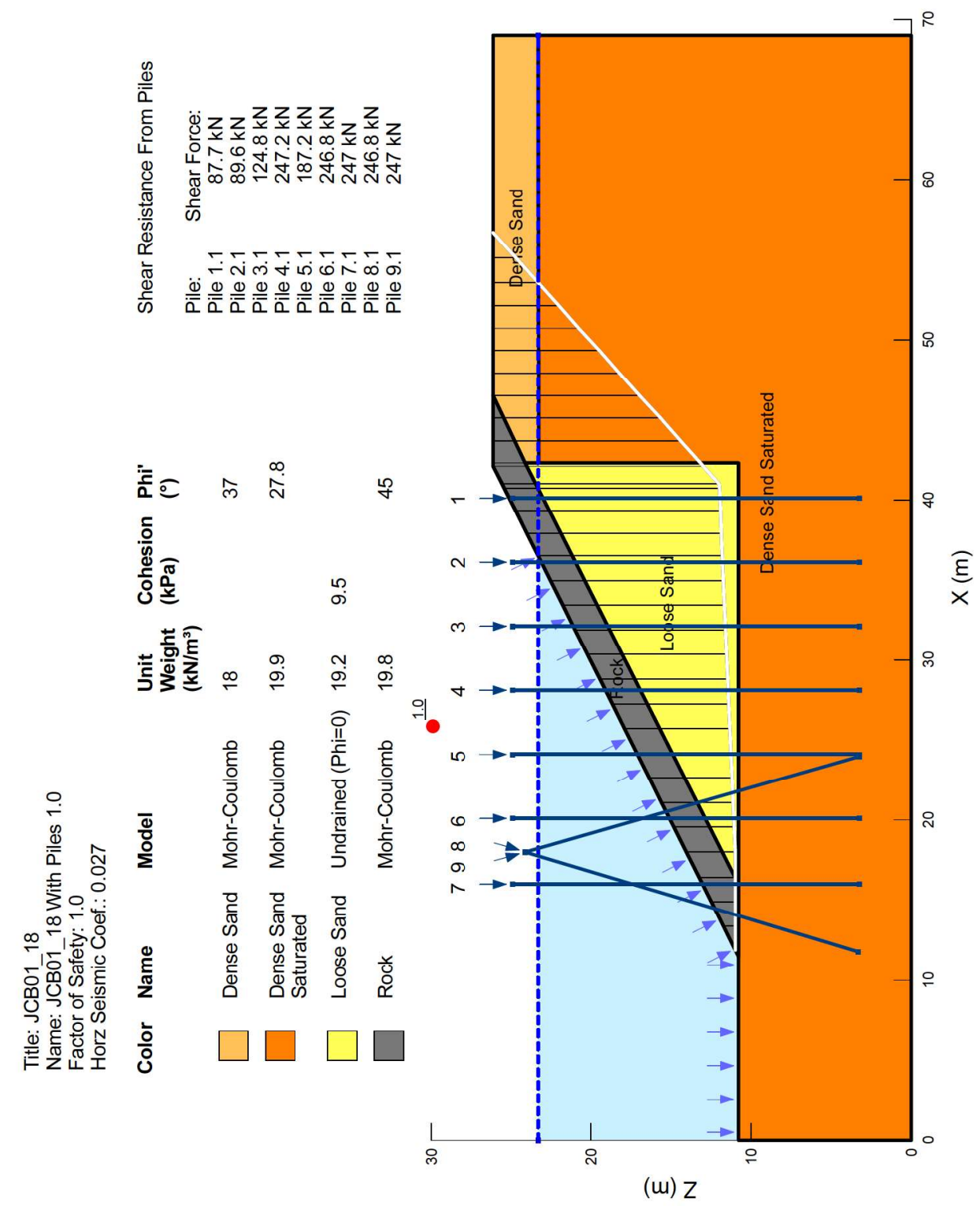




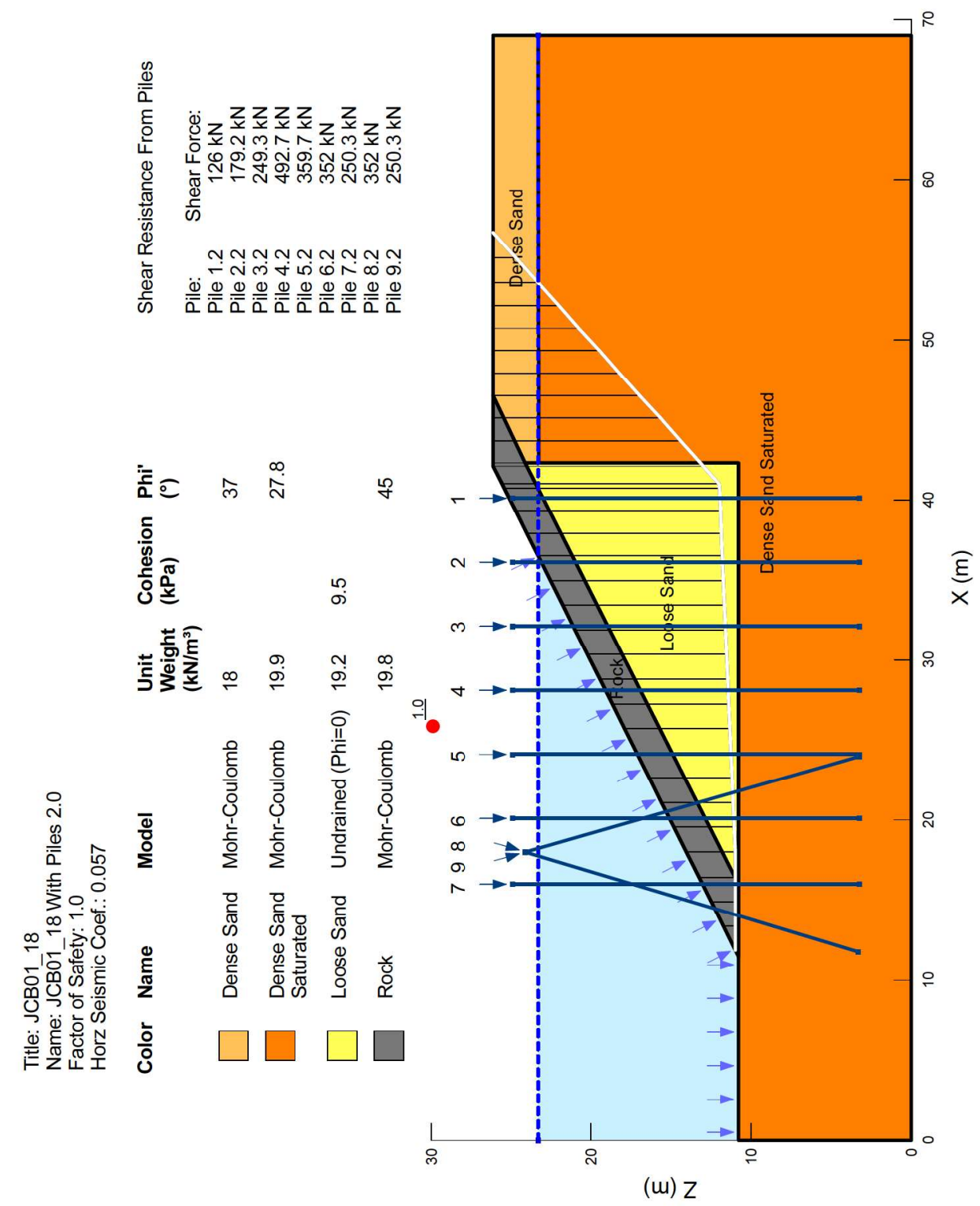




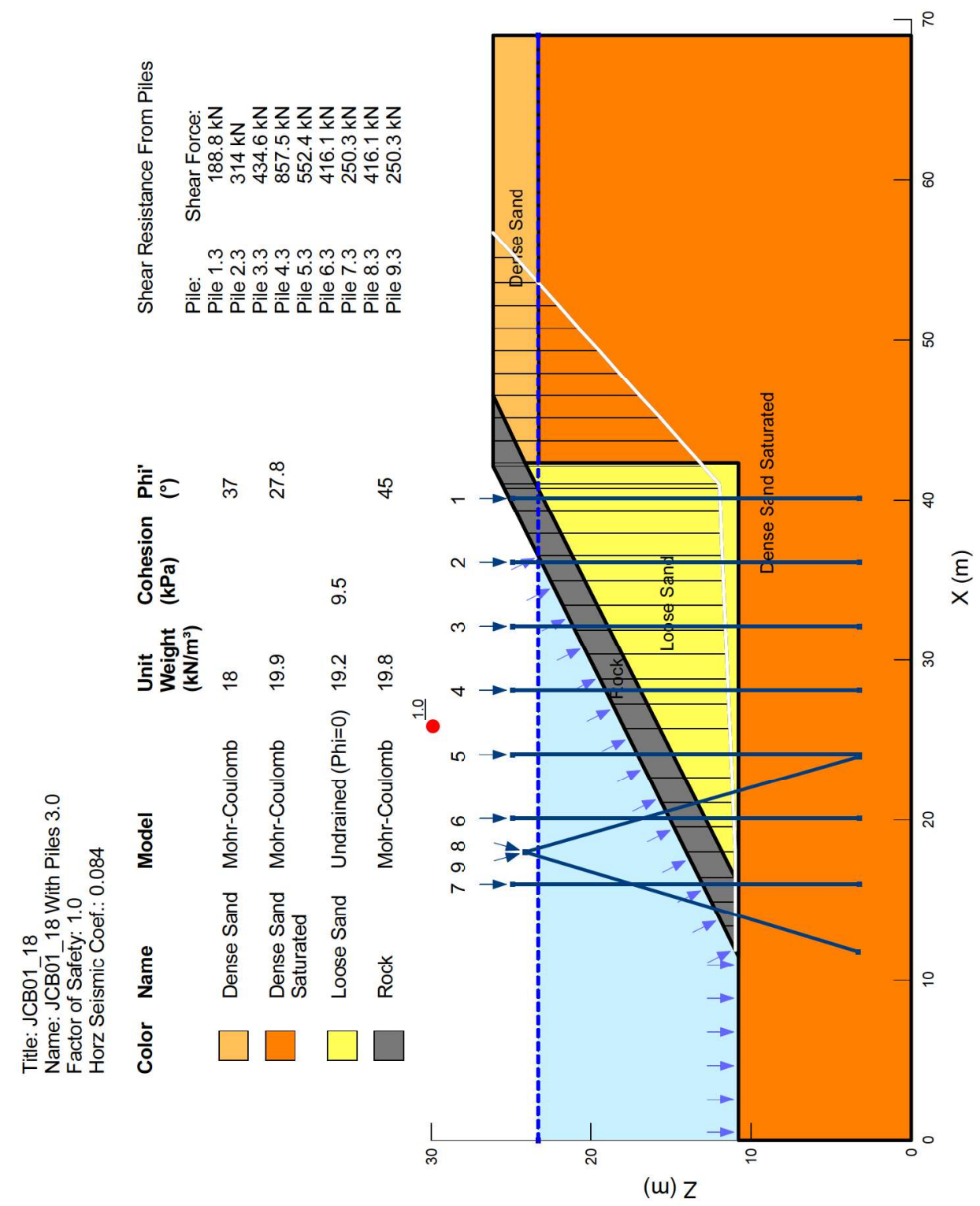




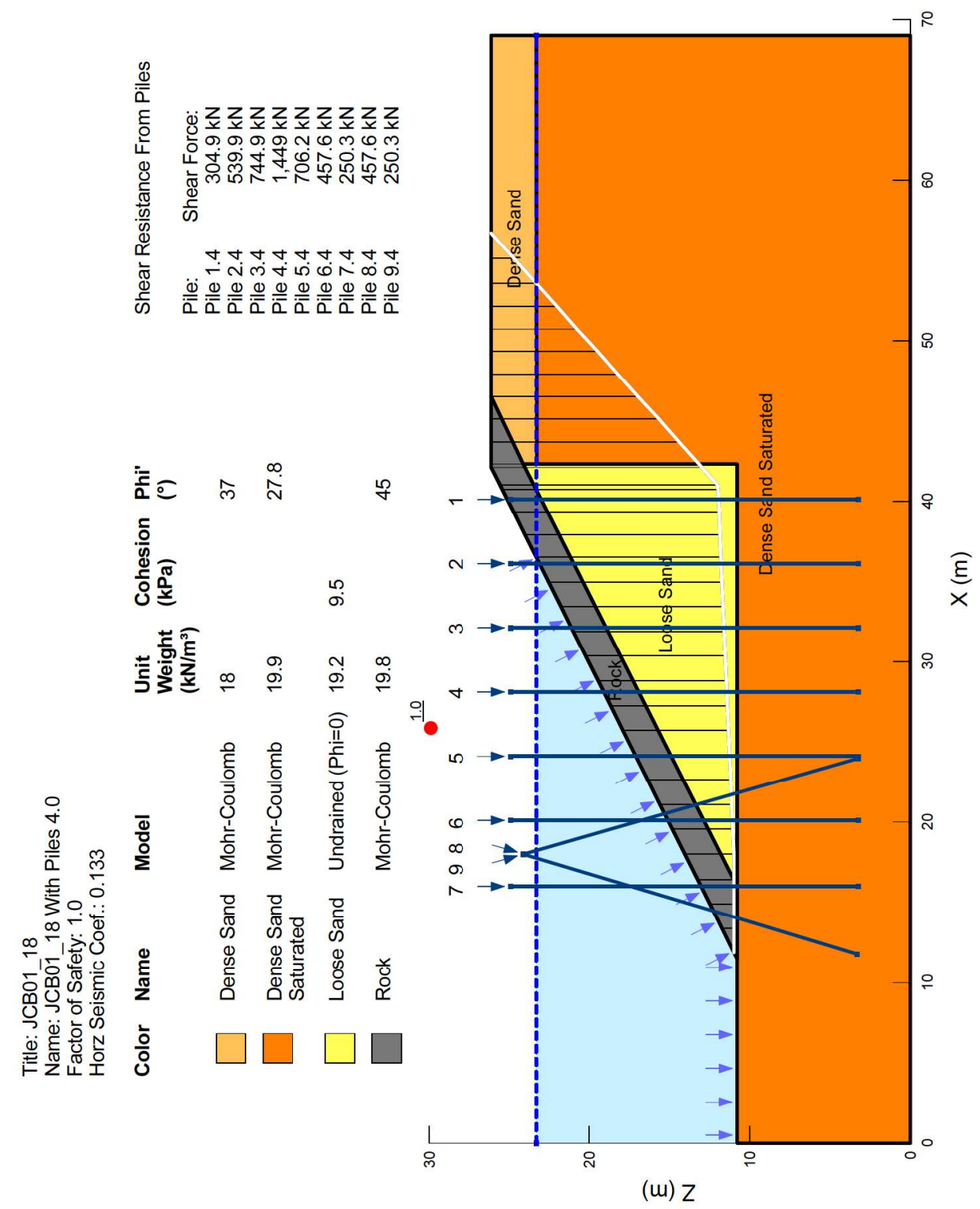




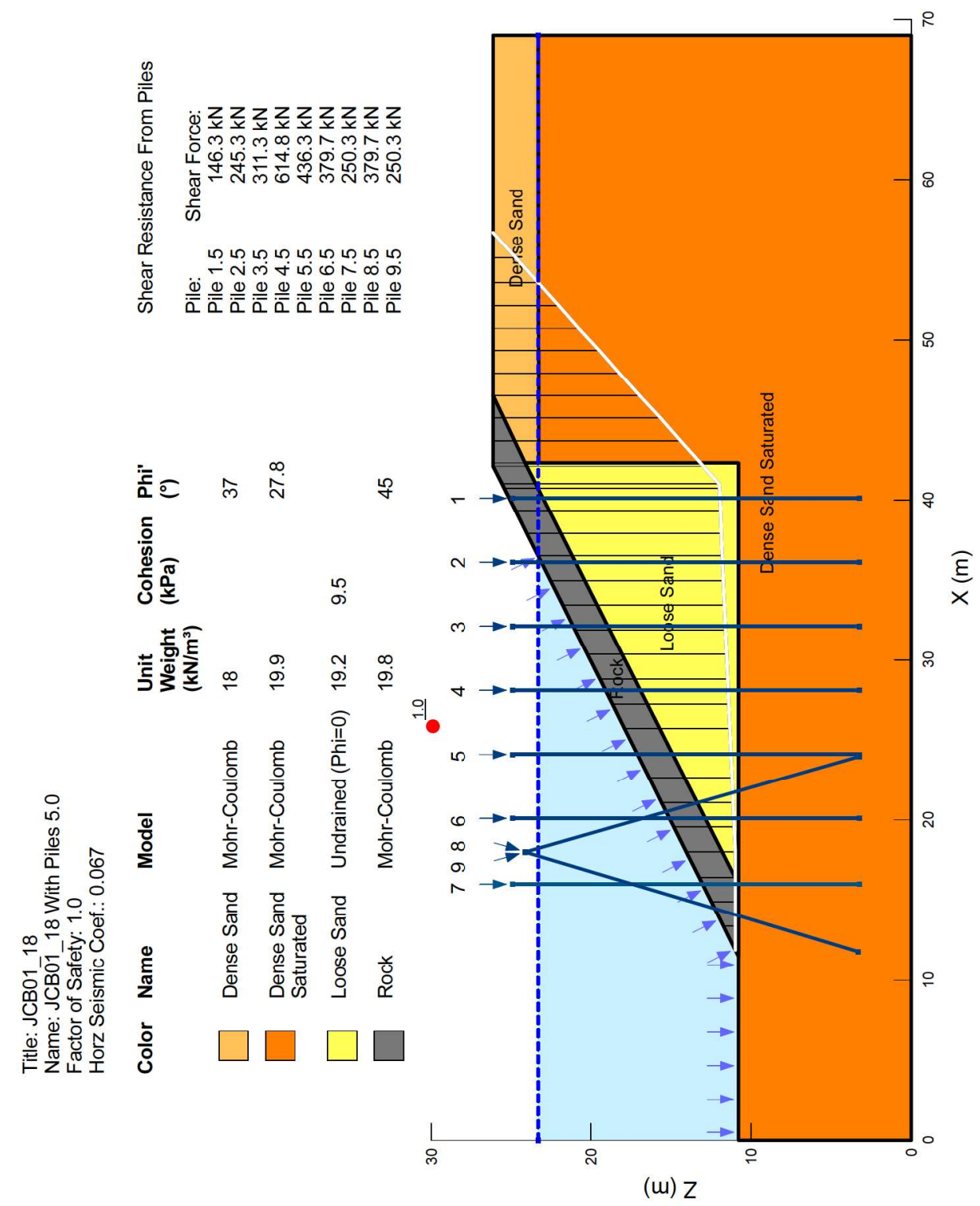









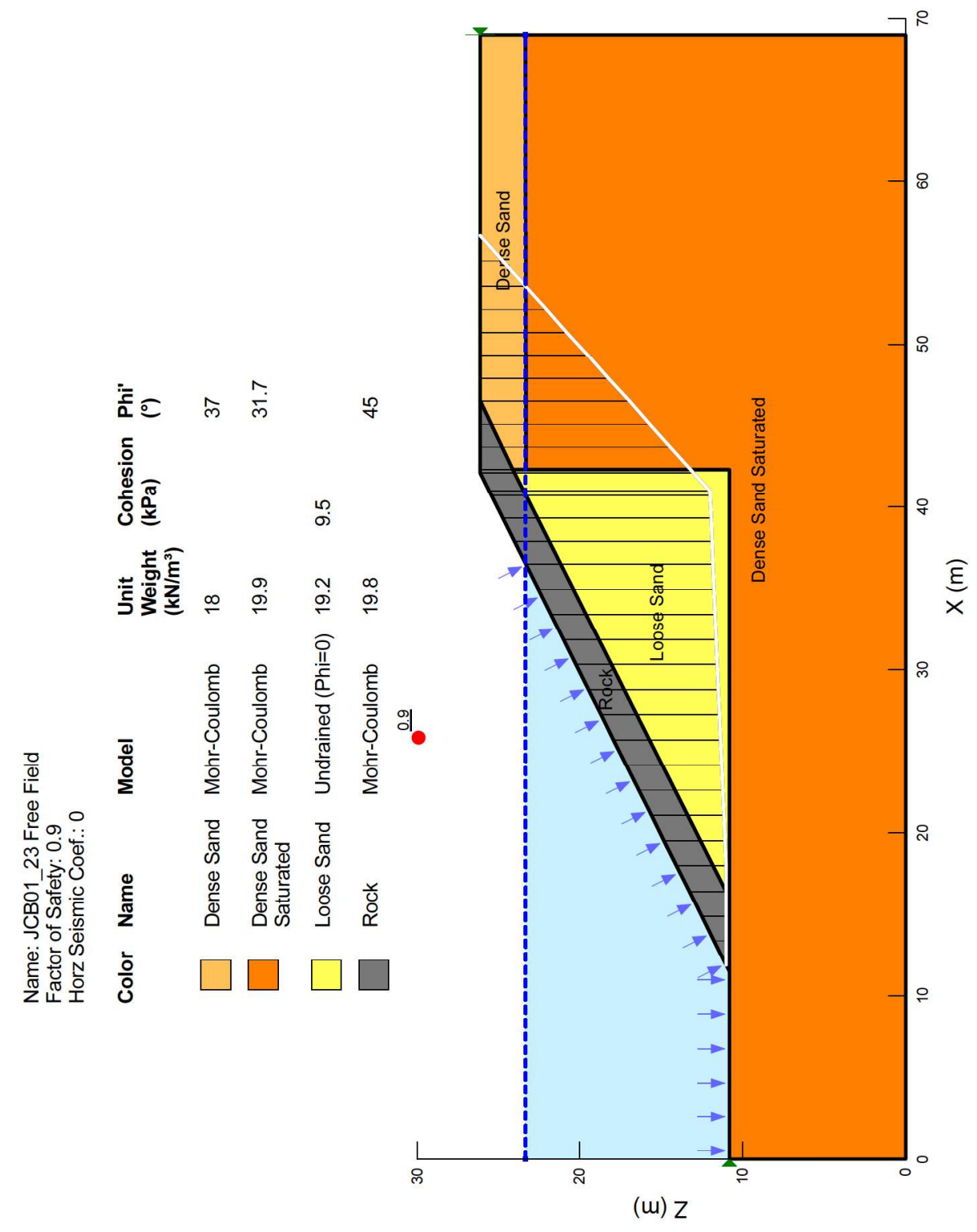









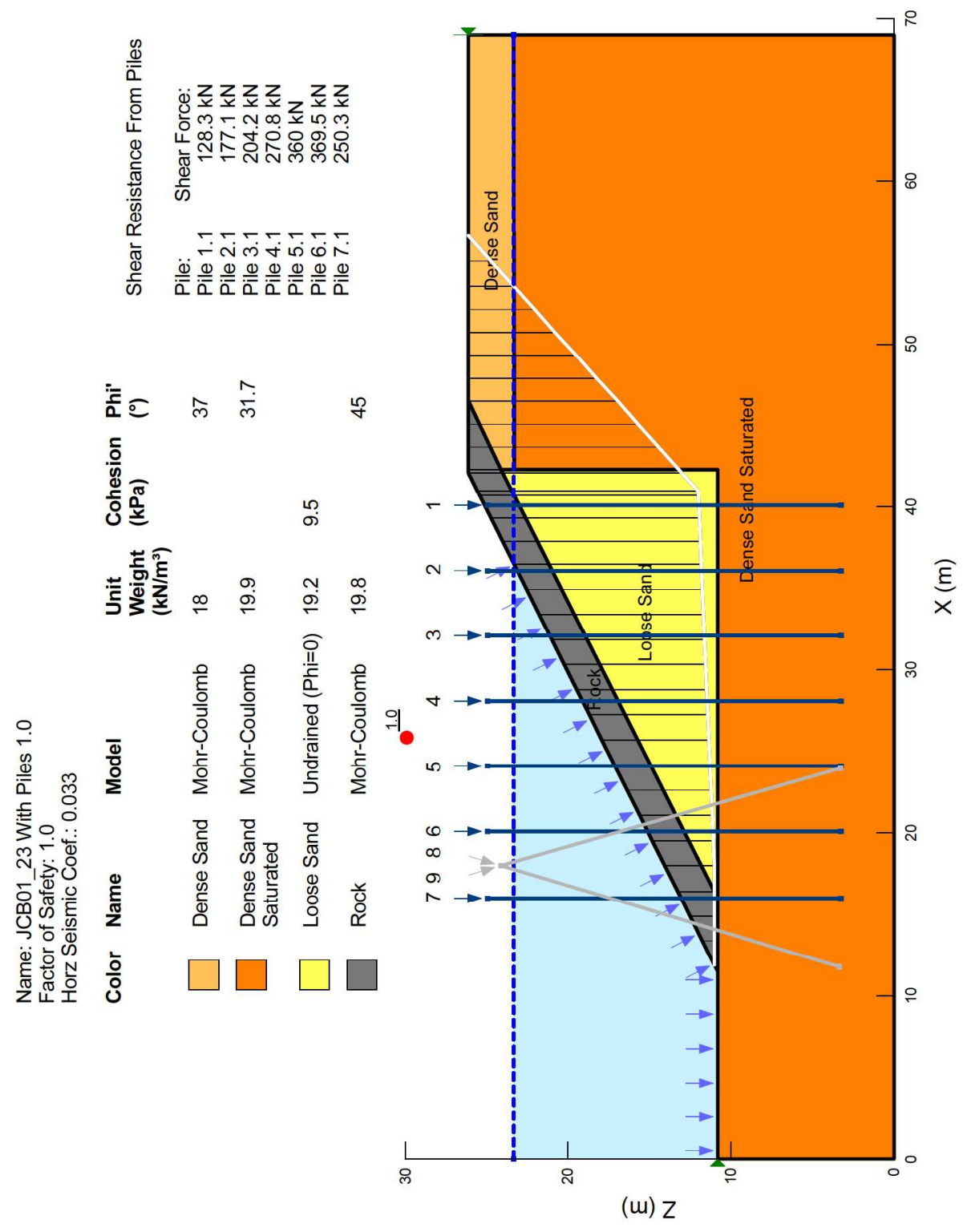




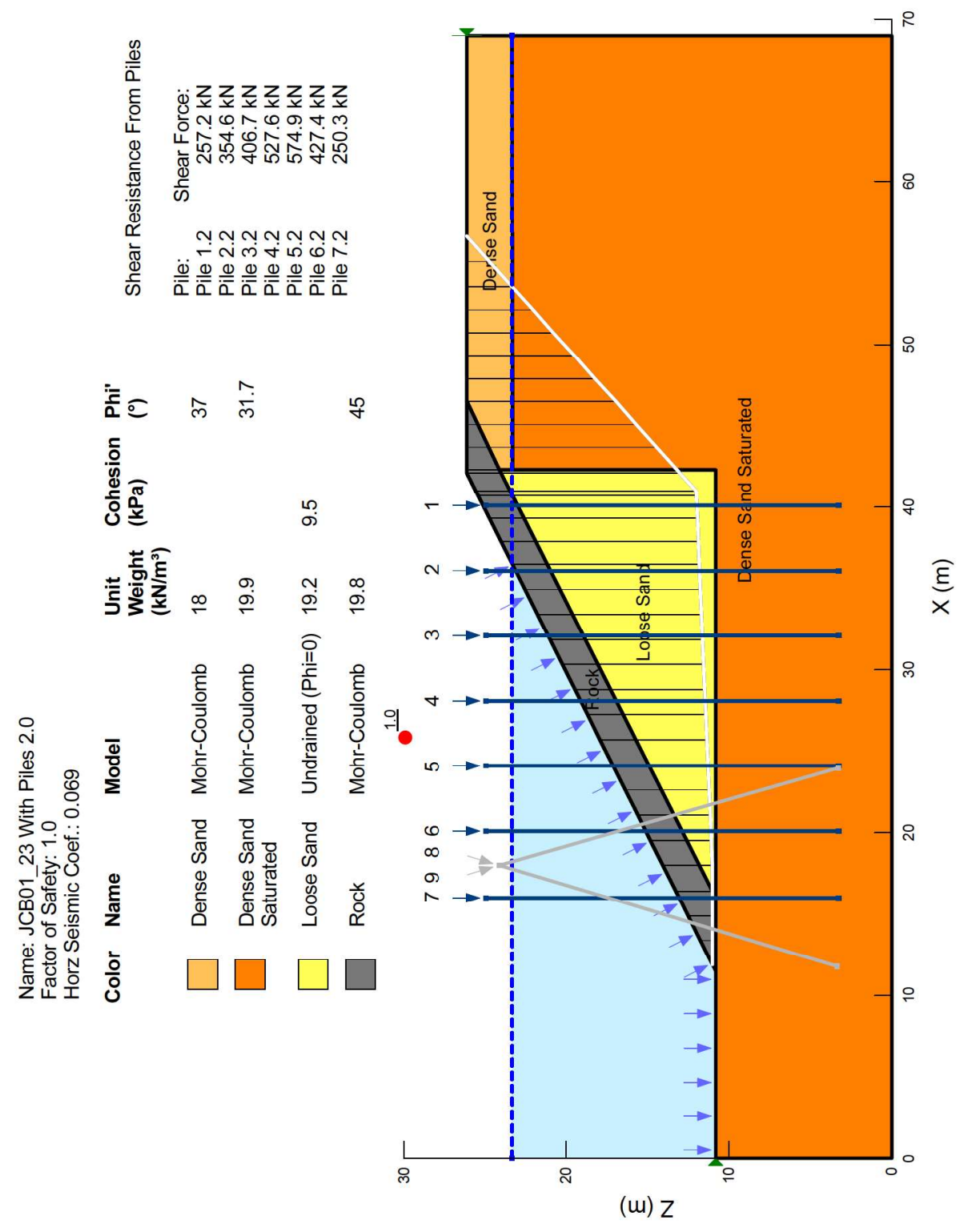









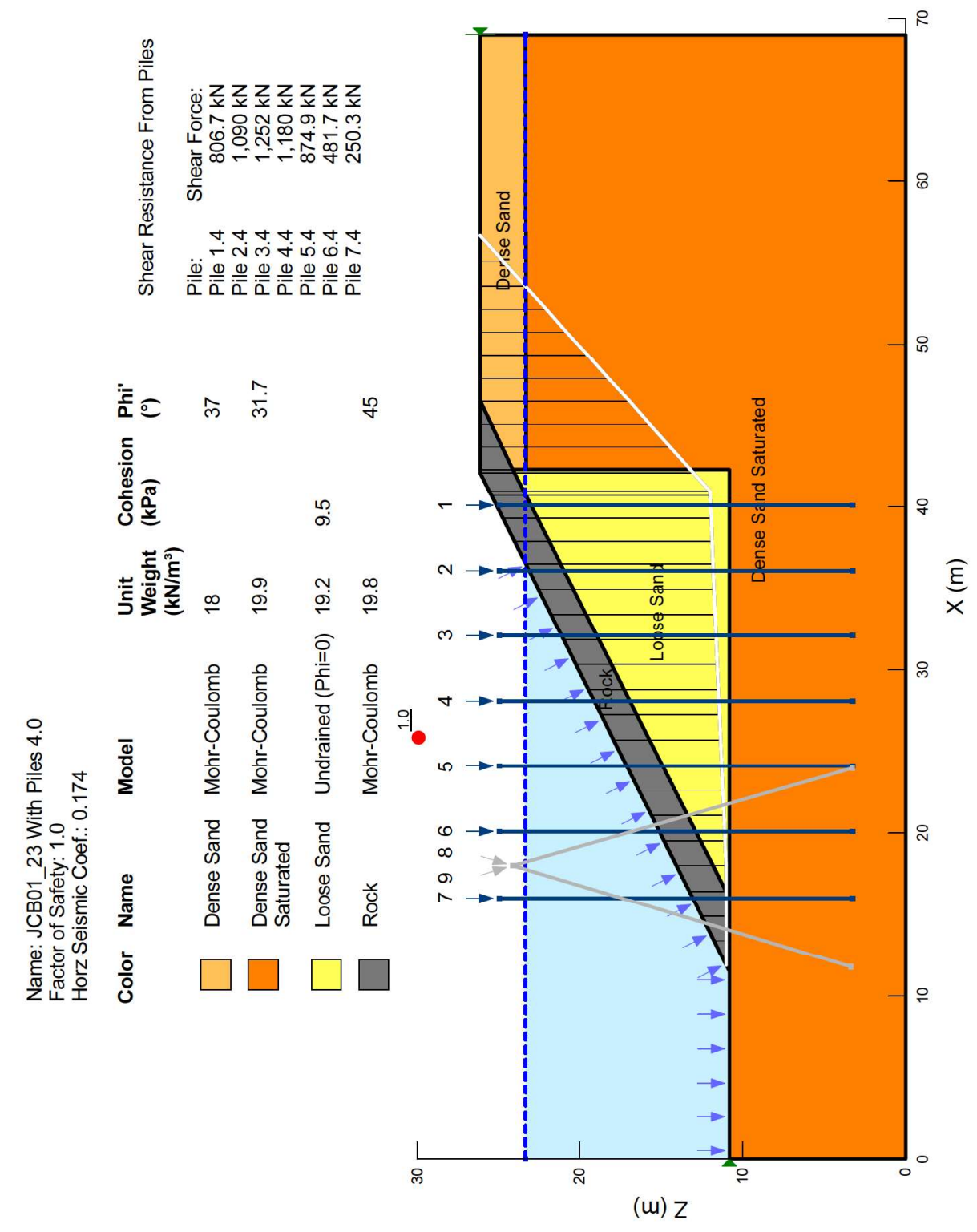









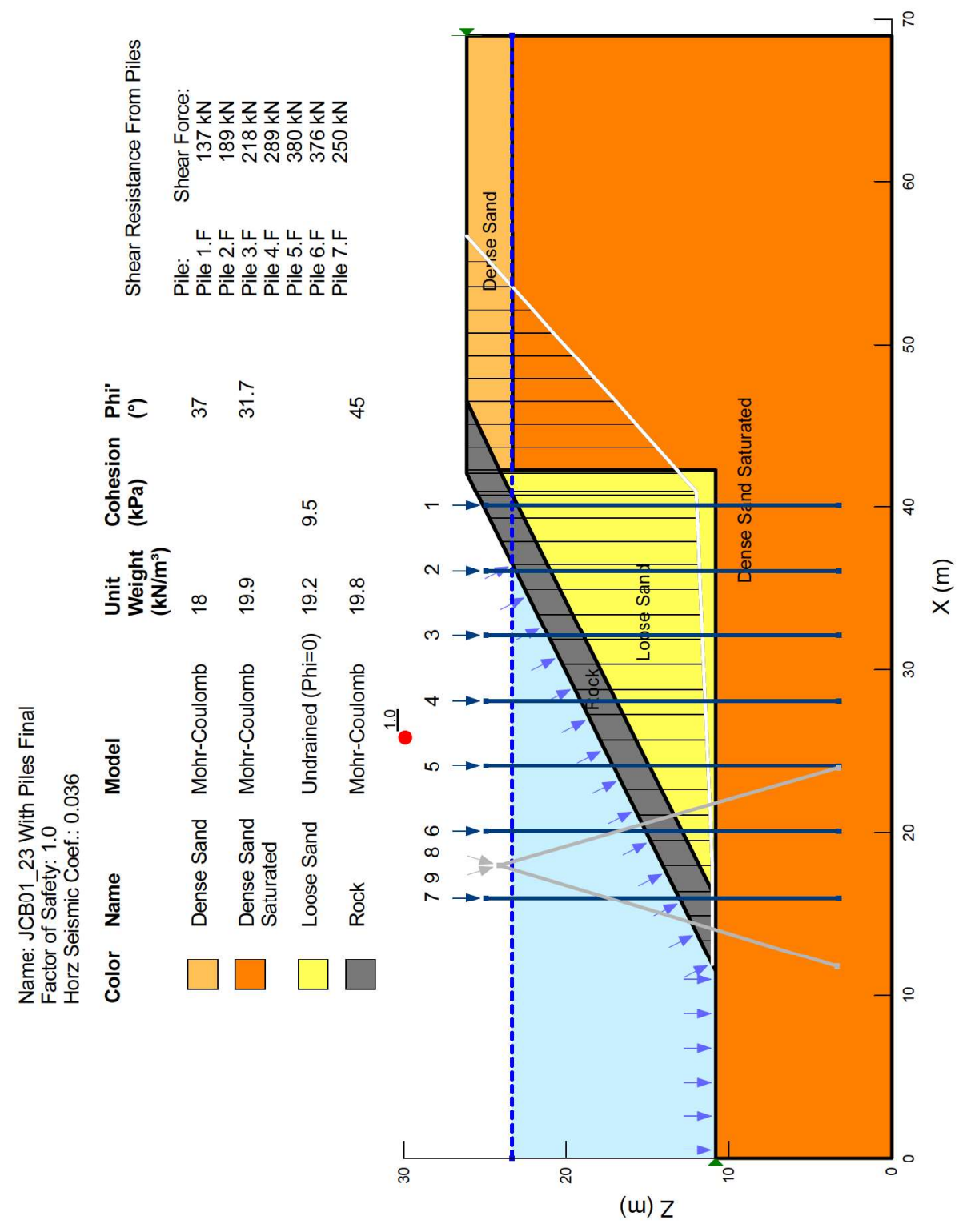

